\title{
Pressure ulcers in pediatric patients : a challenge!
}

Citation for published version (APA):

Schlüer, A. B. (2013). Pressure ulcers in pediatric patients : a challenge! [Doctoral Thesis, Maastricht University]. Maastricht University. https://doi.org/10.26481/dis.20131206as

Document status and date:

Published: 01/01/2013

DOI:

10.26481/dis.20131206as

Document Version:

Publisher's PDF, also known as Version of record

\section{Please check the document version of this publication:}

- A submitted manuscript is the version of the article upon submission and before peer-review. There can be important differences between the submitted version and the official published version of record.

People interested in the research are advised to contact the author for the final version of the publication, or visit the DOI to the publisher's website.

- The final author version and the galley proof are versions of the publication after peer review.

- The final published version features the final layout of the paper including the volume, issue and page numbers.

Link to publication

\footnotetext{
General rights rights.

- You may freely distribute the URL identifying the publication in the public portal. please follow below link for the End User Agreement:

www.umlib.nl/taverne-license

Take down policy

If you believe that this document breaches copyright please contact us at:

repository@maastrichtuniversity.nl

providing details and we will investigate your claim.
}

Copyright and moral rights for the publications made accessible in the public portal are retained by the authors and/or other copyright owners and it is a condition of accessing publications that users recognise and abide by the legal requirements associated with these

- Users may download and print one copy of any publication from the public portal for the purpose of private study or research.

- You may not further distribute the material or use it for any profit-making activity or commercial gain

If the publication is distributed under the terms of Article $25 \mathrm{fa}$ of the Dutch Copyright Act, indicated by the "Taverne" license above, 
PRESSURE ULCERS IN PEDIATRIC PATIENTS: A CHALLENGE! 
ISBN: 978-3-033-04245-2

(c) Copyright Anna-Barbara Schlüer, 2013

Pressure ulcers in pediatric patients: a challenge!

Cover photo: Kinderspital Zürich, used with permission

Printed by: Buchmanufaktur, Winterthur, Switzerland

Layout and cover design: Barbara Simpson, André Rüegger

Chapters 2, 3 and 4 have been published and are reproduced with the permission of the publisher.

Chapters 5 and 7 are accepted for publication and are reproduced with the permission of the publisher.

Chapter 6 is submitted to a scientific journal.

All photographs are used with permission of the patient/family. 


\section{PRESSURE ULCERS IN PEDIATRIC PATIENTS: A CHALLENGE!}

\section{DISSERTATION}

to obtain the degree of Doctor

at Maastricht University,

on the authority of the Rector Magnificus, Prof.dr. L.L.G Soete in accordance with the decision of the Board of Deans,

to be defended in public on Friday 6 December 2013, at 14.00 hours

by

Anna-Barbara Schlüer 
Supervisor:

Prof. dr. JMGA Schols

Co-supervisor:

Dr. RJG Halfens

Assessment Committee:

Prof. dr. JPH Hamers (chairman)

Prof. dr. T. van Achterberg, Radboud University Nijmegen

Prof. dr. RA de Bie

Prof. dr. RRWJ van der Hulst

Prof. dr. LJI Zimmermann 


\section{Contents}

1 General Introduction 9

$\begin{array}{lll}1.1 & \text { Introduction } & 10\end{array}$

$\begin{array}{lll}1.2 & \text { Theoretical framework } & 14\end{array}$

1.3 Scope, aim and research questions of thesis 21

1.4 Structure of thesis 23

1.5 Ethical considerations 24

$\begin{array}{lll}1.6 & \text { References } & 25\end{array}$

2 The Prevalence of Pressure Ulcers in Four Pediatric Institutions 33

$\begin{array}{lll}2.1 & \text { Introduction } & 35\end{array}$

$\begin{array}{lll}2.2 & \text { Methods } & 37\end{array}$

$\begin{array}{lll}2.3 & \text { Results } & 41\end{array}$

$\begin{array}{lll}2.4 & \text { Discussion } & 48\end{array}$

2.5 Conclusion 51

2.6 References 52

3 Pediatric Pressure Ulcer Prevalence: A Multicenter, Cross-Sectional, Point Prevalence Study in Switzerland $\quad 57$

$\begin{array}{lll}3.1 & \text { Introduction } & 59\end{array}$

$\begin{array}{lll}3.2 & \text { Methods } & 61\end{array}$

$\begin{array}{lll}3.3 & \text { Results } & 63\end{array}$

$\begin{array}{lll}3.4 & \text { Discussion } & 69\end{array}$

3.5 Conclusion 72

$\begin{array}{lll}3.6 & \text { References } & 73\end{array}$ 
4 Validation and clinical impact of pediatric pressure ulcer risk assessment scales: A systematic review

$\begin{array}{lll}4.1 & \text { Introduction } & 80\end{array}$

$\begin{array}{lll}4.2 & \text { Methods } & 82\end{array}$

$\begin{array}{lll}4.3 & \text { Results } & 86\end{array}$

$\begin{array}{lll}4.4 & \text { Discussion } & 96\end{array}$

$\begin{array}{lll}4.5 & \text { Limitations } & 98\end{array}$

$\begin{array}{lll}4.6 & \text { Conclusions } & 99\end{array}$

$\begin{array}{lll}4.7 & \text { References } & 100\end{array}$

5 Risk and associated factors of pressure ulcers in hospitalized children over 1 year of age

$\begin{array}{lll}5.1 & \text { Introduction } & 109\end{array}$

5.2 Methods 111

$\begin{array}{lll}5.3 & \text { Results } & 114\end{array}$

$\begin{array}{lll}5.4 \text { Discussion } & 120\end{array}$

$\begin{array}{lll}5.5 & \text { Limitations } & 124\end{array}$

5.6 Practice Implications 125

$\begin{array}{lll}5.7 & \text { References } & 127\end{array}$

6 Pressure ulcers in hospitalized neonates and infants; prevalence, risk factors, preventive measures 131

$\begin{array}{lll}6.1 & \text { Introduction } & 133\end{array}$

6.2 Material and Methods 137

$\begin{array}{lll}6.3 & \text { Results } & 140\end{array}$

$\begin{array}{lll}6.4 \text { Discussion } & 146\end{array}$

$\begin{array}{lll}6.5 & \text { Conclusion } & 148\end{array}$

$\begin{array}{lll}6.6 & \text { References } & 150\end{array}$ 
7 Pressure ulcer treatment in pediatric patients

$\begin{array}{lll}7.1 & \text { Introduction } & 157\end{array}$

$\begin{array}{lll}7.2 & \text { Methods } & 160\end{array}$

$\begin{array}{lll}7.3 & \text { Results } & 162\end{array}$

$\begin{array}{lll}7.4 & \text { Discussion } & 168\end{array}$

7.5 Limitations of this study and implications for further research 170

$\begin{array}{lll}7.6 & \text { References } & 173\end{array}$

8 General discussion 177

8.1 General discussion and future directions 178

8.2 Methodological aspects 183

8.3 Implications for future research 186

8.4 Implications for clinical practice 186

$\begin{array}{lll}8.5 & \text { References } & 188\end{array}$

9 Summary 193

$\begin{array}{ll}\text { Samenvatting } & 199\end{array}$

$\begin{array}{ll}\text { Acknowledgement } & 205\end{array}$

$\begin{array}{ll}\text { Curriculum vitae } & 209\end{array}$ 

1 General Introduction 


\subsection{Introduction}

Pressure ulcers (PUs) are a common and highly relevant nursing care issue in hospitals. They are associated with psychological and physical suffering, increased morbidity and mortality rate and higher costs for health care worldwide (Baharestani, Black, Carville, et al., 2009a, Gorecki, Brown, Nelson, et al., 2009, Allman, Laperde, Noel, et al., 1999; Anthony, Reynolds \& Russell, 2004).

PU development can be attributed to multiple factors that are fairly well-studied in adults and elderly people (Whittington \& Briones, 2004, Horn, Bender, Ferguson, et al., 2004, de Laat, Schoonhoven, Pickkers, et al., 2006, Baharestani et al., 2009a). Through large-scale, nationwide epidemiological studies, the prevalence of PUs in nursing care institutions for adults is now known and well documented. It varies from $4 \%$ to $49 \%$ in intensive care patients (Shahin, Dassen \& Halfens, 2008), from $6 \%$ to $13 \%$ in hospitals and from $4 \%$ to $12 \%$ in nursing homes (Kottner, Wilborn, Dassen, et al., 2009).

While the problem of PUs in adults has received a great deal of attention, far less is known about PUs in children and neonates (Baharestani and Pope, 2007). Recent studies have indicated that PUs are also common in the pediatric population, and in the last ten years greater attention has been paid to this problem. There is greater awareness that pediatric patients in certain health care settings are also at high risk of developing PUs (Kottner, Wilborn \& Dassen, 2010; Noonan, Quigley \& Curley, 2011). Prevalence rates for PUs in hospitalized pediatric patients range from $3 \%$ to $28 \%$ (Kottner et al., 2010). Two cases of pediatric patients are presented in box 1 . 


\section{Case of Alina}

Alina was born after 33 weeks of gestation. Two hours after birth her condition changed to critical due to insufficient breathing. It was unclear if this was due to her preterm birth or to other influences, and she was intubated and transferred to a neonatal intensive care unit (NICU). After admission to the NICU a Relaxatio diaphragmatica was diagnosed, this necessitated a thoracotomy and tightening of the diaphragm within the first 36 hours of Alina's life. About 72 hours after first nasal intubation to support the mechanical ventilation, Alina's condition was stable. The fixation of the nasal tube was routinely checked and refixed. At this point a severe skin breakdown on her nose, diagnosed as a category 3 PU, was assessed. The tube was fixed without pressure or shear to the alinasal or nasal septum, providing the greatest possible relief from the tube. The PU demarcated within the following two days. After extubation, the PU was treated three times a day with pure hydrogel without any secondary dressing. This made it possible to assess any changes in the skin immediately; further, the hydrogel provided the necessary fluid to the intact skin and protected the skin breakdown with a thin layer. Ten days after the first diagnosis of the category $3 \mathrm{PU}$, part of the necrosis peeled off, followed by a total peeling of the necrotic skin at day 20 of Alina's life. After discharge at the age of 28 days, a slightly visible already light and elastic scar could be seen. At the age of six months no visible scar could be seen on Alina's nose and she had no further limitations due to breathing. This case presents a typical localization of a PU in a pre-term neonate as well as effective wound therapy with unusual but positive effects, meeting the special needs of these vulnerable patients. Not only could Alina's skin be kept intact, but also the requirements of treating the category $3 \mathrm{PU}$ could be met, and Alina was not affected by any unnecessary substances from wound dressings. 


\section{Case of Eric}

Eric was 10 years old when, suffering from fulminating septicaemia, he was in very critical condition. He was mechanically ventilated and treated with extracorporeal membrane oxygenation (ECMO) due to insufficient cardiac function for 10 days. He lay on a polyurethane foam mattress, but due to his unstable and critical condition, no regular position changes could be carried out. When ECMO was turned off at day 15 after hospital admission, several occipital PUs were diagnosed. Four of them were necrotic and diagnosed as category 3 PUs, two of them as category 2 and one as a category 1 PU. No active treatment for any of these PUs were performed, although they were carefully assessed for any changes or signs of infection. Four weeks after first diagnosis the largest PU presented as a $4 \times 3 \mathrm{~cm}$ necrosis, which peeled off and presented as granulation tissue. Due to Eric's on-going dialysis at this time and continuous high-dose immunization, wound healing was delayed. In consideration of all these factors an appropriate wound treatment was chosen and was changed twice a week. After another four weeks the wound completely healed with alopecia the size of a one-euro coin. Neither Eric nor his family were affected by the scarring at the time, and they were informed that a surgical intervention could be performed at a later point. 


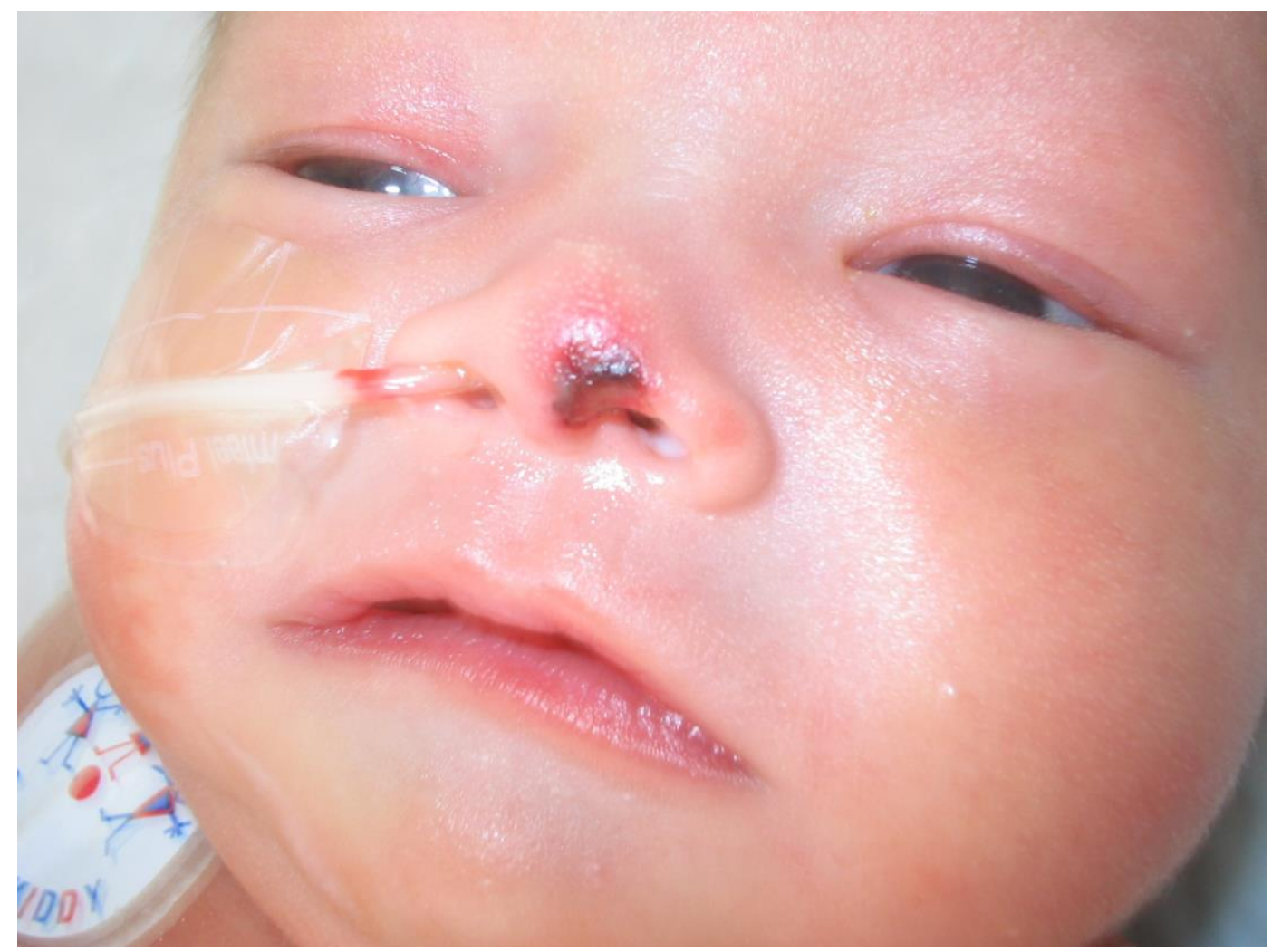

Figure 1: Alina's PU on day 10

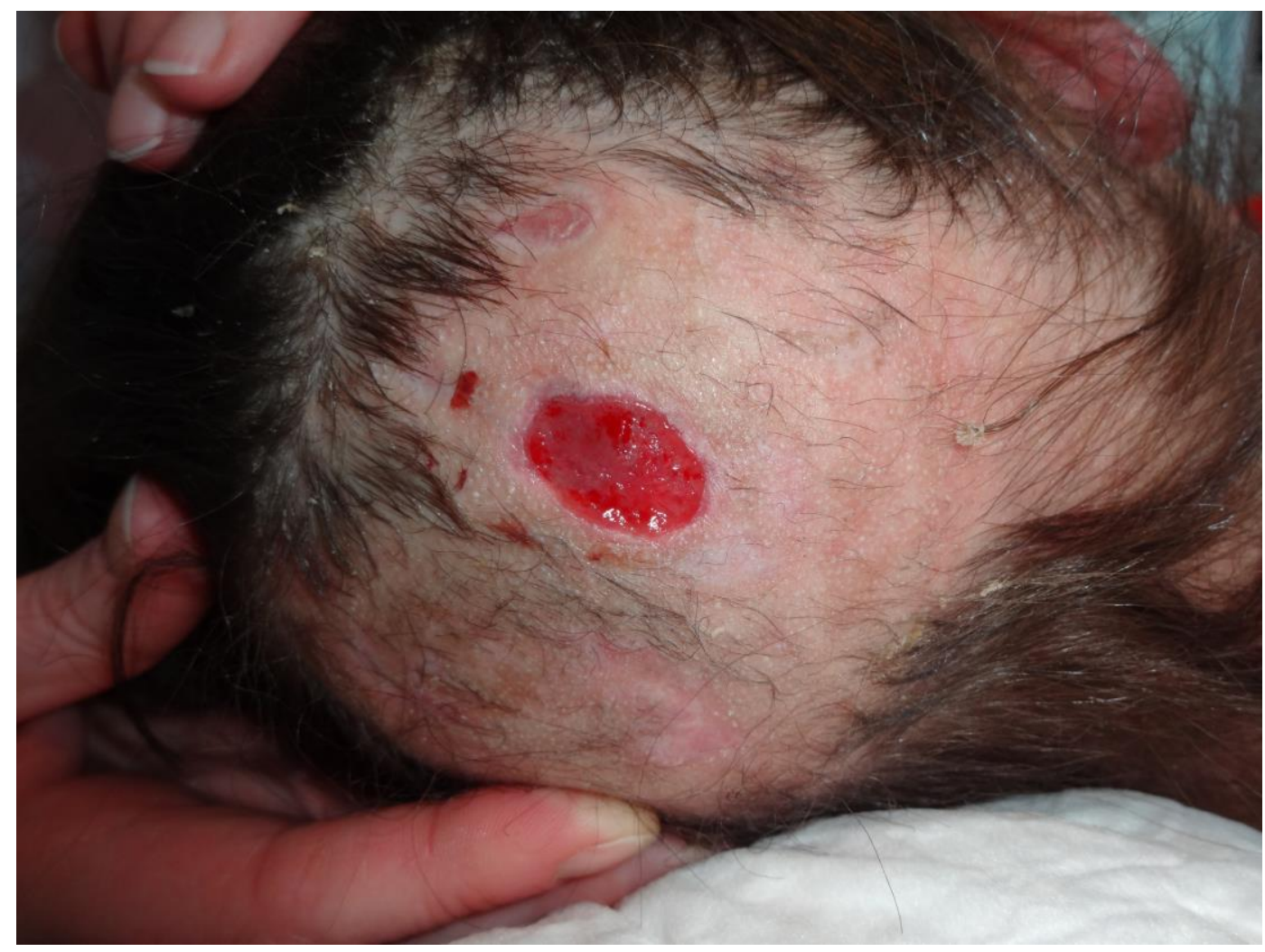

Figure 2: One of Eric's PUs 2 months after admission to the Pediatric Intensive Care Unit 
In this dissertation the relevance and prevalence of PUs in pediatric patients was explored.

In this introduction, the definition and etiology of PUs is first explained. In the second part an overview of the characteristics of pediatric patients with regard to the problem of PUs is presented. Then, the specific aims of this dissertation as well as the related research questions are introduced. Finally, a short overview of the topic and content of each chapter is given and the introduction ends with the ethical considerations of the studies conducted.

\subsection{Theoretical framework}

\subsubsection{Definition and etiology of PUs}

A PU is a localized injury to the skin and/or underlying tissue as a result of pressure, or pressure in combination with shear forces. (National Pressure Ulcer Advisory Panel (NPUAP) and European Pressure Ulcer Advisory Panel (EPUAP), 2009). According to the guidelines of NPUAP and EPUAP, PUs are differentiated into four different categories, with category one being the least severe, and defined as "intact skin with non-blanchable redness of a localized area usually over a bony prominence" and category four the worst, being defined as "full thickness tissue loss with exposed bone, tendon or muscle" (EPUAP/NPUAP, 2009). These EPUAP/NPUAP categories are also used frequently in pediatric settings (Kottner et al., 2010; Baharestani \& Ratliff, 2007, Curley, Quigley \& Lin 2003a). According to Defloor (1999) pressure and shearing force are the main reasons for pressure ulcer development; pressure and/or shearing force is/are needed to cause a PU. The tissue tolerance of a person is an intermediate variable and not a causal factor in the development of PUs. How high the pressure must be and how long it must be maintained to cause skin damage depends on the individual's tissue tolerance (Defloor, 1999). "The tissue tolerance of an individual is influenced by two major components - the tissue tolerance for pressure, meaning the capacity of the tissue to redistribute pressure - and the tissue tolerance for oxygen, meaning factors that influence oxygen distribution 
within the tissue and the oxygen need of the tissue" (Defloor, 1999, p. 211). Tissue mass, patient age, nutritional status and dehydration, medications and mental and physical condition of the patient, body temperature and co-morbidity are relevant determinants which influence tissue tolerance (Defloor, 1999; Nixon, Cranny \& Bond, 2007; Quintavalle, Lyder, Mertz ,et al., 2006; Kottner, 2012).

To what extent these PU etiologies are true for pediatric patients and whether there are any differences in classifying PUs in pediatric patients according to adult categories has not been studied so far and is thus unknown.

\subsubsection{The pediatric patient}

"The United Nations Convention on the Rights of the Child defines a child as "a human being below the age of 18 years". Within this time period one distinguishes between neonate, infants, toddlers, preschool child, school child and adolescent (Unicef, 2003).

A neonate is defined as a child from birth up until its first 28 days of life. This includes preterm neonates, which means neonates born before 40 weeks of gestational age. In preterm neonates one distinguishes further between very low term neonates, which includes neonates between 24 and 31 (full) weeks of gestational age and low term neonates, which means neonates born from 32 weeks of gestational age until 36 weeks of gestational age. Children born after 37 weeks of gestational age are categorized as term-born neonates. A newborn is a neonate within his first hours of life. An infant is a child in the time period from the age of 4 weeks up to its first birthday, followed by toddlers, which are children from the age of 1 up to their third birthday. A preschool child is between 3 and 5 years old, a school child between 6 and 12 years of age; adolescence covers the time from 12 up to the $18^{\text {th }}$ birthday (American Academy of Pediatrics, 2002, World Health Organization, 2005).

It should be kept in mind that pediatric patients, in comparison to adults, are in widely differing health conditions. The overall health status of children is generally better and multi-morbidity is limited to a small percentage of patients, like very low term neonates (born before 32 weeks of gestation age), newborns with congenital 
abnormalities or children with chronic conditions. Survival rates of both critically and chronically ill neonates, infants and children have improved dramatically in recent years, introducing new challenges for medical and nursing care (Jones et al., 2001).

\subsubsection{The skin of pediatric patients}

Children's skin undergoes several changes throughout the first 18 years of life (Butler 2007). The most important function of the skin is to protect against water loss, absorptions of noxious substances, intrusions of microorganisms and physical trauma (Blume-Peytavi, Hauser, Stamatas, et al., 2011). The skin of children is morphologically and functionally different from adult skin (BlumePeytavi et al., 2011, Nikolovski, Stamatas, Kollias, et al., 2008, Stamatas, Nikolovski, Luedtke et al., 2010). Within the first days of life neonates undergo various adaptation processes needed to accommodate the transition from the wet intrauterine environment to the dry outside environment (Blume-Peytavi et al., 2011). During the first months and years the skin continues to develop and evolve its structure and functions (Blume-Peytavi et al., 2011; Butler, 2007) (Figure 3 \& 4).

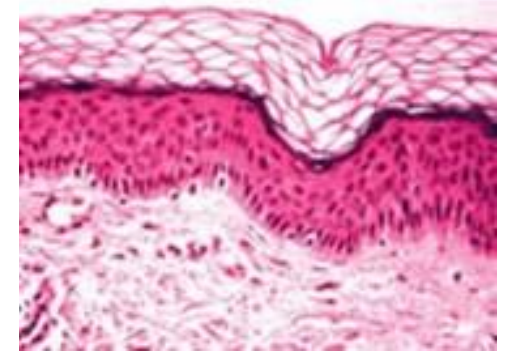

Figure 3: Histology of skin of a newborn

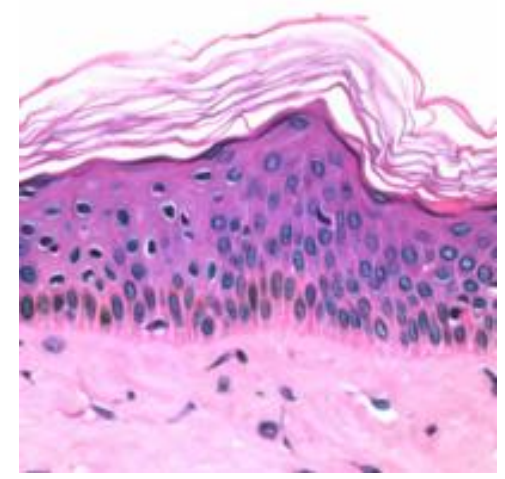

Figure 4: Histology of skin of a child 
The unique physiological needs of children with regard to skin first require some explanation. Physiologically, fluid and electrolyte disturbances occur more frequently and develop more rapidly in infants and young children than in older children and adults. The higher proportion of water content and greater relative surface area of young bodies increases the risk of dehydration under the metabolic demands associated with fever. Skin cells that are not well perfused may be hypoxic and are at risk of breaking down even with minimal trauma (Rossi, 1989).

It is known that any skin breakdown, especially in critically ill neonates and infants, increases the risk of septicemia as well as related severe complications and higher mortality (Dellinger, Mitschell, Rhodes et al., 2013). Pressure ulcers also cause an increase in pain, infection and calorie expenditure in pediatric patients (Curley et al. 2003a, Zollo, Gastisha, Bernes et al. 1996, Samaniego 2003, Cockett, 2001) and therefore it is of great importance to avoid any damage to the fragile skin of pediatric patients.

\subsubsection{Specific PU risk factors and PU risk assessments for children}

Potential risk factors for PUs are immobility and decreased skin sensitivity (Suddaby, Barnett \& Facteau, 2005, Willock, Harris, Harrison, et al. 2005, Willock 2005). These are well known risk factors for adult patients (de Laat et al., 2006; Lindgren, Unosson, Krantz, et al., 2004; Moore \& Cowman, 2008; Nonnemacher, Stausberg, Bartoszek, et al., 2009; Papanikolaou, Lyne \& Ratcliffe, 2007) with some evidence that in pediatric patients these risk factors increase the risk of pressure ulcer development as well (Suddaby et al. 2005, Willock et al. 2005, Willock 2005). With regard to the pediatric patient, sick children in general, but also due to limited communication skills, neonates, infants and toddlers, disabled and neurologically impaired children, seem to be at particular risk of developing pressure ulcers (Willock, 2005; Willock and Maylor, 2004; Curley et al. 2003a, Zollo et al. 1996).

Further, several risk factors with regard to external devices are known for pediatric patients. The consequences of immobility and decreased skin sensitivity and risk factors related to equipment such as tubes, IV catheterization and CPAP have 
been described (Willock, 2005; Willock and Maylor, 2004; Curley et al., 2003). Especially patients in pediatric intensive care units (PICU) are at increased risk for skin failure. Here the pressure of tubes in oscillation and extracorporeal membrane oxygenation as well as the decreased tissue tolerance in these patients due to their critical condition makes these children most vulnerable (Schindler et al., 2007; Curley et al., 2003a).

Furthermore, the need for additional medical and therapeutic aids, such as wheelchairs, unadjusted ortheses and prostheses (Noonan, Quigley, Curley, 2006, Dixon and Ratliff, 2005, Samaniego 2003, Cockett, 2001) are known risk factors for pressure ulcer development in children.

A problem limited to neonates is their immature skin with regard to the friable skin and circulatory system, which leads to extravasation, or skin failure due to strapping or tubing or monitoring sensors (Waterlow, 1997, Parnham, 2012).

Despite the known risk factors, a reliable and valid PU risk assessment tool with validated cut-off points, applicable to a wide range of the juvenile population from neonates to adolescents, is still not available (Anthony, Willock \& Baharestani, 2010). Avoidance of pressure-related injuries and maintenance of skin and tissue integrity are obviously regarded as important goals in the care process, and identifying individuals at risk for developing PUs by structured risk assessments is recommended as a first step for effective PU prevention (Duncan, 2007; Stechmiller et al., 2008). In the published international guidelines by the NPUAP and the EPUAP (2009) it is explicitly stated that "Risk assessment scales are the foundation of risk assessment practice." (p. 24). Over the last five decades more than 30 standardized PU risk scales for adults have been developed, tested and modified. The structure of most of these instruments is comparable: they include a number of items that are deemed important in PU development, like "Mobility", "Continence", "Nutrition" and many more (Bergstrom, Braden, Laguzza, et al., 1987; Waterlow, 1985). Item scores are summed resulting in total scores indicating individual risk. To be useful in clinical practice, PU risk assessment scales must be valid and reliable, they should demonstrate an enhanced quality of care, and they must improve patient outcomes. Above all, application of PU risk assessment scales should reduce PU occurrence (Jull and Griffiths, 2010; Kottner and Balzer, 2010). There are various systematic reviews addressing validity, 
reliability and clinical impact issues of PU risk scales in the adult population (Pancorbo-Hidalgo, Garcia-Fernandez, Lopez-Medina, et al., 2006; Moore and Cowman, 2008; Kottner et al., 2009), but there is no up to date systematic synthesis of empirical evidence about PU risk scales in children. This is a serious limitation since PU risk assessment using an age-appropriate, valid and reliable instrument is also recommended for clinical pediatric practice (Loman 2000; Baharestani and Pope, 2007).

Many of the available assessment tools, like the Braden-Q scale, are modifications of PU risk scales for adults and include variables deemed especially important for PU development in the adult population, e.g. mobility, incontinence, moisture, and nutrition. The relevance and clinical effectiveness of specifically pediatric PU risk scales has not so far been investigated.

\subsubsection{PU Preventive measures for pediatric patients}

Pressure ulcer prevention is multifaceted and requires skills, knowledge and consistency in nursing practice. Risk assessment, skin assessment, repositioning and pressure relief are integral components of effective prevention of PUs in children (Parnham, 2012). The preventive measures taken for children are often those recommended for adult patients (Waterlow, 1997). Baharestani and Ratliff (2007) have highlighted the importance of specific age-related preventive strategies. Preventive measures should meet the individual needs of each child and therefore, with regard to preventive measures, special attention must be paid to neonates and infants (Waterlow, 1997).

Various preventive measures based on the clinical experience of nursing experts in the care of children are known and used. However, no research based preventive measures with regard to special pediatric needs have been established. The preventive measures described for children are skin care, pressure-relieving facilities (sheep skin, silk sheets and gel or water pillows for neonates; special pressure-relieving mattresses for older children (Waterlow, 1997), and regular turning of the child/neonate (Waterlow, 1997). With regard to neonates it seems most important to meet the baby's need with regard to its immature skin (Waterlow, 1997). Timely skin assessment is recommended but no 
frequency is described (Collier, 1999); such assessment includes examining the skin for evidence of new damage (Collier, 1999).

Repositioning should be performed regularly in immobile patients and should pay special attention to the relevant anatomical localizations in children, which are the occipital, sacral, and calcaneal areas (Butler, 2007, Parnham, 2012). Repositioning is not recommended for hemodynamically unstable patients (Butler, 2007). Next to manual repositioning, therapeutic pressure-relieving surfaces may also be required (Parnham, 2012). The range of available support surfaces for children is limited (Parnham, 2012). Foam mattresses aim to redistribute body weight and the movement of a child is only slightly limited (Parnham, 2012). Alternating air systems often do not fit well in children. The active and spontaneous movement of a child is limited in an alternating air system mattress and the lower weight or size of a child will increase the risk that a child lays between the effective parts of such devices (Parnham, 2012). The cells of such matrasses, which are fitted for adults, are described as being too large for children, and pediatric-specific mattress systems are not very common (Law, 2002).

Many PUs in neonates and children develop along medical devices (Curley et al., 2003a; Willock et al., 2005, Parnham, 2012). No specific preventive measures with regard to this fact are available today.

\subsubsection{PU treatment}

Epidemiological studies and empirical evidence report that the most common wound types in pediatric patients include epidermal stripping, extravasation injuries, surgical wounds, incontinence associated dermatitis, chemical and thermal injuries, wounds secondary to congenital abnormalities and pressure ulcers (Baharestani and Ratcliff, 2007, Baharestani, Amjad, Bookout, et al. 2009b). Wound care in pediatric patients needs to take account of several relevant differences from care in adult patients (Baharestani et al., 2009b; Baharestani, 2007; Gabriel, Heinrich, Shores, et al., 2009, Stone McCord and Levy, 2006, Singh, Scott, Bartlett, et al., 2002). 
There are a number of guidelines for wound treatment in adult patients regarding both the treatment of PUs as well as wounds in general (Fan et al., 2010, Goldberg and Diegelmann, 2012, Adams et al., 2012, Moreira and Markovchick, 2012, Henzel et al., 2011, Warriner and Carter, 2010, McGinnies and Stubbs, 2011, Mclnnes et al., 2011, NPUAP/EPUAP, 2009). No specific guideline for wound treatment in pediatric pressure ulcer wounds is available today. Up until now, there has been a lack of knowledge and research to guide clinical practice in the field of treatment of PUs in pediatric patients (Baharestani et al., 2009b, Stone McCord, 2006, Butler, 2007, Cisler-Cahill, 2006).

\subsection{Scope, aim and research questions of thesis}

As has been demonstrated above, there is a considerable lack of knowledge with regard to the problem of pressure ulcers in pediatric patients. First, the prevalence of pressure ulcer in pediatric patients in terms of different age groups or different pediatric care settings (e.g. the PICU) is unknown. In addition, it remains unclear what the major risk factors are for pressure ulcer development in pediatric patients. Furthermore, it is in fact generally unclear which preventive measures are carried out in pediatric patients with regard to pressure ulcer risk and what their effect is in clinical practice. Also, we do not know which risk assessment scales are valid and reliable for pediatric patients and there is still a lack of knowledge and research to guide clinical practice in the field of treatment of PUs in pediatric patients.

The aims of this thesis are therefore to obtain more information about the prevalence, potential risk factors, and specific infant populations at risk for PUs and also about appropriate PU risk assessment tools for the pediatric health care setting. Finally, we also want to explore the prevention and treatment of pressure ulcers in pediatric patients. 
The specific aims of this thesis are:

First, to conduct a pilot study and according to the results to assess the pressure ulcer prevalence on a nationwide level in pediatric hospitals in Switzerland, answering the following research questions:

(1) What is the prevalence of pressure ulcers in pediatric care settings in Switzerland?

(2) What is the prevalence of pressure ulcers in different age groups?

(3) Which factors influence the occurrence of pressure ulcers?

(4) And what are the characteristics of PU patients?

Second, to systematically review empirical evidence about validity, reliability and clinical impact of PU risk assessment scales for children, answering the following research questions:

(1) What PU risk scales for children currently exist?

(2) What is the diagnostic accuracy of their scores?

(3) Are the scores reliable and what is the degree of agreement?

(4) What is the clinical impact of risk scale scores in pediatric practice?

Third, to identify factors associated with the occurrence of pressure ulcers in hospitalized pediatric patients between one and 18 years of age. Furthermore, to identify anatomical regions associated with the highest risk of pressure ulcer occurrence and to identify risk factors of PUs in hospitalized pediatric patients older than one year of age (>1year).

(1) What factors are associated with the occurrence of pressure ulcers in hospitalized pediatric patients between 1 and 18 years of age?

(2) Which anatomical regions are associated with the highest risk of pressure ulcer occurrence?

(3) What are risk factors for PUs in hospitalized pediatric patients 1-18 years of age? 
Fourth, to assess prevalence, severity and localizations, but also risk factors and preventive measures taken in hospitalized neonates and infants in different care settings according to PU occurrence using the following research questions:

(1) What is the prevalence and severity of PUs in hospitalized neonates and infants in different pediatric hospital departments?

(2) What are the most frequent localizations where pressure ulcers occur?

(3) What are the risk factors of neonates and infants with PUs?

(4) Which preventive measures against PUs were taken in these patients?

Fifth, to assess PU treatment in Swiss hospitalized pediatric patients, and to determine whether there are differences in pressure ulcer treatment according to demographic characteristics of the patients. The following research questions were formulated for this study:

(1) Which pediatric patients show severe PUs of category 2, 3 and 4 compared with patients at risk (patients with category $1 \mathrm{PU}$ )?

(2) What is the current PU treatment in Swiss pediatric hospitals?

(3) Are there any differences in the treatment of severe PUs (category 2 to 4 ) according to demographic characteristics of patients?

\subsection{Structure of thesis}

This thesis consists of eight chapters. In each of chapters two to seven a different study is presented, followed by a general discussion in chapter eight. This chapter eight includes a discussion of the results in relation to the existing literature, implications for clinical practice and implications for research. The thesis is completed with a final summary in English, Dutch and German.

Chapter two presents the results of the first pilot study on pressure ulcer prevalence in four Swiss pediatric hospitals. Few studies are available about the prevalence of pressure ulcers in pediatric patients. To obtain more information about the problem of pressure ulcers in pediatric patients, a nationwide pressure ulcer prevalence study was conducted in Switzerland. 
The results of the first Swiss nationwide pressure ulcer prevalence study in pediatric hospitals are presented in chapter three. This study was undertaken to acquire more insight into the problem, the patients at risk and to identify factors that increase the risk of pressure ulcer development in pediatric patients.

Chapter four presents the results of a systematic review of the empirical evidence about validity, reliability and clinical impact of PU risk assessment scales for children.

In chapters five and six, factors associated with the occurrence of pressure ulcers in hospitalized pediatric patients between 1 and 18 years of age (Chapter five) and neonates and infants (Chapter six) were assessed. It is important to know and identify anatomical regions associated with the highest risk of pressure ulcer occurrence and to identify risk factors for PUs in hospitalized pediatric patients in different age groups.

Chapter seven contains an overview of pressure ulcer treatment conducted in hospitalized Swiss pediatric patients with regard to the unique needs of children with wound care.

\subsection{Ethical considerations}

The studies presented in this thesis were approved by all cantonal ethics committees, and when necessary by the ethics board of the hospitals concerned. After the patients and their legal representatives had been verbally informed of the study's content and aim, they also received the information in written form along with an informed consent form to sign. The information letter as well as the informed consent form for the legal representatives was available in eight different languages (German, French, Italian, English, Portuguese, Albanian, Serbian, and Turkish). Children 10 years of age and older, as well as their legal representatives, were both asked to give their written consent. 


\section{$1.6 \quad$ References}

Adams SB, Sabesan VJ, Easley ME. (2012). Wound healing agents. Critical Care Nursing Clinics North America; 24: 255-260.

Allmann RM, Goode PS, Burst N, Bartolucci AA, Thomas DR. (1999). Pressure Ulcers, Hospitals Complications and Disease Severity: Impact on Hospital Costs and Length of Stay. Advances in Wound Care; 12: 22-30.

American Academy of Pediatrics (AAP). (2002). Newborns, Infants, and Toddlers, http://patiented.aap.org/categoryBrowse.aspx?catID=5001 Accessed 24 April 2013.

Anthony D, Reynolds T, Russell L. (2004). The role of hospital acquired pressure ulcer in length of stay. Clinical Effective Nursing; 8: 4-10.

Anthony D, Willock J, Baharestani M. (2010). A comparison of Braden Q, Garvin and Glamorgan risk assessment scales in pediatrics. Journal of Tissue Viability; 19: 98-105.

Baharestani MM, Black J M, Carville K, Clark M, Cuddigan JE, Dealey C, Defloor T, Harding KG, Lahmann NA, Lubbers MJ, Lyder CH, Ohura T, Orsted HL, Reger SI, Romanelli M, Sanada H. (2009a). Dilemmas in measuring and using pressure ulcer prevalence and incidence: an international consensus. International Wound Journal; 6: 97-104.

Bahasterani MM, Amjad I, Bookout K, et al. (2009b) V.A.C. Therapy in the management of pediatric wounds: clinical review and experience. International Wound Journal;6: 1-26.

Baharestani MM., 2007. An overview of neonatal and pediatric wound care knowledge and considerations.Ostomy Wound Management; 53:34-6, 38, 40.

Baharestani MM, Ratliff CR. (2007). Pressure Ulcers in Neonates and Children: An NPUAP White Paper. Advances in Skin and Wound Care; 20: 208-220. 
Baharestani MM, Pope E. (2007). Chronic wounds in neonates and children. In: Krasner, D., Rodeheaver, G., Sibbald, G. (Eds.), Chronic Wound Care. HMP Communications, Malvern, PA, 679-693.

Bergstrom N, Braden BJ, Laguzza A, Holman V. (1987). The Braden scale for predicting pressure sore risk. Nursing Research; 36: 205- 210.

Blume-Peytavi U, Hauser M, Stamatas GN, Pathirana D, Garcia Bartels N. (2012). Skin care practices for newborn and infants: review of the clinical evidence for best practices. Pediatric Dermatolgy; 29: 1-14.

Butler CT. (2007). Pediatric Skin Care: Guidelines for Assessment, Prevention and Treatment. Dermatology Nursing; 19: 471-486.

Cisler-Cahill L. (2006). A protocol for the use of amorphous hydrogel to support wound healing in neonatal patients: An adjunct to nursing skin care. Neonatal Network; 25: 267- 273.

Cockett A. (2001). A research review to identify the factors contributing to the development of pressure ulcers in pediatric patients. Journal of Tissue Viability; 12: 16-23.

Collier M. (1999). Blanching and non-blanching hyperaemia. Journal of Wound Care; 8: 63-4.

Curley MA, Quigley SM, Lin M. (2003a). Pressure ulcers in pediatric intensive care: Incidence and associated factors. Pediatric Critical Care Medicine; 4: 284290.

Curley MAQ, Razmus IS, Roberts KE, Wypij D. (2003b). Predicting pressure ulcer risk in pediatric patients: the Braden-Q Scale. Nursing Research;52: 22-33.

Dixon, M. \& Ratliff, C. (2005).Pediatric pressure ulcer prevalence- one hospital's experience. Ostomy Wound Management; 51: 44-46 \& 48-50.

Defloor T. (1999). The risk of pressure ulcer sores: a conceptual scheme. Journal of Clinical Nursing; 8: 206-216. 
De Laat E, Schoonhoven L, Pickkers P, Verbeek, A, Van Achterberg T. (2006). Epidemiology, risk and prevention of pressure ulcers in critically ill patients: a literature review. Journal of Wound Care; 15: 269-275.

Dellinger RP, Levy MM, Rhodes A, Annane D, Gerlach H, Opal SM, Sevransky JE, Sprung CL, Douglas IS, Jaeschke R, Osborn TM, Nunnally ME, Townsend SR, Reinhart K, Kleinpell RM, Angus DC, Deutschman CS, Machado FR, Rubenfeld GD, Webb S, Beale RJ, Vincent JL, Moreno R; Surviving Sepsis Campaign Guidelines Committee including The Pediatric Subgroup. (2013). Surviving Sepsis Campaign: international guidelines for management of severe sepsis and septic shock, 2012. Intensive Care Medicine; 39: 165-228.

Duncan KD. (2007). Preventing pressure ulcers: the goal is zero. The Joint Commission Journal on Quality and Patient Safety; 33: 605-610.

Fan K, Tang J, Escandon J,Kirsner RS.(2011). State of the art in topical wound healing products.Plastic Reconstructive Surgery;127(Supl): 44S-59S.

Gabriel A, Heinrich C, Shores J, et al. (2009). Outcomes of vacuum-assisted closure for the treatment of wounds in a pediatric population: case series of 58 patients. Journal Plastic Reconstructive Aesthetic Surgery; 62: 1428-1436.

Goldberg SR, Diegelmann RF. (2012). WoundHealing Primer. Critical Care Nursing Clinics North America; 24: 165-178.

Gorecki C, Brown JM, Nelson EA, Briggs M, Schoonhoven L, Dealey C, Defloor T, Nixon J; European Quality of Life Pressure Ulcer Project group. (2009). Impact of pressure ulcers on quality of life in older patients: a systematic review. Journal of American Geriatriatric Society; 57: 1175-83.

Henzel K, Bogie KM, Guihan M, Ho CH. (2011). Pressure ulcer management and research priorities for patients with spinal cord injury: Consensus opinion from $\mathrm{SCl}$ QUERI Expert Panel on Pressure ulcer research implementation. Journal Rehabiltation Research Device; 48: xi-xxxii. 
Horn SD, Bender SA, Ferguson ML, Smout RJ, Bergstrom N, Taler G, Cook AS, Sharkey SS, Voss AC. (2004). The National Pressure Ulcer Long-Term Care Study: pressure ulcer development in long-term care residents. Journal of American Geriatriatric Society; 52: 359-67.

Jones I, Tweed C, Marron M. (2001). Pressure area care in infants and children: Nimbus pediatric system. British Journal of Nursing; 11: 789-795.

Jull A, Griffiths P. (2010). Is pressure sore prevention a sensitive indicator of the quality of nursing care? A cautionary note. International Journal of Nursing Studies; 47: 531-533.

Kottner J, Balzer K, Dassen T, Heinze S. (2009). Pressure ulcers: a critical review of definitions and classifications. Ostomy Wound Management; 55: 22-29.

Kottner J, Balzer K. (2010). Do pressure ulcer risk assessment scales improve clinical practice? Journal of Multidisciplinary Healthcare; 3: 103-111.

Kottner J. (2012). Was sind Dekubitus? in Schröder G, Kottner J. (2012).

Dekubitus und Dekubitusprophylaxe. Hans Huber, Bern.

Kottner J, Wilborn D, Dassen T. (2010). Frequency of pressure ulcers in the pediatric population: a literature review and new empirical data. International Journal of Nursing Studies; 47: 1330-1340.

Law J. (2002). Transair Paediatric Mattress replacement system evaluation. British Journal of Nursing; 11: 343-346.

Lindgren M, Unosson M, Fredrikson M, Ek AC. (2004). Immobility-a major risk factor for development of pressure ulcers among adult hospitalized patients: a prospective study. Scandinavian Journal of Caring Science; 18: 57-64.

Loman DG, (2000). Assessment of skin breakdown risk for children. Journal of Child and Family Nursing; 3: 234-238.

McGinnis E, Stubbs N. Pressure-relieving devices for treating heel pressure ulcers (Review). (2011). The Cochrane Library; Issue 9. 
McInnes E, Jammali-Blasi A, Bell-Syer S, Dumville J, Cullum N. (2012).

Preventing pressure ulcers- are pressure redistributing support surfaces effective? A Cochrance systematic review and meta-analysis. International Journal of Nursing Studies; 49: 345-359.

Moore ZE, Cowman S. (2008). Risk assessment tools for the prevention of pressure ulcers. Cochrane Database Systematic Reviews; 16: CD006471.

Moreira ME, Markovchick VJ. (2012). Wound management. Critical Care Nursing Clinics North America; 24: 215-37.

National Pressure Ulcer Advisory Panel (NPUAP) and European Pressure Ulcer Advisory Panel (EPUAP). Prevention and treatment of pressure ulcers: clinical practice guideline. National Pressure Ulcer Advisory Panel, 2009, Washington DC.

Nikolovski J, Stamatas GN, Kollias N, Wiegand BC. (2008). Barrier function and water-holding and transport properties of infant stratum corneum are different from adult and continue to develop through the first year of life. Journal Investigation in Dermatology; 128: 1728-36.

Nixon J, Cranny G, Bond S. (2007). Skin alterations of intact skin and risk factors associated with pressure ulcer development in surgical patients: a cohort study. International Journal of Nursing Studies; 44: 655-63.

Nonnemacher M, Stausberg J, Bartoszek G, Lottko B, Neuhaeuser M, Maier I. (2009). Predicting pressure ulcer risk: a multifactorial approach to assess risk factors in a large university hospital population. Journal of Clinical Nursing; 18: 99107.

Noonan C, Quigley S, Curley MA. (2011). Using the Braden Q Scale to Predict Pressure Ulcer Risk in pediatric patients. Journal Pediatric Nursing; 26: 566-575.

Noonan C, Quigley S, Curley MAQ. (2006). Skin integrity in hospitalized infants and children. Journal of Pediatric Nursing; 6: 445- 453.

Papanikolaou P, Lyne P, Ratcliffe J. (2007). Using the discrete choice experimental design to investigate decision-making about pressure ulcer prevention by community nurses. Health Society Care Community; 15: 588-98. 
Pancorbo-Hidalgo PL, Garcia-Fernandez FP, Lopez-Medina IM, Alvarez-Nieto C. (2006). Risk assessment scales for pressure ulcer prevention: a systematic review. Journal of Advanced Nursing; 54: 94-110.

Parnham A. (2012). Pressure ulcer risk assessment and prevention in children. Nursing Children and Young People; 24: 24-29.

Quintavalle PR, Lyder CH, Mertz PJ, Phillips-Jones C, Dyson M. (2006). Use of high-resolution, high-frequency diagnostic ultrasound to investigate the pathogenesis of pressure ulcer development. Advances in Skin Wound Care; 19: 498-505.

Rossi E. (1996). Pädiatrie. $3^{\text {rd }}$ edition, Stuttgart; New York: Thieme.

Samaniego IA, (2003). A sore spot in pediatrics: risk factors for pressure ulcers. Pediatric Nursing; 29: 278-282.

Schindler CA, Mikhailov TA, Fischer K, Lukasiewicz G, Kuhn EM, Duncan L. (2007). Skin integrity in critically ill and injured children. American Journal of Critical Care; 16: 568-574.

Shahin ES, Dassen T, Halfens RJ. (2008). Pressure ulcer prevalence in intensive care patients: a cross-sectional study. Journal Evaluationin Clinical Practice; 14: 563-8.

Singh DJ, Bartlett SP, Low DW, Kirschner RE.(2002). Surgical Reconstruction of Pediatric Pressure Sores: Long-Term Outcome. Journal Plastic Reconstructive Aesthetic Surgery; 109: 265-269.

Stamatas GN, Nikolovski J, Luedtke MA, Kollias N, Wiegand BC. (2010). Infant skin microstructure assessed in vivo differs from adult skin in organization and at the cellular level. Pediatric Dermatology; 27: 125-31.

Stechmiller JK, Cowan L, Whitney JD, Phillips L, Aslam R, Barbul A, Gottrup F, Gould L, Robson MC, Rodeheaver G, Thomas D, Stotts N. (2008). Guidelines for the prevention of pressure ulcers. Wound Repair and Regeneration; 16: 151-168.

Stone McCord S, Levy ML. (2006). Practical guide to pediatric wound care. Seminars in plastic surgery; 20: 192-199. 
Suddaby EC, Barnett S, Facteau L. (2005). Skin breakdown in acute care pediatrics. Pediatric Nursing; 31: 132-138 \& 148.

United Nations (UN) General assembly. (1989). Convention on the Rights of the Child. Document A/RES/44/25. available at:

http://www.hakani.org/en/convention/Convention_Rights_Child.pdf, accessed 30.05.2013.

Warriner III RA, Carter MJ. (2010). The current state of evidence-based protocols in wound care. Plastic Reconstructive Surgery; 127 (Suppl): 144S-153S.

Waterlow J. (1997). Pressure sore risk assessment in children. Pediatric Nursing; 9: 21-24.

Waterlow J. (1985). Pressure sores: a risk assessment card. Nursing Times; 81: 49-55.

Whittington KT, Briones R. (2004). National Prevalence and Incidence Study: 6year sequential acute care data. Advances in Skin and Wound Care; 17: 490-4.

Willock J, Maylor M. (2004). Pressure ulcers in infant and children. Nursing Standards; 24: 56-62.

Willock J, Askew C, Bolland R, Maciver H, James N. (2005). Multicenter research: lessons from the field. Pediatric Nursing; 17: 31- 33.

Willock J. (2005). Identifying the characteristics of children with pressure ulcers. Nursing Times; 101: 40-43.

The World Health Organization (WHO). The World Health Report 2005 - make every mother and child count. Available at: http://www.who.int/whr/2005/en/, Accessed 23 April 2013.

Zollo M, Gostisha M, Berens R, Schmidt J, Weigle C. (1996). Altered skin integrity in children admitted to a pediatric intensive care unit. Journal of Nursing Care Quality; 11: 62-67. 



\section{The Prevalence of Pressure Ulcers in Four Pediatric Institutions}

Schlüer AB, Cignacco E, Müller M, Halfens R. (2009). The prevalence of pressure ulcers in four pediatric institutions. Journal of Clinical Nursing; 18: 3244-3252. 


\section{Abstract}

Aim and Objective: Pressure ulcers are a common nursing care issue in hospitals. They are associated with psychological and physical suffering, an increased morbidity and mortality rate and higher overall health care costs. The aim of the current study is to describe the frequency of pressure ulcers in a pediatric care setting and to identify the population at risk, as well as to assess the factors predisposing to the development of pressure ulcers.

Design: A point prevalence study.

Methods: The study was conducted in four pediatric hospitals in the Germanspeaking part of Switzerland and included children from the age of 0-18 years. The method of data collection was a direct systematic inspection and assessment of the skin, taking into account the clinical condition of the patient for risk assessment. A valid risk assessment and data collection instrument was used and, each patient was assessed by a previously instructed rater pair.

Results: Of all possible patients, $81 \%(n=155)$ were included. An overall pressure ulcer prevalence of $27.7 \%$ (including grade 1 ) was registered. Thirty-six patients (84\%) had category 1 ulcers, including many caused by external medical devices. Sixty-five percent $(n=100)$ of all patients were considered at risk (Braden score $\leq$ 20) of developing a pressure ulcer. Thirty-five percent of patients in the risk group were afflicted with one or more pressure ulcers.

Conclusion: The prevalence of pressure ulcers in pediatric patients is greater then previously appreciated and the problem requires further exploration. The high percentage of category 1 pressure ulcers caused by medical devices requires nursing interventions to prevent lesions for these patients.

Relevance to Clinical Practice: The high prevalence rate in pediatric patients is disconcerting and requires further exploration in terms of interventions needed to improve outcomes for this patient group. 


\section{$2.1 \quad$ Introduction}

Pressure ulcers are a common nursing care issue in hospitals. They are associated with psychological and physical suffering, an increased morbidity and mortality rate and higher costs in health care institutions worldwide. In the Netherlands, annual expenses for the prevention and therapy of pressure ulcers amount to approximately US $\$ 350$ million, which constitutes about $1.3 \%$ of the total annual health care costs (Bours et al. 2002). In Germany, the average cost of a pressure ulcer treatment and therapy is estimated at 50,000 Euro. The annual economic and financial cost is estimated to be between 1.5 and 3 billion Euros (Woltemade 2004). In the UK the treatment costs for one pressure ulcer vary from $£ 1,064$ (Category 1 ) to $£ 10,551$ (Category 4) and total costs in the UK amount to £1.4-2.1 billion annually (Bennett et al., 2004). It can be assumed that with sufficient prevention measures in England, up to $£ 324,000$ per hospital could be saved every year (Thomson \& Brooks 1999).

Through large-scale, nationwide epidemiological studies, the prevalence of pressure ulcers in nursing care institutions for adults is known and well documented today. It varies from 9-33\% (Bours et al. 2002, Dassen 2002, Heller 2003, Hopkins et al. 2000, Lahmann et al. 2002, Meraviglia et al. 2002, O’Dea 1999, Tannen et al. 1999, Thoroddsen 1999, Whittington et al. 2000). Besides evidence-based preventive nursing interventions, a first step in improving care quality is the periodic collection of data regarding prevalence and incidence of pressure ulcers. Accordingly, the Agency for Healthcare Research and Quality (AHRQ, 2000) recommends periodic prevalence studies to evaluate the efficiency of pressure ulcer prevention programs and standards (Whittington et al. 2000).

Pediatric patients are often excluded from pressure ulcer prevalence studies. This fact may be surprising, since the few studies conducted in pediatric care settings show a prevalence rate variation between $0.47 \%$ and $23 \%$ for this specific group (Dixon and Ratliff 2005, Suddaby et al., 2005, McLane et al., 2004, Groeneveld et al., 2004, Baldwin 2002, Willock et al. 2000). The incidence rate lies between 0.29\% and 32.8\% (Dixon and Ratliff 2005, Suddaby et al. 2005, Groeneveld et al. 
2004, Baldwin 2002, Willock et al. 2000, Curley et al. 2003). Pressure ulcers cause an increase in pain, infection and calorie expenditure in pediatric patients (Curley et al. 2003, Schmidt et al. 1998, Zollo et al. 1996, Samaniego 2003, Cockett, 2001). Sick children, premature infants and toddlers, but also disabled and neurologically impaired children, seem to be at particular risk of developing pressure ulcers (Curley et al. 2003, Schmidt et al. 1998, Zollo et al. 1996).

One known risk factor for the development of pressure ulcers in the pediatric care setting is the need for additional medical and therapeutic aids, such as wheelchairs, unadjusted ortheses and prostheses (Samaniego 2003, Cockett, 2001). Further potential risk factors mentioned are immobility and decreased skin sensitivity (Suddaby et al. 2005, Willock et al. 2005, Willock 2005). Furthermore, it should be kept in mind that pediatric patients are, in comparison to adults, in widely differing health conditions. The overall health status of children is generally better and multi-morbidity is limited to a small percentage of patients only. Survival rates of both critically and chronically ill infants and children, on the other hand, have improved dramatically in recent years, introducing new challenges for medical and nursing care, among them an increase in the pressure ulcer risk (Jones et al. 2001). Moreover, age-related, limited communication faculties of infants and toddlers or of mentally handicapped children lead to an increased pressure ulcer risk (Curley et al. 2003, Willock 2005, Willock and Maylor, 2004).

Due to the above-mentioned lack of information, there is an urgent need for studies of pressure ulcer prevalence in the pediatric population to improve the quality of health care. The aim of the current study is to describe the frequency of pressure ulcers in a pediatric care setting and to identify the population at risk, as well as to assess the factors predisposing to the development of pressure ulcers. 


\section{$2.2 \quad$ Methods}

\subsubsection{Design}

A multicenter, descriptive point prevalence study was conducted in four pediatric hospital institutions on 6 July 2006. All pediatric disciplines in the participating sites were included and represented.

A convenience sample of all hospitalized children from the age of 24 hours (including premature babies) up to and including 17 years was considered in the study. Children had to have been hospitalized for at least one day in the respective institutions. All wards (including burn patients, premature babies and rehabilitation patients) were included. Those excluded were children who were hospitalized in psychiatric wards as well as children whose legal representatives did not allow their participation or who themselves refused to participate.

\subsubsection{Ethical aspects}

The study was performed following approval from the local ethics board. After the patients and their families had been verbally informed about the study's content and aim, they were given the same information in written form as well as the 'informed consent' sheet to sign. Children 10 years of age and older were asked to give their own written consent.

\subsubsection{Data collection}

To assess the prevalence, severity, risk factors as well as the preventive and therapeutic interventions of pressure ulcers the instrument of Bours et al. was used in this study (Bours et al. 1999). This instrument is widely used in Europe and includes six categories of data to be collected: (1) characteristics of the health care institutions, (2) characteristics of the ward or team, (3) characteristics of the patients (demographic and clinical data), (4) assessment of the risk of pressure 
ulcer development using the Braden scale, (5) assessment of the severity of pressure ulcers and (6) preventive interventions already in place.

The Braden Scale is one of the most well-known and widely used tools for evaluating pressure ulcer risk, as its good psychometric properties in assessing risk have been verified. The Braden Scale has also been used previously to assess pressure ulcer risk in pediatric patients (Samaniego 2003, Suddaby et al. 2005). It includes six subscales, five of which have four, and the sixth three answer categories (Dassen et al. 2001, Boes 2000, Bergstrom et al. 1998, Bergstrom et al. 1987). For the composite score of the Braden scale, a Pearson correlation coefficient between the two raters was established at $r=0.81$ (Bours et al. 1999). Internal consistency with the total Braden scale has been demonstrated by Halfens et al. (2000) and is judged as being sufficient, with a Cronbach's alpha value of 0.78 . Interrater reliability for the individual risk factors varied between 0.71 and 0.86 (Cohen's kappa). The stability of the Braden score between the first and the second measurement and between the second and third measurement has been established at $r=0.52$ (Halfens et al. 2000). The total scores range from 6 to 23 points, with the lower score indicating a higher risk for the patient of developing a pressure ulcer. There is no agreement regarding the cut-off point of the Braden scale for defining patients at risk. The cut-off score varies between 16-21 and highlights the importance of the specificity and sensitivity of risk assessment tools (Defloor \& Grypdonck, 2004). In the present study the cut-off point for patients at risk was set at $\leq 20$, following the recommendation of the European Pressure Ulcer Advisory Panel (EPUAP, 2004).

\subsubsection{Procedure for collecting the data}

The method of data collection was a direct and systematic inspection and judgment of the skin, as well as of the clinical condition of the patient before the risk assessment. The EPUAP (EPUAP, 2004) pressure ulcer grading system was used. Category 1 ulcers were measured by finger pressure because transparent disks were not available on all institutions.

Demographic and clinical data, such as date of birth, weight and size, body mass index and diagnosis were collected from patients' charts. The criteria were 
assessed by a rater pair for each patient. A total of ten rater pairs were involved in the inquiry. On each unit, an internal and an external rater were working together. If the pair disagreed on their assessment, they were asked to find consensus. If no consensus could be found, the external rater was given the right of decision.

\subsubsection{Selection and preparatory training of the raters}

To be selected, raters were required to have had more than two years of nursing practice with children. In all participating hospitals, nurses who either worked as wound consultants in their units or as clinical nursing specialists acted as raters. Preparatory training included methodological aspects, detailed and exact information about the progression of the data collection, the role and responsibilities of the raters, as well as a detailed introduction to the measurement instruments and a special training in rating pressure ulcer grading and using the Braden scale in infants.

\subsubsection{Pilot study}

A balanced incomplete block design with 15 children and 10 rater pairs was used to assess the inter-rater reliability for grading and risk assessment (Fleiss 1981). The grading of pressure ulcers had sufficient inter-rater reliability (Kappa 0.81). For risk assessment with the Braden scale an analysis of variance concerning discrepancies between rater pairs was used. No significant discrepancies or variations occurred $(p<0.001)$. The intra-class correlation coefficient of reliability of the Braden scale was estimated at ICC $=0.98$. As to whether the patient developed a pressure ulcer or not, three of 60 observations differed, which represents a data consistency of $98 \%$. The inter-rater agreement for the different pressure ulcer categories deviated for only two of the fifteen patients, with one rater pair considering a pressure ulcer as non-existent whilst the three other rater pairs assessed it as category 1 and two rater pairs rating a pressure ulcer as category 1 whereas two other pairs classified the same ulcer as category 2 . 


\subsubsection{Statistical analysis}

SPSS (version 14.01 for Windows) was used to analyse the study data with descriptive and uni-variate statistical methods. Distributions and frequencies were calculated. The description of correlation between dependent variables and influencing factors was conducted with cross tabs. Group differences were accorded to the type of data with nonparametric tests for categorical and not normally distributed data. For the analysis of the correlation between Braden score and variables, a uni-variate analysis of variance was performed. The relationship between pressure ulcers and possible influencing and conflicting factors were studied by logistic regression. To find the most suitable model for the analysis of variance as well as logistic regression, the following variables were applied to the model: age, sex, operation, BMI, preventive action, Braden score, institutions, disciplines and all quality indicators of the institutions. The data were entered into the model followed by a forward stepwise selection of the important variables according to the use of likelihood quotients. The entry and removal probabilities were 0.05 and 0.10 . The Receiver Operating Characteristics curve (ROC), which plots sensitivity against 1-specificity over the range of Braden scores, was used to confirm the cut-off value of the Braden scale. A p-value of 0.05 and lower is statistically significant. 


\section{$2.3 \quad$ Results}

The overall sample size of potential study participants was 213 , of whom 191 (100\% adjusted sample) met the inclusion criteria; of these, 36 dropped out, with $28(15 \%)$ refusing to participate. The other eight patients dropped out because of unexpected discharge, examination or operations with a duration of more than the length of the total survey. In the four selected clinics, the participation rate differed from $15-83$ children (69\%-80\%). The total number of participants was $155(81 \%)$.

\subsubsection{Demographic characteristics}

Demographic characteristics are presented in Table 1. Twenty one percent of all patients were hospitalized on a surgical ward $(n=33)$, a third of all patients were on a pediatric medical ward $(n=51)$, while a fifth of all patients were in a rehabilitation setting $(n=30)$ and a quarter of all patients were neonates $(n=41)$. Eighty-six patients $(55.5 \%)$ were male. Due to the comparatively high rate of neonatology patients, age distribution is not very symmetric. If one considers the children in the age group of less than one year of age only $(n=56 ; 36 \%)$, the average age in weeks is 7.6 weeks with a Median of three weeks. Twenty five percent $(n=38)$ of all patients were 12 years and older.

Table 1: Demographic features of the study sample

\begin{tabular}{l|l|r|r|r|r|r|r}
\hline \multicolumn{2}{l}{} & Mean & Median & SD & min & $\max$ & IQR \\
\hline Duration of stay \\
$\begin{array}{l}\text { according to divisions } \\
\text { (weeks) }\end{array}$ & Surgery & 3.5 & 1 & 6.8 & 0 & 28 & 3 \\
& Pediatric medical & 3.5 & 1 & 7.8 & 0 & 38 & 2 \\
& Rehabilitation & 46 & 22 & 71.2 & 1 & 305 & 55.5 \\
& Neonatology & 1.7 & 1 & 1.9 & 0 & 7 & 3 \\
\hline Age (years) & Male & 5.4 & 4 & 5.7 & 0 & 86 & 5 \\
& Female & 6.6 & 6 & 6.6. & 0 & 305 & 5.75 \\
\hline Age group $<1$ year & & 7.6 & 3 & 11.4 & 0 & 47 & 5 \\
(weeks) & & & & & & & \\
\hline
\end{tabular}

The length of stay varies, too, with the overall duration showing an average of 11.2 weeks, a Median of one week and a range of 304 weeks. Allowing for the different settings, including the rehabilitation settings where patients tend to stay longer, it 
is crucial to note that for patients whose stay lasts for less than one week $(n=63)$, the average is 3.2 days (SD 2.1; Median $=3$ ).

Patients with a pediatric medical care problem constitute the largest group ( $\mathrm{n}=51$, $33 \%)$ of participants, with cardiologic $(n=12,8 \%)$ and oncology patients $(n=8,5 \%)$ as subpopulations of these pediatric medical patients. These are followed by patients hospitalized in a neonatal intensive care unit (NICU) $(n=41,27 \%)$ and by patients in a rehabilitation care setting $(n=30,19 \%)$. Beyond these categories, surgical patients $(n=33,21 \%)$ - including orthopedic patients $(n=10,6.5 \%)-$ also constitute a significant number.

\subsubsection{Pressure ulcer risk}

The average Braden score is 18.6 (SD 3.7), with the lowest score at 7 and a maximum score of 23 (Fig.1).

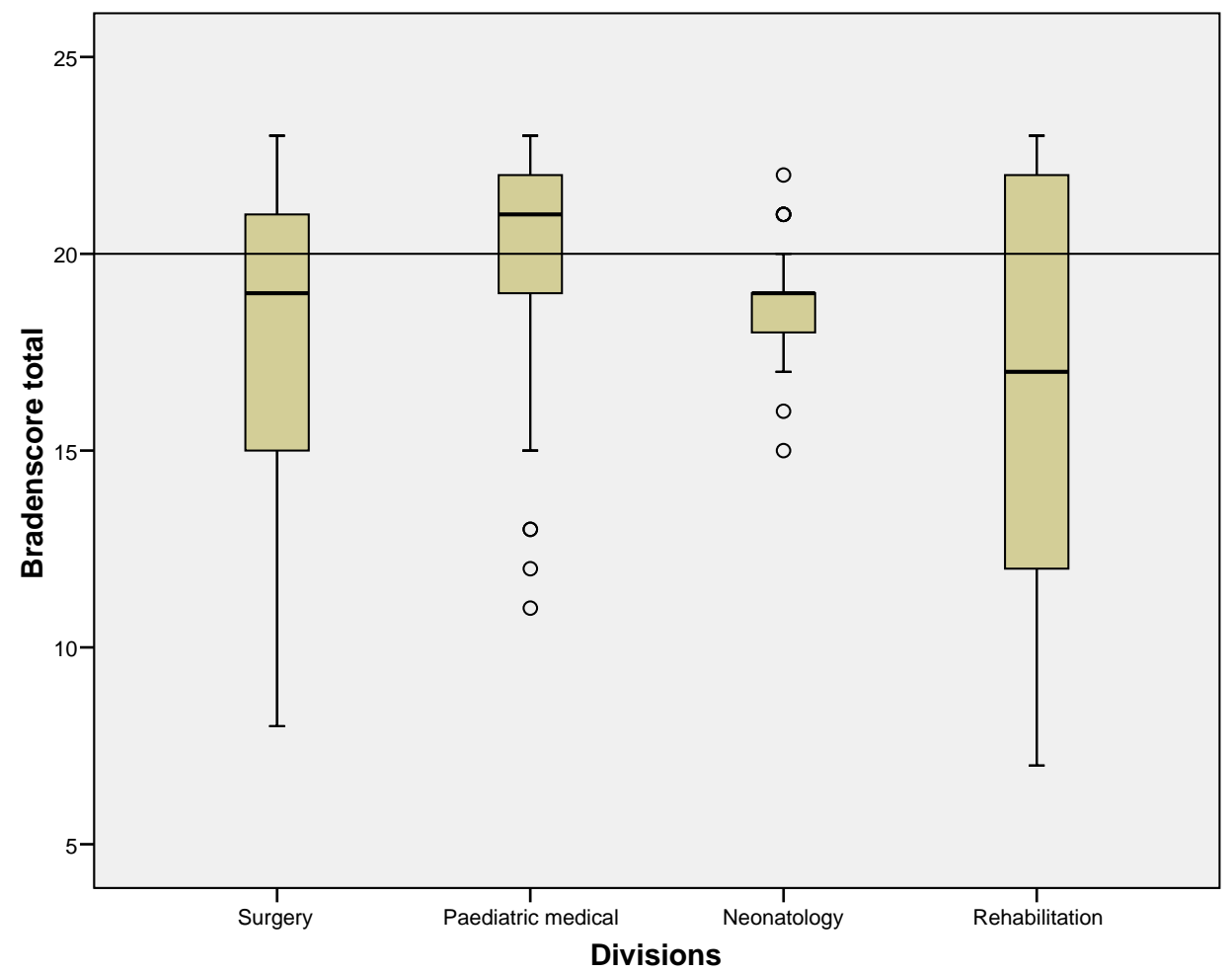

Figure 1: Braden Score per division, patient with and without risk with cut-off line for patient at risk/not at risk at 20.

The average of the overall Braden score for patients at risk (Braden score less than 21) is 16.8 (SD 3.4) and for the patients not at risk 21.8 (SD 0.8). 
Of all patients, $100(64.5 \%)$ were considered to be at risk of developing pressure ulcers. The average risk as related to age group shows a statistically significant difference, $\left(X^{2}=12.79 ; p<0.05\right)$ (Table 2$)$. The most crucial statistical significance of patients at risk is found in relation to the various medical disciplines $\left(X^{2}=18.42\right.$; $p<0.001)$. Two thirds of the patients hospitalized on a surgical ward, either with surgical treatment or in a rehabilitation care setting, must be considered at risk of being afflicted with a pressure ulcer. The patient group most at risk is that of neonatology patients, with a percentage of $84.5 \%$.

Table 2: Age and divisions distribution patient at risk

\begin{tabular}{|c|c|c|c|c|c|c|c|c|c|c|c|}
\hline & & \multicolumn{5}{|c|}{ Age categories } & \multicolumn{5}{|l|}{ Divisions } \\
\hline & & $<1$ & $1<4$ & $4<8$ & $8<12$ & $12<18$ & Surgery & Pedi. & Neo. & Rehab. & Total \\
\hline $\begin{array}{l}\text { Patient } \\
\text { not at risk }\end{array}$ & $\begin{array}{l}n \\
(\%)\end{array}$ & $\begin{array}{r}13 \\
(23.2)\end{array}$ & $\begin{array}{r}5 \\
(27.8)\end{array}$ & $\begin{array}{r}5 \\
(25)\end{array}$ & $\begin{array}{r}12 \\
(21.8)\end{array}$ & $\begin{array}{r}20 \\
(52.6)\end{array}$ & $\begin{array}{r}10 \\
(30.3)\end{array}$ & $\begin{array}{r}29 \\
(56.9)\end{array}$ & $\begin{array}{r}6 \\
(14.6)\end{array}$ & $\begin{array}{r}10 \\
(33.3)\end{array}$ & $\begin{array}{r}55 \\
(35.5)\end{array}$ \\
\hline $\begin{array}{l}\text { Patient at } \\
\text { risk }\end{array}$ & $\begin{array}{l}n \\
(\%)\end{array}$ & $\begin{array}{r}43 \\
(76.8)\end{array}$ & $\begin{array}{r}13 \\
(72.2)\end{array}$ & $\begin{array}{r}15 \\
(75)\end{array}$ & $\begin{array}{r}11 \\
(47.8)\end{array}$ & $\begin{array}{r}18 \\
(47.4)\end{array}$ & $\begin{array}{r}23 \\
(69.7)\end{array}$ & $\begin{array}{r}22 \\
(43.1)\end{array}$ & $\begin{array}{r}35 \\
(85.4)\end{array}$ & $\begin{array}{r}20 \\
(66.7)\end{array}$ & $\begin{array}{r}100 \\
(64.5)\end{array}$ \\
\hline Total & $\begin{array}{l}n \\
\text { (\%) }\end{array}$ & $\begin{array}{r}56 \\
(36)\end{array}$ & $\begin{array}{r}18 \\
(11)\end{array}$ & $\begin{array}{r}20 \\
(13)\end{array}$ & $\begin{array}{r}23 \\
(15)\end{array}$ & $\begin{array}{r}38 \\
(25)\end{array}$ & $\begin{array}{r}33 \\
(21.3)\end{array}$ & $\begin{array}{r}51 \\
(32.9)\end{array}$ & $\begin{array}{r}41 \\
(26.5)\end{array}$ & $\begin{array}{r}30 \\
(19.4)\end{array}$ & 155 \\
\hline \multicolumn{7}{|c|}{ Mann Whitney: 1917.5 ** } & \multicolumn{5}{|c|}{$X 2: 18.42$ ** } \\
\hline
\end{tabular}

2.3.3 The prevalence of pressure ulcers

Of the 155 children taking part in this study, a total of 43 showed one or more pressure ulcers on the day of inquiry, which constitutes a prevalence rate of $27.7 \%$ (Table 3). Among these 43 patients, $34(79 \%)$ showed one, seven (16\%) were affected by two and two patients (5\%) showed five occurrences of pressure ulcers. The most frequent type of pressure ulcer found was of category 1 . The prevalence of pressure ulcers of category 2 and higher was $4.5 \%(n=7)$, with one patient suffering from a category 4 ulcer. No significant demographic differences between patients with and without pressure ulcers were found with the only difference relating to the length of stay before the measurement, which was higher for patients with a pressure ulcer (Table 4). 
Table 3: Prevalence of pressure ulcers

\begin{tabular}{|r|r|}
\hline $\begin{array}{r}\text { Number of pressure } \\
\text { ulcers per patient }\end{array}$ & Total (\%) \\
\hline 1 & $34(21.9)$ \\
\hline 2 & $7(4.5)$ \\
\hline 3 & 0 \\
\hline 4 & 0 \\
\hline 5 & $2(1.2)$ \\
\hline
\end{tabular}

\begin{tabular}{|r|r|}
\hline $\begin{array}{r}\text { Prevalence of pressure } \\
\text { ulcer per category }\end{array}$ & Total (\%) \\
\hline overall & $43(27.7)$ \\
\hline 1 & $36(23.2)$ \\
\hline 2 & $6(3.9)$ \\
\hline 3 & 0 \\
\hline 4 & $1(0.6)$ \\
\hline
\end{tabular}

Table 4: Characteristics of patients with a pressure ulcer

\begin{tabular}{|c|c|c|c|c|c|}
\hline & & \multicolumn{4}{|l|}{ Pressure ulcer } \\
\hline & & Yes & No & & Total (\%) \\
\hline & & $43(27.7 \%)$ & $112(72.3 \%)$ & & \\
\hline & & n (\%) & n (\%) & $\mathrm{X}^{2}$ & \\
\hline \multirow[t]{2}{*}{ Sex } & Male & $26(30.2 \%)$ & $60(68.8 \%)$ & \multirow{2}{*}{$\begin{array}{l}0.6 \\
\text { n.s. }\end{array}$} & 86 (55.5\%) \\
\hline & Female & $17(24.6 \%)$ & $52(75.4 \%)$ & & 69 (44.5\%) \\
\hline \multirow[t]{4}{*}{ Divisions } & Surgery & $10(30 \%)$ & $23(70 \%)$ & \multirow{4}{*}{$\begin{array}{l}10.7 \\
\text { n.s. }\end{array}$} & $33(21.3 \%)$ \\
\hline & Ped. Med. & $12(24 \%)$ & $39(76 \%)$ & & 51 (32.3\%) \\
\hline & Neo. & $11(27 \%)$ & $30(73 \%)$ & & $41(26.5 \%)$ \\
\hline & Rehab. & $10(33 \%)$ & $20(67 \%)$ & & 30 (19.4\%) \\
\hline \multirow{2}{*}{$\begin{array}{l}\text { Age groups } \\
<1 \text { year (in weeks) }\end{array}$} & $<20$ & $15(31.9 \%)$ & $32(68.1 \%)$ & \multirow{2}{*}{$\begin{array}{l}7.4 \\
\text { n.s. }\end{array}$} & 47 (83.9\%) \\
\hline & $21-52$ & $2(22.2 \%)$ & 7 (77.8\%) & & $9(16.1 \%)$ \\
\hline \multirow{5}{*}{$\begin{array}{l}\text { Age groups } \\
>1 \text { year (in years) }\end{array}$} & $>1$ (details & ee above) & & \multirow{5}{*}{$\begin{array}{l}3.1 \\
\text { n.s. }\end{array}$} & $56(36.1 \%)$ \\
\hline & 1 to 4 & $2(11.1 \%)$ & $16(88.9 \%)$ & & $18(11.6 \%)$ \\
\hline & 4 to 8 & $5(25 \%)$ & 15 (75\%) & & 20 (12.9\%) \\
\hline & 8 to 12 & $7(30.4 \%)$ & $16(69.6 \%)$ & & $23(14.8 \%)$ \\
\hline & $>12$ & $12(30.4 \%)$ & $26(68.4 \%)$ & & 38 (24.5\%) \\
\hline \multirow{2}{*}{$\begin{array}{l}\text { Operation } \\
\text { in last two weeks }\end{array}$} & No & $34(27.6 \%)$ & $89(72.4 \%)$ & \multirow{2}{*}{$\begin{array}{l}0.0 \\
\text { n.s. }\end{array}$} & $123(79.4 \%)$ \\
\hline & Yes & $9(28.1 \%)$ & $23(71.9 \%)$ & & $32(20.6 \%)$ \\
\hline Age in years & $\begin{array}{l}\text { Mean (SD) } \\
\text { Median }\end{array}$ & $\begin{array}{r}6.14 \\
(6.02) \\
6.5\end{array}$ & $\begin{array}{r}5.84 \\
(6.18) \\
4\end{array}$ & \multicolumn{2}{|r|}{$\begin{array}{r}\text { Mann-Withney: } \\
(0.993) \text { n.s. }\end{array}$} \\
\hline Length of stay in days & $\begin{array}{l}\text { Mean (SD) } \\
\text { Median }\end{array}$ & $\begin{array}{r}74.72(118.00) \\
25\end{array}$ & $\begin{array}{r}83.52 \\
(285.61) \\
9\end{array}$ & \multicolumn{2}{|r|}{$\begin{array}{r}\text { Mann-Withney: } \\
(0.019)^{*}\end{array}$} \\
\hline
\end{tabular}

${ }^{* *}=p<0.001 \stackrel{*}{=} p<0.05$ n.s. $=$ not significant 
Anatomic localization varies and nearly half of the pressure ulcers were located in an anatomic area, which cannot be precisely specified ( $n=25,43 \%)$ (Table 5). Most of these pressure ulcers where assessed along equipment, such as tubes, splints or monitoring cable.

Only a marginal number of pressure ulcers $(n=2,3 \%)$ developed at home, with most $(n=45,78 \%$ ) developing on the ward where the child was hospitalized. Most of the pressure ulcers $(n=47,81 \%)$ had developed in the two weeks before the inquiry. Only nine pressure ulcers $(16 \%)$ had persisted between two weeks and three months and two pressure ulcers (3\%) remained for more the six months.

Table 5: Anatomic localizations of pressure ulcers

\begin{tabular}{|l|r|}
\hline $\begin{array}{l}\text { Anatomic } \\
\text { localizations }\end{array}$ & $\mathrm{n}(\%)$ \\
\hline Other area & $25(43.1)$ \\
\hline Heels & $9(15.6)$ \\
\hline Ankle & $6(10.4)$ \\
\hline Ear & $6(10.4)$ \\
\hline Bottom & $5(8.6)$ \\
\hline Knee & $2(3.4)$ \\
\hline Elbow & $2(3.4)$ \\
\hline Sacrum & $1(1.7)$ \\
\hline Hip & $1(1.7)$ \\
\hline Occiput & $1(1.7)$ \\
\hline
\end{tabular}

2.3.4 The prevalence of pressure ulcers in the risk group

Thirty five percent of all patients in the risk group were afflicted with one or more pressure ulcers. In the group of patients classified as not being at risk, a pressure ulcer prevalence of $14.5 \%(n=8)$ was found. Alternatively, $81.4 \%$ of the patients with a pressure ulcer were assigned to the risk group (Sensitivity: 0.8). The specificity of the Braden scale in this survey was 0.42 . Using pressure ulcer and the total Braden score a Receiver Operating Characteristics Curve (ROC) plotting sensitivity and 1-specificity for each possible Braden score was then constructed. 
The Area under the Curve (AUC) was 0.7 (Cl: 0.604-0.794). A cut-off score of 20 provided a high sensitivity and an adequate specificity. At a score of 16 , sensitivity was 0.395 and specificity was 0.134 . At a cut-off score of 18 the sensitivity was 0.605 and specificity 0.241 .

\section{ROC Curve}

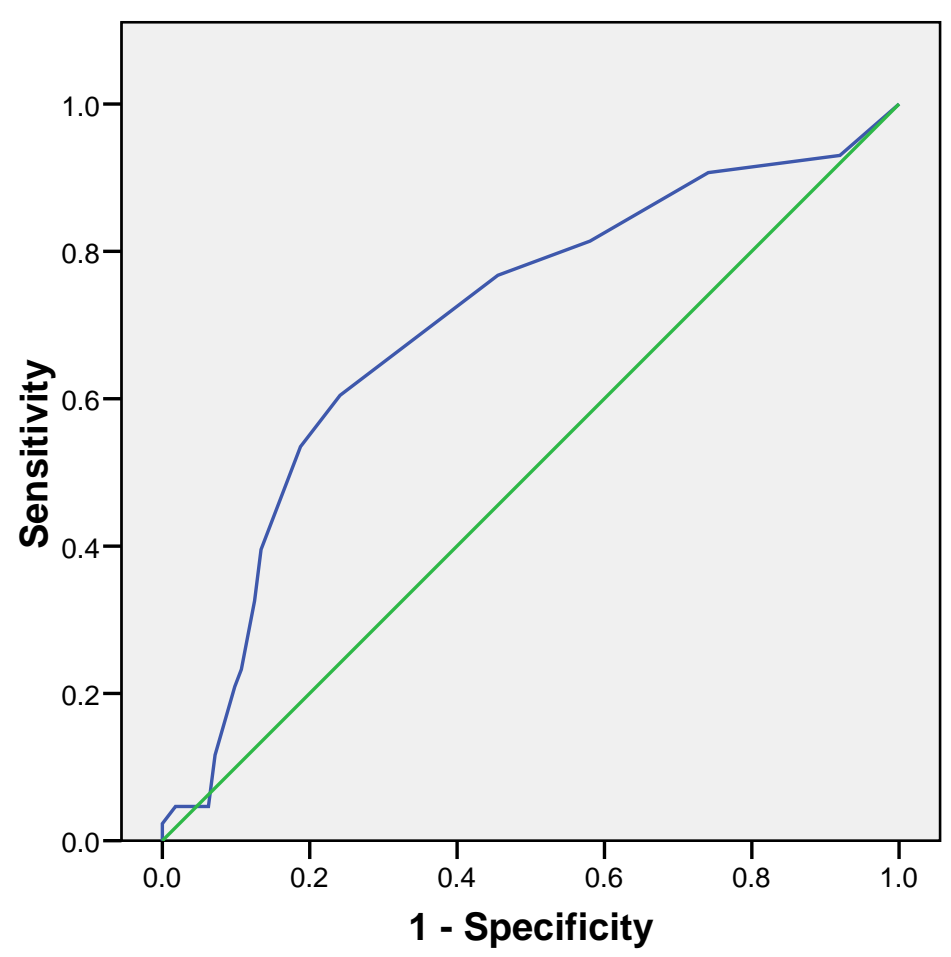

Figure 2: Braden Scale ROC curve with diagonal reference line.

\subsubsection{Pressure ulcers and influencing factors}

The risk factors age, sex, operation, BMI, preventive action taken, Braden score, institutions, wards and all quality indicators of the institutions were examined with a multiple logistic regression analysis. Only the Braden score, institution and wards contributed significantly to the fit. The odds ratios and associated confidence intervals of the variables in the final model are presented in Table 6. The HosmerLemeshow-test shows an adequate goodness of fit for this model $(p=0.57$; Nagelkerke $\mathrm{R}^{2}=0.32$ ). 
Table 6: Logistic regression model with pressure ulcer as dependent variable

\begin{tabular}{|c|c|c|c|c|c|c|c|c|c|}
\hline \multicolumn{10}{|c|}{ Variables in the Equation } \\
\hline & & \multirow[b]{2}{*}{ B } & \multirow[b]{2}{*}{ S.E. } & \multirow[b]{2}{*}{ Wald } & \multirow[b]{2}{*}{ df } & \multirow[b]{2}{*}{ Sig. } & \multirow[b]{2}{*}{$\operatorname{Exp}(B)$} & \multicolumn{2}{|c|}{$\begin{array}{l}95 \% \text { Cl for EXP } \\
\text { (B) }\end{array}$} \\
\hline & & & & & & & & Lower & Upper \\
\hline \multirow[t]{10}{*}{$\begin{array}{l}\text { Step } \\
1\end{array}$} & $\begin{array}{r}\text { Braden } \\
\text { Score }\end{array}$ & .170 & .056 & 9.196 & 1 & .002 & 1.186 & 1.062 & 1.324 \\
\hline & Division & & & 13.447 & 3 & .004 & & & \\
\hline & Division (1) & -2.816 & 1.249 & 5.087 & 1 & .024 & .060 & .005 & 691 \\
\hline & Division (2) & -3.107 & 1.359 & 5.229 & 1 & .022 & .045 & .003 & .641 \\
\hline & Division (3) & -5.109 & 1.489 & 11.780 & 1 & .001 & .006 & .000 & .112 \\
\hline & Institution & & & 15.019 & 3 & .002 & & & \\
\hline & $\begin{array}{r}\text { Institution } \\
(1)\end{array}$ & -2.714 & .925 & 8.599 & 1 & .003 & .066 & .011 & .407 \\
\hline & $\begin{array}{r}\text { Institution } \\
(2)\end{array}$ & -5.759 & 1.519 & 14.373 & 1 & .000 & .003 & .000 & .062 \\
\hline & $\begin{array}{r}\text { Institution } \\
(3)\end{array}$ & 18.474 & $\begin{array}{r}10031 . \\
722 \\
\end{array}$ & .000 & 1 & .999 & $1 \mathrm{E}+008$ & .000 & \\
\hline & Constant & 3.751 & 1.701 & 4.861 & 1 & .027 & 42.543 & & \\
\hline
\end{tabular}

a. variable(s) entered on step 1: Bradenscore, Division, Institution 


\subsection{Discussion}

Our study reveals a high prevalence rate of $27.7 \%$ in the four pediatric hospitals. This rate is higher than the previously found prevalence rates in pediatric care settings, which varied between $0.47 \%$ and $23 \%$ (Dixon \& Ratliff 2005, Suddaby et al. 2005, McLane et al. 2004, Groeneveld et al. 2004, Baldwin 2002, Willock et al. 2000). The prevalence of pressure ulcers in the risk group was $35 \%$ and $14.5 \%$ in the non-risk group.

This high prevalence rate demands critical appraisal. First, an already well-known problem is the diagnosis of pressure ulcers of category 1 (Halfens et al. 2001). Several authors have therefore recommended defining pressure ulcer prevalence by starting the grading system at category 2 (Defloor and Gryponck 2004, Halfens et al. 2001). In this study, however, the prevalence of pressure ulcers at categroy 2 and above accounts for only $4.5 \%$ of the total. This value is comparable to the prevalence of pressure ulcers in the study of Suddaby et al. (2005) and Groeneveld et al. (2004) (both 5.1\%). In several pediatric studies the rates differentiated between a pressure ulcer prevalence rate as well as a skin breakdown wounds rate caused by, for example, diaper rash or cast areas (McLane et al. 2004, Zollo et al 1996, Samaniego 2003).

Second, most pressure ulcers developed on the ward. Over $85 \%$ were facility acquired. Their persistence in $81 \%$ of the cases was less than two weeks, which mirrors the findings of previous studies (McLane et al. 2004, Groeneveld et al. 2004). Although not all pressure ulcers are preventable, the high prevalence rates indicate a need to improve preventive actions as well as risk assessment and to start raising staff's awareness of the pressure ulcer issue in the pediatric health care setting (McLane et al. 2004, Curley at al. 2003).

One known risk factor for the development of pressure ulcers in the pediatric care setting is the additional need for medical and therapeutic aids, such as wheelchairs, unadjusted ortheses and prostheses (Samaniego 2003, Cockett 2001). Pediatric patients are unable to differentiate pressure from or sensory perceptions of such devices properly and are for this reason most vulnerable. 
Equipment-related risk factors, e.g. those connected with traction, tubes and iv.catheterization, are additional potential risk factors in the pediatric health care setting (McLane et al. 2004, Zollo et al. 1996, Samaniego 2003, Willock et al. 2005, Noonan et al. 2006). The most frequent localization of a pressure ulcer in the present study is, in almost $50 \%$ of the cases, in 'other anatomic parts'. The reason for this might be the fact that the majority of pressure ulcers were developed with reference to splints or cables and tubes. Another frequently affected area is the lower extremity with ankle and heels as well as the ear. Furthermore, it is known that, for children, the ear, the occiput and the nose are the anatomic sites most likely to develop a pressure ulcer (Suddaby et al. 2005, McLane et al. 2004, Groeneveld et al. 2004, Curley et al. 2003). In this study, however, we had a remarkably low incidence of pressure ulcers in the occiput.

More than two thirds of all patients were defined as being at risk in the present study. According to individual disciplines, the overall Braden score of surgical and rehabilitative patients is lower than for others, indicating a higher risk of pressure ulcer development. One possible explanation could be that the sample of surgical and rehabilitation patients had a high level of other impairments, with differing conditions influencing the health status of a child. In our setting patients in these two divisions are often limited in their activity and mobility opportunities. In surgical patients skin sensitivity is often limited due to oedema, intense pain therapy and peridural analgesia. In the rehabilitation care setting, chronically ill as well as physically handicapped children are treated. Immobility and reduced sensation has been previously defined as a major risk factor in the study of Willock et al. (2005).

The neonatology sample in this study shows homogeneity for both the Braden score and the overall population at risk. Due to their special condition, specifically their underdeveloped skin cells, such as the dermis and epidermis bond which is still weak, it seems plausible that this population is most affected by pressure ulcers in varying anatomic locations related to the positioning of tubes or cables. Further studies are needed to establish the special risk factors of this highly vulnerable population.

Although the prevalence rate for pressure ulcers in pediatric patients described in this study is high and demands further exploration of the phenomenon, some critical points need to be mentioned. The small sample size, especially for the 
different divisions, as well as the heterogeneity of the clinics involved, only allow limited generalization of the findings to other institutions. An adapted, reliable and valid risk assessment tool, applicable to the wide range of population from neonates to adolescents, in combination with validated cut-off points, is still not available for the pediatric population (Curley et al. 2003a, Cockett, 2001, Willock, 2005, Jones et al. 2001). The cut-off for patients at risk with $\leq 20$ is high, but seems the most precise and accurate for this setting. At the time of data collection for the present study the Braden-Q scale was the only tool available for risk assessment in the pediatric population (Curley et al. 2003b). Still it is not validated for children more than eight years of age and no validated German version is available. Recently, a new tool - the Glamorgan Pediatric Pressure Ulcer Risk assessment scale - has been developed and should be considered for use in further studies (Willock et al., 2008, Willock et al. 2007a, Willock et al. 2007b). Due to this lack of alternatives the Braden scale was used to assess pressure ulcer risk. The use of the Braden scale is problematic insofar as no defined cut-off point for specifying patients at risk is known. Further, it has been criticized that the Pearson correlation is not appropriate for the validation of tools like the Braden Scale (Bland \& Altman, 1986). Thus, a validation according to this recommendation of results is completely missing. Further criticisms claim that the Braden scale offers inadequate reliability and insufficient predictive performance (Papanikolaou et al, 2007).

However, the data collected for this study mark an important first step in recognizing the relevance of the pressure ulcer issue in the pediatric health care setting. Larger studies are necessary to validate our findings and to generalize the result to the general pediatric hospital population. 


\subsection{Conclusion}

Children are beyond doubt at risk of developing pressure ulcers. The evaluated prevalence rate in pediatric patients is disconcerting and requires further exploration in terms of preventive and therapeutic interventions to improve outcome for this patient group.

\subsubsection{Relevance to Clinical Practice}

It is vital that pediatric nurses are trained to recognize the early stages of pressure ulcers. Further, they need to be aware of the specific risk factors for children. To avoid pressure, the performance of an appropriate risk assessment for this patient group and preventive interventions based on evidence are mandatory. 


\subsection{References}

Baldwin KM. (2002). Incidence and prevalence of pressure ulcers in children. Advances in Skin and Wound Care; 15: 121-124.

Bennett G, Dealey C, Posnett J. (2004). The cost of pressure ulcer in the UK. Age Ageing; 33: 230-235.

Bergstrom N, Braden BJ, Laguzza A, Holman V. (1987). The Braden scale for predicting pressure sore risk. Nursing Research; 36: 205- 210.

Bergstrom N, Braden B, Kemp M, Champagne M, Ruby E. (1998). Predicting pressure ulcer risk. A multisite study of the predictive validity of the Braden scale. Nursing Research; 47: 261- 269.

Bland JM, Altman DG. (1986). Statistical methods for assessing agreement between two methods of clinical measurement. Lancet i; 307-310.

Boes C. (2000). Die Reliabilität und Validität der Braden Skala zur Einschätzung eines Druckgeschwürrisikos. Pflege; 13: 397-402.

Bours GJJ, Halfens RJG, Lubbers M, Haalboom JRE. (1999). The development of a national registration form to measure the prevalence of pressure ulcers in the Netherlands. Ostomy Wound Management; 45: 28-40.

Bours GJ, Halfens RJ, Abu Saad HH, Grol RT. (2002). Prevalence, prevention and treatment of pressure ulcers: descriptive study in 89 institutions in the Netherlands. Research in Nursing Health; 25: 99-110.

Cockett A. (2001). A research review to identify the factors contributing to the development of pressure ulcers in pediatric patients. Journal of Tissue Viability; 12: 16-23.

Curley MAQ, Quigley SM, Lin M. (2003a). Pressure ulcers in pediatric intensive care: Incidence and associated factors. Pediatric Critical Care Medicine; 4: 284290. 
Curley MAQ, Razmus IS, Roberts KE, Wypij D. (2003b). Predicting pressure ulcer risk in pediatric patient: the Braden-Q Scale. Nursing Research; 52: 22-33.

Dassen T, Eisermann H, Halfens R, Balzer U, Schmiedl C, Schmitz G. et al. (2001). Pilotstudie zur Dekubitusprävalenz: Der erste Schritt zu vergleichbaren Zahlen. Pflegezeitschrift; 5: 337 -341.

Dassen T. (2002). Dekubitus Sturzereignisse Pflegeabhängigkeit Prävalenzerhebung 2002. Berlin: Zentrum für Human- und Geisteswissenschaften Institut für Medizin-/Pflegepädagogik und Pflegewissenschaft Humboldt Universität.

Defloor T, Grypdonck MFH. (2004). Validation of pressure ulcer risk assessment scales: a critique. Journal of Advanced Nursing; 48: 613-621.

Dixon M, Ratliff C. (2005). Pediatric pressure ulcer prevalence- one hospital's experience. Ostomy Wound Management; 51: 44-46 \& 48-50.

Fleiss J. (1981). Balanced incomplete block designs for inter-rater reliability studies. Applied psychological measurement; 5: 105-122.

Groeneveld A, Anderson M, Allen S, Bressmer S, Golberg M, Magee B, et al. (2004). The prevalence of pressure ulcers in a tertiary care pediatric and adult hospital. Journal of Wound Ostomy and Continence; 31: 108-122.

Halfens RJG, van Achterberg T, Bal RM. (2000). Validity and reliability of the Braden scale and the influence of other risk factors: a multi centre study. International Journal of Nursing Studies; 37: 313-319.

Halfens RJ, Bours GJ, Bronner CM. (2001). The impact of assessing the prevalence of pressure ulcers on the willingness of health care institutions to plan and implement activities to reduce the prevalence. Journal of Advanced Nursing; 36: 617-625.

Heller R. (2003). Dekubitushäufigkeit im Akutspital. Unpublished Masterthesis, Universität Maastricht, Maastricht. 
Hopkins B, Hanlon M, Yauk S, Sykes S, Rose T, Cleary A. (2000). Reducing nosocomial pressure ulcer in an acute care facility. Journal of Nursing Care Quality; 14: 28-36.

Jones I, Tweed C, Marron M. (2001). Pressure area care in infants and children: Nimbus pediatric system. British Journal of Nursing; 11: 789-795.

Lahmann N, Dassen T, Balzer K, Eisermann H, Halfens R, Heinze C, et al. (2002). Dekubitusprävalenz -eine Studie in elf Gesundheitseinrichtungen: Zahlen die warnen. Pflegezeitschrift; 2: 111-114.

McLane KM, Bookout, K., McCord, S., McCain, J. \& Jefferson, L.S. (2004). The 2003 national pediatric pressure ulcer and skin breakdown prevalence survey. Journal of Wound Ostomy and Continence; 31: 168-178.

Meraviglia M, Becker Grobe SJ, King M. (2002). Maintenance of skin integrity as a clinical Indicator of nursing care. Advances in Skin and Wound Care; 15: 24-29.

Noonan C, Quigley S, Curley MAQ. (2006). Skin integrity in hospitalized infants and children. Journal of Pediatric Nursing; 6: 445- 453.

O'Dea K. (1999). The prevalence of pressure damage in acute care hospital patients in the UK. Journal of Wound Care; 8: 192-194.

Papanikolaou P, Lyne P, Ratcliffe J. (2007). Using the discrete choice experimental design to investigate decision-making about pressure ulcer prevention by community nurses. Health Society Care Community; 15: 588-98.

Samaniego IA, (2003). A sore spot in pediatrics: risk factors for pressure ulcers. Pediatric Nursing; 29: 278-282.

Schmidt JF, Berens JR, Zollo MB, Weisner M, Weigle CG. (1998).Skin breakdown in children and high-frequency oscillatory ventilation. Arch Phys Med Rehabil; 79: 1565-1569.

Suddaby EC, Barnett S, Facteau L. (2005). Skin breakdown in acute care pediatrics. Pediatric Nursing; 31: 132-138 \& 148. 
Tannen A, Dassen T, Bours G, Halfens R. (2004). A comparison of pressure ulcer prevalence: concerted data collection in the Netherlands and Germany. International Journal of Nursing Studies; 41: 607-612.

Thomson JS, Brooks RG. (1999). The economics of preventing and treating pressure ulcers: a pilot study. Journal of Wound Care; 8: 312-316.

Thoroddsen A. (1999). Pressure sore prevalence: a national survey. Journal of Clinical Nursing; 8: 170-179.

Whittington K, Patrick M, Roberts JL. (2000). A national study of pressure ulcer prevalence and incidence in acute care hospitals. Journal of Wound Ostomy and Continence; 27: 209-215.

Willock J, Hughes J, Tickle S, Rossiter G, Johnson C, Pye H. (2000). Pressure sores in children- the acute hospital perspective. Journal of Tissue Viability; 10: $59-62$.

Willock J, Maylor M. (2004). Pressure ulcers in infant and children. Nursing Standards; 24: 56-62.

Willock J, Askew C, Bolland R, Maciver H, James N. (2005). Multicenter research: lessons from the field. Pediatric Nursing; 17: 31 - 33.

Willock J. (2005). Identifying the characteristics of children with pressure ulcers. Nursing Times; 101: 40-43.

Willock J, Baharestani M, Anthony D. (2007a). A risk assessment sacle for pressure ulcers in children. Nursing Times; 103: 32-33.

Willock J, Baharestani MM, Anthony D. (2007b). The development of the Glamorgan pediatric pressure ulcer risk assessment scale. Journal of Children's and Young People's Nursing; 01: 211-218.

Willock J, Anthony D, Richardson J. (2008). Interrater reliability of the Glamorgan Pediatric Pressure Ulcer Risk Assessment Scale. Pediatric Nursing; 20: 1419.

Woltemade, N. (2004). Dekubitus Pflege-Ratgeber. Available at: www.dekubitus.de/index.htm. Accessed: 3, 2006. 
Zollo M, Gostisha M, Berens R, Schmidt J, Weigle C. (1996). Altered skin integrity in children admitted to a pediatric intensive care unit. Journal of Nursing Care Quality; 11: 62-67. 


\section{Pediatric Pressure Ulcer Prevalence: A Multicenter, Cross-Sectional, Point Prevalence Study in Switzerland}

Schlüer AB, Halfens RJ, Schols JMGA. (2012). Pediatric pressure ulcer prevalence: A multicenter, cross-sectional, point prevalence study in Switzerland. Ostomy Wound Management; 58: 18-31. 


\section{Abstract}

Pressure ulcers (PU) are a common care problem in hospitals. Although these lesions often are considered as a problem of older patients, also pediatric patients are confronted with PUs. The aim of this study was to assess the prevalence of PU in pediatric care settings. A cross-sectional study was conducted in all 14 pediatric hospitals in the German-speaking part of Switzerland and included all hospitalized children from $0-18$ years. The method of data collection involved a direct systematic inspection and assessment of the skin. A standardized data collection instrument was used and each patient was assessed by a previously instructed rater pair. The total number of participating children was $n=412(75 \%)$. An overall PU prevalence of $35 \%$ (including category 1 ) was registered. Most of the patients $(80 \%)$ had category 1 ulcers. Patients in Pediatric Intensive Care Units (PICU) were affected mostly, followed by neonates and newborns. The prevalence of PUs in pediatric patients is greater than expected and the problem therefore requires further exploration. The high percentage of category $1 \mathrm{PU}$ requires a focus on interventions to prevent lesions for these patients. Future studies are needed to further assess the risk factors especially for patients in PICUs. 


\subsection{Introduction}

A pressure ulcer (PU) is a localized injury to the skin and/or underlying tissue as a result of pressure, or pressure in combination with shear forces(National Pressure Ulcer Advisory Panel (NPUAP) and European Pressure Ulcer Advisory Panel (EPUAP), 2009). While this care problem has gained a great deal of attention in adults, far less is known about PUs in children and neonates (Baharestani and Pope, 2007). It should be kept in mind that pediatric patients, in comparison to adults, are in widely differing health conditions. The overall health status of children is generally better and multi-morbidity is limited to a small percentage of patients only. Survival rates of both critically and chronically ill infants and children have improved dramatically in recent years, introducing new challenges for medical and nursing care (Jones, Tweed, Marron, 2001). One of these is an increase of pressure ulcer risk (Jones et al., 2001). In addition, several risk factors predisposing a pressure ulcer in children are known including the need for additional medical and therapeutic aids, such as wheelchairs, unadjusted ortheses and prostheses (Samaniego, 2003, Cockett, 2001). The consequences of immobility and decreased skin sensitivity (Suddaby, Bernett, Facteau, 2005, Willock, Askew, Bolland, Maciver, James, 2005, Willock, 2005) and risk factors related to equipment, like tubes and IV catheterization and CPAP have been described earlier (Samaniego, 2003, McLane, Bookout, McCord, McCain, Jefferson, 2004, Zollo, Gostisha, Berens, Schmidt, Weigle, 1996, Noonan, Quigley, Curley, 2006, Schlüer, Cignacco, Müller, Halfens, 2009). Limited agerelated communication skills of infants and toddlers or of mentally handicapped children lead to an increased pressure ulcer risk as well (Willock, 2005, Curley, Razmus, Roberts, Wypij, 2003, Kottner, Wilborn, Dassen, 2010). The skin may be affected due to external influences like increased pressure and friction and shear forces due to intervention with external devices. Especially in patients in the pediatric intensive care units (PICU) the influence due to pressure of tubes for patient on oscillation and extracorporeal membrane oxygenation as well as a decreased tissue tolerance in these patients due to their critical life condition, 
increases the risk for skin failure and makes these patients in critical life conditions most vulnerable (Baharestani and Pope, 2007, Curley et al., 2003).

Recent investigations indicate that PUs are also common in infants and children: reported PU prevalence rates including all PU categories range from approximately $3 \%$ to $28 \%$ in hospitals (Kottner et al., 2010). The prevalence for PU within the group for children in hospitals being at risk, diagnosed through a risk assessment tool has been reported to lie at 35\% (Schlüer et al., 2009). The few published incidence and prevalence figures vary widely (Willock and Maylor, 2004, Kottner et al., 2010) and therefore it is difficult to make any evidence based statements about PU frequency in pediatric populations. Often basic reporting issues like descriptions of samples, inclusion and exclusion criteria, or provision of clear PU definitions are missing in studies or vary between studies conducted earlier. Due to these methodological considerations, the results of these earlier studies are hardly comparable (Kottner et al., 2010). There is a deficit of research about pediatric PU risk assessment and age specific PU interventions (Willock and Maylor, 2004) and the magnitude of this health problem in the pediatric population is in fact largely unknown. Having a clear understanding of the incidence and prevalence of PUs is important for the evaluation of the effectiveness of PU prevention, of resource requirements, and of resource allocation to this group.

\subsubsection{Study purpose}

Due to the general and specific lack of information about PUs among this population, there is a need for studies on pressure ulcer prevalence in the pediatric population to recognize the actuality and the extent of the problem and to improve the quality of PU-care. Therefore, the aim of the current study was to assess the prevalence of pressure ulcers in pediatric care settings and age groups, as well as to assess influencing factors and characteristics of these PU patients. 


\subsection{Methods}

\subsubsection{Study design}

A multicentre, cross-sectional study was conducted in all 14 pediatric hospitals in the German-speaking part of Switzerland in June 2009. These hospitals have a total of approximately 70 wards. All pediatric disciplines at the participating sites were included. These involved children from all departments like PICU, Neonatal intensive care units (NICU), all surgical disciplines, all pediatric medical disciplines as well as the departments for pediatric rehabilitation care. All hospitalized children aged 24 hours (including premature babies) up to and including 17 years of age were included in the study. Children had to be hospitalized for at least one day in the respective institutions. Exclusion criteria were a) hospitalization in psychiatric wards, b) children whose legal representatives did not allow participation, and c) children who refused to participate. The ethics board of each hospital approved the study where necessary, as well as all cantonal ethics committees. After the patients and their families had been verbally informed about the study's content and aim, they were given the same information in written form along with an informed consent form to sign. The information letter as well as the informed consent form for the parents was available in eight different languages (German, French, Italian, English, Portuguese, Albanian, Serbian, Turkish). Children 10 years of age and older were asked to give their own written consent.

\subsubsection{Measurements}

To assess the prevalence, severity, as well as predisposing factors of pressure ulcers the instrument and method of data collection of the Dutch National Prevalence Measurement Care Problems (LPZ) (Halfens, Meijers, Neyens et al., 2010) was used in this study. This instrument is widely used in Europe and has been shown to be reliable and valid (Bours, Halfens, Lubbers, Haalboom, 1999). It collects the following categories of data: (1) patient characteristics (demographic and clinical data), (2) assessment of the prevalence and severity of pressure ulcers, (3) PU risk assessment using the Braden scale, (4) predisposing factors for 
PU development, (5) preventive interventions, as well as (6) therapeutic interventions. In addition to the original instrument, we assessed also all installations on the patient's body at the time of the assessment (e.g. tubes, IV catheterizations, Continuous positive airways pressure (CPAP), splints, and other installations). These adaptations based on the findings of a previous study (Schlüer et al., 2009) were verified by the clinical nurse specialists in the participating hospitals.

The method of data collection related to PUs themselves was a direct and systematic inspection and judgment of the skin, as well as of the clinical condition of the patient. The EPUAP (NPUAP/EPUAP, 2009) pressure ulcer category system of four categories was used. Demographic and clinical data, such as date of birth, weight and size, body mass index and diagnosis, were collected from the patient charts.

PU risk assessment was predicted using the original Braden scale (Bergstrom, Braden, Laguzza, Holman, 1987). The Braden Scale is one of the most wellknown and widely used tools for evaluating pressure ulcer risk in adults, as its good psychometric properties in assessing risk have been verified. The Braden Scale has also been used previously to assess pressure ulcer risk in pediatric patients (Samaniego, 2003, Suddaby et al., 2005, Schlüer et al., 2009). It includes six subscales, five of which have four and one, which has three answer categories (Bergstrom et al., 1987, Bergstrom, Braden, Kemp, Champagne, Ruby, 1998).

Previously trained rater pairs gathered data of each patient. Each rater pair consisted of a health care worker working on the measured ward, and a health care worker not working at that ward. A total of 35 rater pairs were involved in the inquiry. If the pair disagreed on their assessment, they were asked to find a consensus. If no consensus could be reached, the rater not working on that ward was given the right of decision. To be selected, raters were required to have more than two years of nursing practice with children. In all participating hospitals, nurses who worked either as wound consultants in their units or as clinical nurse specialists acted as raters. Preparatory training included methodological aspects, detailed information about the data collection, the role and responsibilities of the raters, a detailed introduction to the measurement instruments, and special training in the grading of a pressure ulcer as well as in the Braden scale in infants 
and children. Pilot studies in all sites with more than two rater pairs were conducted to assess the inter-rater reliability for grading and risk assessment ${ }^{20}$, with a balanced incomplete block design. A data consistency of $95 \%$ as to whether the patient developed a pressure ulcer or not was observed. Overall, inter-rater reliability (Kappa 0.79 ) for the grading of pressure ulcers was sufficient.

\subsubsection{Data analysis}

Predictive Analytics Software (PASW) (version 18, formerly SPSS) was used to analyze the study data with descriptive and uni-variate statistical methods. Distributions and frequencies were calculated. The relations between dependent variables and influencing factors were conducted with cross tabs. Group differences were due to the type of data tested with nonparametric tests for categorical and not normally distributed data. The relationship between pressure ulcers and possible influencing and confounding factors were studied by logistic regression analysis. To find the most suitable model for the analysis of variance as well as logistic regression, the following variables were applied to the model: age, sex, operation, BMI, preventive action, Braden score, institutions and divisions. The data were entered into the model followed by a forward stepwise selection of the important variables according to the use of likelihood quotients. The entry and removal probabilities were 0.05 and 0.10 . A p-value of 0.05 and lower was considered as statistically significant.

\subsection{Results}

\subsubsection{Demographics}

The overall sample size of potential study participants who met the inclusion criteria was $560(100 \%)$. The total number of participants was $412(75 \%)$, because 141 (25\%) dropped out before the assessment. In 67 cases (12\%), either the parents or the child refused participation. Sixty patients were excluded due to unexpected discharge or because examination or operations lasted longer than 
the survey (11\%). Four patients were not assessed due to an unexpected change in their condition to a critical level. Only 5 patients dropped out due to language problems of the parents.

In the 14 clinics, the participation rate ranged from 6-97 patients (43-100\%). The length of stay was on average 25 days and showed a median of 7 days. Out of the 412 assessed patients, $67 \%(n=275)$ had been hospitalized for less than 14 days. In this subcategory, the average length of stay was 5 days, with a median of 3 days. Patients with an oncology diagnosis, acute gastroenteritis, pneumonia and a cardiology diagnose consisted the largest group with 32\% $(n=130)$ and are sampled as pediatric medical division, followed by neonates $(n=109,27 \%)$, and patients in the surgery divisions (including, plastic and burn surgery, visceral surgery, neurosurgery and orthopedic and trauma patients) ( $n=99,24 \%)$. The patient population in the PICU consisted of 36 children $(9 \%)$. Furthermore, 33 patients $(8 \%)$ were hospitalized for rehabilitation and 5 because of psychosomatic problems (1\%).

The average age of all patients was four years with a median of one year. Approximately $50 \%(n=203)$ was less than one year old on the day of inquiry. In this subgroup, the average age was 6 weeks, with a median of 3 weeks (table 1). 
Table 1: demographic characteristics

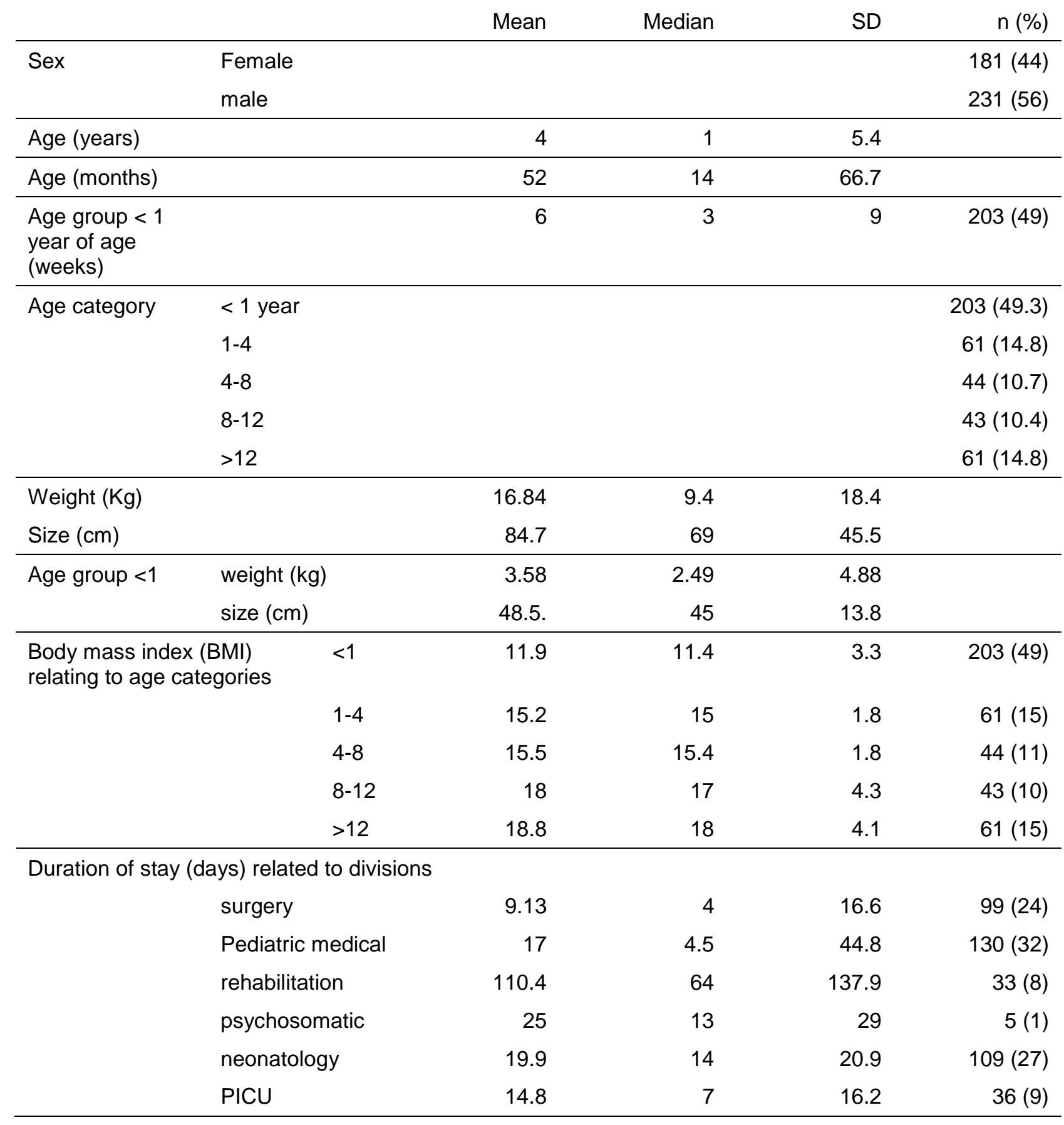



3.3.2 Pressure ulcer prevalence and characteristics of patient showing a pressure ulcer

Of the 412 patients taking part in this study, a total of 142 showed one or more pressure ulcers on the day of inquiry, which constitutes a PU prevalence rate of 35 $\%$. Out of these 142 patients 77 (54\%) showed one, 35 (25\%) two, $17(12 \%)$ three, 6 four (4\%), 2 five (2\%), 3 six (1\%), 1 nine and one patient showed 10 pressure ulcers. This constitutes in a total number of 269 PU's (table 2).

Table 2: pressure ulcer prevalence according to divisions, age category and sex

\begin{tabular}{llrrr}
\hline & & $\begin{array}{r}\text { PU yes } \\
\mathrm{n}(\%)\end{array}$ & $\begin{array}{r}\text { PU no } \\
\mathrm{n}(\%)\end{array}$ & total n (\%) \\
\hline Sex n.s. & Male & $84(36.4)$ & $147(63.6)$ & $231(56.1)$ \\
& Female & $58(32)$ & $123(68)$ & $181(43.9)$ \\
\hline Age category** & $<1$ & $88(43.3)$ & $115(56.7)$ & $203(49.3)$ \\
& $1-4$ & $15(24.6)$ & $46(75.6)$ & $61(14.8)$ \\
& $4-8$ & $7(15.9)$ & $37(84.1)$ & $44(10.7)$ \\
& $8-12$ & $13(30.2)$ & $30(69.8)$ & $43(10.4)$ \\
& $>12$ & $19(31.1)$ & $42(68.9)$ & $61(14.8)$ \\
\hline Division $^{* *}$ & Surgery & $33(33.3)$ & $66(66.7)$ & $99(24)$ \\
& Rehabilitation & $5(15.2)$ & $28(84.8)$ & $33(8)$ \\
& Pediatric medical & $41(31.5)$ & $89(68.5)$ & $130(31.6)$ \\
& Psychosomatic & 0 & $5(100)$ & $5(1.2)$ \\
& PICU & $16(44.4)$ & $20(55.6)$ & $36(8.7)$ \\
& Neonatology & $47(43.1)$ & $62(56.9)$ & $109(26.5)$ \\
\hline ** signifiant $p \leq 0.05$ & $\quad$ & &
\end{tabular}

${ }^{* *}$ signifiant $p \leq 0.05 \quad$ n.s.: not significant

The most frequent type of PU was PU category 1 (94\%). The prevalence of category 2 and higher was $3 \%(n=16)$. A total of three PU category 3 and 2 PU category 4 where assessed. The three children with category 3 PU were all 16 years of age, with multiple diagnoses and treated for orthopedic surgery. One PU category 3 occurred within the last 2 weeks on the ward where the patient was hospitalized while the two other PUs category 3 existed since 3-6 month after being occurred in another hospital. The two children with category 4 PU were 9 respectively 16 years of age. The younger child was treated after a multiple trauma incident in the surgery department and developed the PU cat 4 within the last two weeks while the other patient was treated for an orthopedic surgery indication. The PU in this patient already existed for more than one year and developed in another care setting. 
The PU prevalence differed between the divisions ( $X 2: 13.8$, df: $5, p=0.002)$ with the highest PU prevalence of $44 \%$ for patients in PICU (table 2 ).

As can be seen in table 3 the prevalence of PU for patients with an external device is $40 \%$. According to the age category the PU prevalence for patients younger than 1 year of age lays at $43 \%$, followed by $31 \%$ for patients older than 12 years of age. Related to the length of stay, patients with a PU stayed slightly longer in hospital, than without a PU ( $p=0.036)$ (table 3).

Within the risk group for PU (meaning patients with a Braden scale score $\leq 20) 93$ patients showed a PU $(49 \%)$, whereas $24 \%(n=46)$ of the patients not at risk had a PU ( $X^{2}: 26.4 ;$ df: $\left.1 ; p<0.001\right)$. According to divisions the PU prevalence for patients at risk is $50 \%$ for patient after a surgical intervention as well as neonates, $46 \%$ for pediatric medical patients, $25 \%$ for patients in the rehabilitation setting and $60 \%$ for patients in the PICU. Seventy six percent of all patients with at least one PU were assessed as being at risk (sensitivity $67 \%$ ), while the percentage of patients who did not have a pressure ulcer although they were assessed as being at risk, was $40 \%$ (specificity).

Table 3: Characteristics of patient showing a PU

\begin{tabular}{|c|c|c|c|c|c|}
\hline & & \multicolumn{4}{|l|}{ Pressure ulcer } \\
\hline & & yes n (\%) & no n (\%) & $X 2,(d f), p$ & total $n(\%)$ \\
\hline & & $142(34.5 \%)$ & $270(65.5)$ & & \\
\hline \multirow{2}{*}{$\begin{array}{l}\text { Patient with medical } \\
\text { devices* }\end{array}$} & Yes & $131(39.5)$ & $201(60.5)$ & & $332(83.6)$ \\
\hline & No & $11(16.9)$ & $54(83.1)$ & $\begin{array}{r}12.0,(1) \\
\mathrm{p}<0.001\end{array}$ & $65(16.4)$ \\
\hline \multirow[t]{5}{*}{ Age category (years) } & $<1$ & 88 (43.3) & $115(56.7)$ & & 203 (49.3) \\
\hline & $1-4$ & $15(24.6)$ & $46(75.4)$ & & $61(14.8)$ \\
\hline & $4-8$ & 7 (15.9) & $37(84.1)$ & & $44(10.7)$ \\
\hline & $8-12$ & $13(30.2)$ & $30(69.8)$ & & $43(10.4)$ \\
\hline & $>12$ & $19(31.1)$ & $42(68.9)$ & $\begin{array}{r}17.1,(4) \\
p=0.14\end{array}$ & $61(14.8)$ \\
\hline \multirow[t]{2}{*}{ Age in month* } & Mean (sd) & $43(67)$ & $57(66)$ & $\begin{array}{r}\text { Mann- } \\
\text { Whitney- } \\
\text { U-test }\end{array}$ & $p=0.002$ \\
\hline & Median & 2 & 28 & & \\
\hline \multirow[t]{2}{*}{$\begin{array}{l}\text { Length of stay } \\
\text { (days) }^{*}\end{array}$} & Mean (sd) & $24(49)$ & $23(58)$ & $\begin{array}{r}\text { Mann- } \\
\text { Whitney- } \\
\text { U-test }\end{array}$ & $p=0.036$ \\
\hline & Median & 10 & 7 & & \\
\hline
\end{tabular}

*significant $\mathrm{p}<0.05$ 


\subsubsection{PU influencing factors}

The risk factors age, sex, surgery (which means that the patient had at least one surgical intervention during the present hospitalization), BMI, preventive action, Braden score, institution and division were examined with a multiple logistic regression analysis. The factors division, age, Braden score and institution contributed significantly to fit into the model. The Hosmer Lemeshow-test showed an adequate goodness of fit for this model (Nagelkerke $R 2=0.248$ ) (table 4 ). This means that those remaining four variables explain $25 \%$ of the variance when PU is the dependent variable.

Table 4: Regressions model with PU as dependent variable

\begin{tabular}{|l|l|r|r|r|r|r|r|}
\hline \multicolumn{2}{|l|}{} & $\begin{array}{c}\text { Regression } \\
\text { coeffient B }\end{array}$ & Standard error & Wald & df & Sig. & Exp(B) \\
\hline Schritt 0 & Konstante & -.563 & .106 & 28.038 & 1 & .000 & .570 \\
\hline
\end{tabular}




\subsection{Discussion}

Our study reveals a very high PU prevalence rate of $35 \%$ in the fourteen pediatric hospitals. However the prevalence rate of category 2 and higher is only $3 \%$. Especially the age of the patients, the Braden risk score for PU development as well as the institution in which the patients were hospitalized appear to be related to the development of PU.

The prevalence rate of $35 \%$ is higher than previously found prevalence rates in pediatric care settings, which varied from 3\% (Noonan et al., 2006, Dixon and Ratliff, 2005) to $28 \%$ (Schlüer et al., 2009). This high prevalence rate demands a critical appraisal. First, an already well-known problem is the diagnosis of pressure ulcers category 1 (Halfens, Bours, Bronner, 2001). Furthermore, most category 1 PUs are reversible (Halfens et al., 2001). Several authors have therefore recommended defining pressure ulcer prevalence by starting the category system at category 2 (Halfens et al., 2001, Defloor and Grypdonck, 2004). Moreover, in our interrator pretest we found a 95\% agreement, suggesting that our findings are reliable. And even, if category $1 \mathrm{PU}$ will not be defined as a pressure ulcer, a category $1 \mathrm{PU}$ can be considered as the most important risk factor (Defloor and Grypdonck, 2004, Noonan, Quigley, Curley, 2011), which subsequently can be interpreted as for this study that a lot of pediatric patient in fact are at high risk of developing PUs. The data collection in all involved clinics took part at one day within the same time span from the morning $(7.30 \mathrm{am})$ to as longest to $3 \mathrm{pm}$ in the afternoon. This is so far important as it's been known from the adult population that approximately $50 \%$ of all category 1 PUs disappear during the day, whereas on the other hand around $22 \%$ of all category 1 PUs worsen during the day (Halfens et al., 2001). No study related to this particular phenomenon has been undertaken so far for the pediatric setting.

The prevalence of pressure ulcers category 2 and above accounts for $3 \%$ of the total. This is lower than the prevalence of pressure ulcers in the study of Suddaby et al. (2005) and Groeneveld et al. (2004) (both 5.1\%) and also lower as the PU prevalence in an earlier study of Schlüer et al. (2009) (4.5\%). This means that however a lot of patients are vulnerable, in fact the progression to a higher 
category occurs rather infrequently. Nevertheless this implies that the diagnosis of a category $1 \mathrm{PU}$ requires a related preventive intervention.

The most affected patient group in this study involved very young patients in the PICU setting showing mostly category $1 \mathrm{PU}$. This is in line with results of Curley et al. (2003). The prevalence of PU of nearly $45 \%$ in this patient group and the figure of $60 \%$ being at risk is disconcerting and needs special attention. Patients in the NICU care setting show an overall prevalence of $43 \%$. Children treated in a NICU or/and PICU care setting are most vulnerable due to several factors like the immaturity of the skin in very young neonates and newborns and anatomical, physiological and immunological differences (Schlüer et al., 2009, Curley et al., 2003). In general these children are in a critical clinical condition and often undergo life saving treatments. If one takes in consideration that at these patients often a lot of external medical devices are applied, which might affect the skin, the high vulnerability for getting a PU seams feasible (Schlüer et al., 2009, Curley et al., 2003, Kottner et al., 2010, Baharestani, 2007). Until now, there is a lack of longitudinal research on the development and deterioration of PUs in pediatric patients.

Although not all pressure ulcers are preventable, the high prevalence rate detected in this study indicate a need to improve PU care and to start raising staff's awareness of the pressure ulcer issue in the pediatric health care setting; especially in the PICU and/or NICU care setting (McLane et al. 2004, Schlüer et al., 2009, Curley et al., 2003, Kottner et al., 2010). Preterm babies, Newborn babies, Infants and toddlers are unable to judge pressure or sensory perceptions from technical devices properly and are for this reason most vulnerable. Besides their communication possibilities and skills are limited due to their age and development status.

An adapted, reliable and valid risk assessment tool, applicable to the wide range of population from neonates to adolescents, in combination with validated cut-off points, is still not available for the pediatric population (Kottner, Hauss, Schlüer, Dassen, 2013). At the time of data collection for the present study the Braden- $Q$ scale as well as Glamorgan scale were the only tools available for risk assessment in the pediatric population (Curley et al., 2003, Willock, Baharestani, Anthony, 2007a, Willock, Baharestani, Anthony, 2007b, Willock, Anthony, Richardson, 
2008). The Braden- $Q$ developed and introduced for immobile patients from 21 days of age still is not validated for children more than eight years of age and no validated German version is available. There is also a lack of a validated German version of the Glamorgan scale. Therefore, due to this lack of alternatives the original Braden scale was used to assess pressure ulcer risk. The use of the Braden scale for this target group is problematic insofar as no defined cut-off point for specifying children at risk is known. Additionally, it is claimed that the Braden scale offers inadequate reliability and insufficient predictive performance (Papanikolaou, Lyne, Anthony, 2007).

Due to this aspect and the findings presented in this study the question arises whether in the pediatric population a prevalence rate for children with and without external medical devices like tubes, and fixation devices might be an important marker. The impact of pressure and friction and shear forces due to these external devices seems much more risky for children than for adults, as these devices seem responsible for most of the pressure ulcers in pediatric patients (Schlüer et al., 2009, Baharestani, 2007, Kottner et al., 2013, Willock et al., 2007a, Willock et al., 2007b, Willock et al., 2008, Baharestani and Ratliff, 2007). On the other hand it should be noted that there are only a few studies that have investigated factors for PU development in the pediatric population (Cockett, 2001, Schlüer et al., 2009).

There are several limitations to this study. We have to realize that prevalence studies are always subject to daily variations. However in general it shows that prevalence figures over the years are relative constant (Halfens et al., 2001). No findings about detailed differences in specific age categories can be presented. The number of eligible patients was affected by the requirement of a signed informed consent of both parents and all patients older than 10 years of age. Studies elsewhere are necessary to validate our findings and to generalize the results to other pediatric care settings. Further studies are needed to establish the special risk factors of this highly vulnerable population and possibly incorporate these into a target group specific risk assessment instrument. Furthermore one has to establish the fact that in this studies only older children show category 3 and 4 PU. Detailed research according to this phenomena is needed. 


\subsection{Conclusion}

This study confirms the relevance and importance of a high quality of care to target the issue of Pressure Ulcers in pediatric care, especially in PICU and NICU care settings. The prevalence rate is high, or at least the risk of developing a pressure ulcer is high. Especially the use of medical devices seems to cause pressure ulcers in hospitalized children. Therefore, it is important that staff will be trained in the early recognition of pressure ulcers, in risk factors for children and in evidence based preventive methods. 


\subsection{References}

Baharestani MM., 2007. An overview of neonatal and pediatric wound care knowledge and considerations. Ostomy Wound Management; 53: 34-6, 38, 40.

Baharestani MM, Ratliff CR. (2007). Pressure Ulcers in Neonates and Children: An NPUAP White Paper. Advances in Skin and Wound Care; 20: 208-220.

Baharestani MM, Pope E. (2007). Chronic wounds in neonates and children. In: Krasner, D., Rodeheaver, G., Sibbald, G. (Eds.), Chronic Wound Care. HMP Communications, Malvern, PA, 679-693.

Bergstrom N, Braden B, Kemp M, Champagne M, Ruby E. (1998). Predicting pressure ulcer risk. A multisite study of the predictive validity of the Braden scale. Nursing Research; 47: 261- 269.

Bergstrom N, Braden BJ, Laguzza A, Holman V. (1987). The Braden scale for predicting pressure sore risk. Nursing Research; 36: 205- 210.

Bours GJJ, Halfens RJG, Lubbers M, Haalboom JRE. (1999). The development of a national registration form to measure the prevalence of pressure ulcers in the Netherlands. Ostomy Wound Management; 45: 28-40.

Cockett A. (2001). A research review to identify the factors contributing to the development of pressure ulcers in pediatric patients. Journal of Tissue Viability; 12: 16-23.

Curley MAQ, Razmus IS, Roberts KE, Wypij D. (2003). Predicting pressure ulcer risk in pediatric patients: the Braden-Q Scale. Nursing Research; 52: 22-33.

Dixon, M. \& Ratliff, C. (2005).Pediatric pressure ulcer prevalence- one hospital's experience. Ostomy Wound Management; 51: 44-46 \& 48-50.

Defloor T, Grypdonck MFH. (2004). Validation of pressure ulcer risk assessment scales: a critique. Journal of Advanced Nursing; 48: 613-621. 
Fleiss J. (1981). Balanced incomplete block designs for inter-rater reliability studies. Applied psychological measurement; 5: 105-122.

Groeneveld A, Anderson M, Allen S, Bressmer S, Golberg M, Magee B, et al. (2004). The prevalence of pressure ulcers in a tertiary care pediatric and adult hospital. Journal of Wound Ostomy and Continence; 31: 108-122.

Halfens R, Meijers J, Neyens J, van Nie N, Schols J, Wolters S, Rijcken S. (2010). Available at: http://www.lpz-um.eu/eng/about-lpz, accessed 21 January 2012

Halfens RJ, Bours GJ, Bronner CM. (2001). The impact of assessing the prevalence of pressure ulcers on the willingness of health care institutions to plan and implement activities to reduce the prevalence. Journal of Advanced Nursing; 36: 617-625.

Jones I, Tweed C, Marron M. (2001). Pressure area care in infants and children: Nimbus pediatric system. British Journal of Nursing; 11: 789-795.

Kottner J, Hauss A, Schlüer AB, Dassen T. (2013). Validation and clinical impact of pediatric pressure ulcer risk assessment scales: A systematic review. International Journal of Nursing Studies; 50: 807-818.

Kottner J, Wilborn D, Dassen T. (2010). Frequency of pressure ulcers in the pediatric population: a literature review and new empirical data. International Journal of Nursing Studies; 47: 1330-1340.

McLane KM, Bookout, K., McCord, S., McCain, J. \& Jefferson, L.S. (2004). The 2003 national pediatric pressure ulcer and skin breakdown prevalence survey. Journal of Wound Ostomy and Continence; 31: 168-178.

National Pressure Ulcer Advisory Panel (NPUAP) and European Pressure Ulcer Advisory Panel (EPUAP). Prevention and treatment of pressure ulcers: clinical practice guideline. National Pressure Ulcer Advisory Panel, 2009, Washington DC.

Noonan C, Quigley S, Curley MA. (2011). Using the Braden Q Scale to Predict Pressure Ulcer Risk in pediatric patients. Journal Pediatric Nursing; 26: 566-575.

Noonan C, Quigley S, Curley MAQ. (2006). Skin integrity in hospitalized infants and children. Journal of Pediatric Nursing; 6: 445- 453. 
Papanikolaou P, Lyne P, Ratcliffe J. (2007). Using the discrete choice experimental design to investigate decision-making about pressure ulcer prevention by community nurses. Health Society Care Community; 15: 588-98.

Samaniego IA, (2003). A sore spot in pediatrics: risk factors for pressure ulcers. Pediatric Nursing; 29: 278-282.

Schlüer AB, Cignacco E, Müller M, Halfens RJ. (2009). The prevalence of pressure ulcers in four pediatric institutions. Journal of Clinical Nursing; 18: 32443252.

Suddaby EC, Barnett S, Facteau L. (2005). Skin breakdown in acute care pediatrics. Pediatric Nursing; 31: 132-138 \& 148.

Willock J, Maylor M. (2004). Pressure ulcers in infant and children. Nursing Standards; 24: 56-62.

Willock J, Askew C, Bolland R, Maciver H, James N. (2005). Multicenter research: lessons from the field. Pediatric Nursing; 17: 31 - 33.

Willock J. (2005). Identifying the characteristics of children with pressure ulcers. Nursing Times; 101: 40-43.

Willock J, Baharestani M, Anthony D. (2007a). A risk assessment sacle for pressure ulcers in children. Nursing Times; 103: 32-33.

Willock J, Baharestani MM, Anthony D. (2007b). The development of the Glamorgan pediatric pressure ulcer risk assessment scale. Journal of Children's and Young People's Nursing; 01: 211-218.

Willock J, Anthony D, Richardson J. (2008). Interrater reliability of the Glamorgan Pediatric Pressure Ulcer Risk Assessment Scale. Pediatric Nursing; 20: 1419.

Zollo M, Gostisha M, Berens R, Schmidt J, Weigle C. (1996). Altered skin integrity in children admitted to a pediatric intensive care unit. Journal of Nursing Care Quality; 11: 62-67. 



\section{Validation and clinical impact of pediatric pressure ulcer risk assessment scales: A systematic review}

Kottner J, Hauss A, Schlüer AB, Dassen, T. (2013). Validation and clinical impact of pediatric pressure ulcer risk assessemnt scales: A systematic review. International Journal of Nursing Studies (2013); 50: 807-818. 


\section{Abstract}

Background: Pressure ulcer risk assessment using an age-appropriate, valid and reliable tool is recommended for clinical pediatric practice.

Objectives: (1) What PU risk scales for children currently exist? (2) What is the diagnostic accuracy of their scores? (3) Are the scores reliable and what is the degree of agreement? (4) What is the clinical impact of risk scale scores in pediatric practice?

Design: Systematic review.

Data sources: MEDLINE (1950 to December 2010), EMBASE (1989 to December 2010), CINAHL (1982 to December 2010), reference lists.

Review methods: Two reviewers independently screened databases, selected and evaluated articles and studies. Diagnostic accuracy, reliability/agreement, and experimental studies investigating the performance and clinical impact of PU risk scale scores in the pediatric population ( 0 to 18 years) were included. PU development was used as reference standard for diagnostic accuracy studies. Methodological quality of the validity and reliability studies was assessed based on the QUADAS and QAREL checklists.

Results: The search yielded 1141 hints. Finally, 15 publications describing 12 pediatric pressure ulcer risk scales were found. Three of these scales (Neonatal Skin Risk Assessment Scale for Predicting Skin Breakdown, Braden Q Scale, Burn Pressure Skin Risk Assessment Scale) were investigated in prospective validation studies. Empirical evidence about interrater reliability and agreement is available for four instruments (Neonatal Skin Risk Assessment Scale for Predicting Skin Breakdown, Starkid Skin Scale, Glamorgan Scale, Burn Pressure Ulcer Risk Assessment Scale). No studies were identified investigating the clinical impact.

Conclusions: Sound empirical evidence about the performance of pediatric pressure ulcer risk assessment scales is lacking. Based on the few results of this review no instrument can be regarded as superior to the others. Whether the application of pressure ulcer risk assessment scales reduces the pressure ulcer 
incidence in pediatric practice is unknown. Maybe clinical judgment is more efficient in evaluating pressure ulcer risk than application of risk scale scores. 


\subsection{Introduction}

A pressure ulcer (PU) is localized injury to the skin and/or underlying tissue as a result of pressure, or pressure in combination with shear (National Pressure Ulcer Advisory Panel (NPUAP) and European Pressure Ulcer Advisory Panel (EPUAP), 2009). While this phenomenon has gained a great deal of attention in adults, far less is known about PUs in the pediatric population including children from birth to adolescence (Baharestani and Pope, 2007). Recent investigations indicate that PUs are common in infants and children: reported PU prevalence rates including all PU categories range from approximately 3\% (Dixon and Ratliff, 2005; Noonan et al., 2006) to $23 \%$ (Suddaby et al. 2005) to $27 \%$ (Schlüer et al., 2009).

Avoidance of pressure-related injuries and maintenance of skin and tissue integrity are regarded as important goals in the care process. Identifying individuals at risk for developing PUs by structured risk assessments is recommended as a first step for effective PU prevention (Duncan, 2007; Stechmiller et al., 2008). In the recently published international guideline by the NPUAP and the EPUAP (2009) it is explicitly stated that "Risk assessment scales are the foundation of risk assessment practice." (p. 24).

During the last five decades more than 30 standardized PU risk scales for adults were developed, tested and modified. The structure of most of these instruments is comparable: They include a number of items that deemed important for PU development, like "Mobility", "Continence", "Nutrition" and many more (e.g. Bergstrom et al., 1987; Waterlow, 1985). Item scores are summed resulting in total scores indicating individual risk. To be useful in clinical practice PU risk assessment scales must be valid and reliable, they should demonstrate an enhanced quality of care, and they must improve patient outcomes. Above all, application of PU risk assessment scales should reduce PU incidence (Jull and Griffiths, 2010; Kottner and Balzer, 2010).

There are various systematic reviews addressing validity, reliability and clinical impact issues of PU risk scales in the adult population (e.g. Pancorbo-Hidalgo et al., 2006; Moore and Cowman, 2008; Kottner et al. 2009) but there is no up to date systematic synthesis of empirical evidence about PU risk scales in children. This is 
a serious limitation since PU risk assessment using an age-appropriate, valid and reliable tool is also recommended for clinical pediatric practice (Loman 2000; Baharestani and Pope, 2007).

To our knowledge a review published by Gray in 2004 was the only attempt to systematically review performance measures of pediatric PU risk scales. He identified limited evidence to support the use of the Braden $Q$ scale (Curley et al., 2003) and the Neonatal Skin Risk Assessment Scale (Huffines and Logsdon, 1997). Although he performed a systematic database search the review methods, the study selection and the data extraction process were not well described and a quality appraisal of included studies was not conducted.

When investigating validity different approaches may be used (Streiner and Norman, 2008). Regarding PU risk scales one question is most important: Does the obtained score measure PU risk correctly? Most often this question is answered by diagnostic accuracy studies: estimated PU risk scale scores are compared with subsequent PU development (yes/no). In these studies application of a prospective design is crucial to establish causes (PU risk) and effects (PU development). On the other hand, using PU development as a reference standard is limited because preventive measures usually reduce PU risk determined by the scale scores under investigation (Defloor and Grypdonck, 2004). Consequently, when investigating diagnostic accuracy preventive measures should be taken into account (Halfens, 2000; Kottner and Balzer, 2010).

Estimates of interrater reliability and agreement are also important quality issues for PU risk scale scores because in clinical practice the instruments are usually used by different team members scoring the same child. Interrater reliability and agreement are often used synonymously but both of these terms are conceptually distinct (De Vet et al., 2006; Kottner, 2009; Griffiths and Murrells, 2010). Interrater reliability can be defined as the degree to which two or more raters are able to differentiate among subjects under similar assessment conditions whereas interrater agreement is the degree to which raters achieve identical results (Kottner et al., 2011). Both, interrater reliability and agreement are needed to evaluate the instrument's performance. 
Evidence of validity and reliability of scores is necessary but not sufficient to determine whether a scale should be used in practice. Also important is the question of the clinical importance of the scores: How do PU risk scale scores influence clinical decisions and management based on the scores (e.g. starting or withholding therapeutic interventions)? Randomized study designs are the best way to assess the clinical impact of the scores and subsequent clinical decisionmaking. Before-after studies may also be used but contain higher risk of bias (Knottnerus et al., 2009; Lijmer and Bossuyet, 2009).

The overall aim of this study was to systematically review empirical evidence about validity, reliability and clinical impact of PU risk assessment scales for children. The objectives were to address the following questions:

(1) What PU risk scales for children currently exist?

(2) What is the diagnostic accuracy of their scores?

(3) Are the scores reliable and what is the degree of agreement?

(4) What is the clinical impact of risk scale scores in the pediatric practice?

\subsection{Methods}

\subsubsection{Search}

A concurrent search was run in the databases MEDLINE (1950 to December 03, 2010) and EMBASE (1989 to December 03, 2010) via Ovid. The database CINAHL (1982 to December 2010) was searched using EBSCOHOST. To identify as many relevant sources as possible a broad search strategy was applied containing terms to identify the population and the condition. Due to incomplete reporting, inconsistent indexing, and a lack of availability of subject headings, no other search filters were used to maximize sensitivity (De Vet et al., 2008; Leeflang et al., 2008; Kottner et al., 2011). For both searches subject headings and natural language terms were used in all fields:

\#1 child* OR infant* OR pediatric ${ }^{*}$ 
\#2 pressure ulcer OR pressure ulcers OR bedsore OR bedsores OR bed sore OR bed sores OR decubitus

\section{\#3 \#1 AND \#2}

Reference lists from potentially relevant studies were screened as well. Finally, using the Science Citation Index (SCl) and Scopus, articles were searched citing the included articles from the database and reference list search (forward search). The database searches and study selections were conducted independently by two reviewers. Due to the wide coverage of the SCI (11000 journals) and Scopus (18000 journals plus conference proceedings) it was decided to take no other steps to locate other literature.

\subsubsection{Study selection}

The results of the database and reference list searches were screened by two investigators independently. The target population consists of infants from 0 to 23 month (including premature newborns), children from 2 to 12 years, and adolescents from 13 to 18 years). No setting was excluded. More specific inclusion criteria were set according to the four study questions:

(1) What PU risk scales for children currently exist? We included every source introducing or describing a standardized PU risk scale.

(2) What is the diagnostic accuracy of their scores? Studies were included when they used a prospective design and PU development (incidence) of any PU category as reference standard. Prospective designs are considered crucial for PU risk validation (Pancorbo-Hidalgo et al., 2006), because the degree of PU risk (quantified by risk scales) was regarded as the predictor for possible subsequent PU development. Consequently, studies using cross sectional designs were excluded due to their inability to establish relations between possible predictors and the outcome PU development. Temporality can only investigated in longitudinal studies (Twisk, 2003). Studies using other validation approaches (e.g. known groups) were also excluded. 
(3) Are the scores reliable and what is the degree of agreement? All studies comparing PU risk scale scores of different raters using the same scale (interrater) or of the same raters using the same scale at different times (intrarater) were included (Kottner et al., 2011). No raters or rater pairings were excluded.

(4) What is the clinical impact of risk scale scores in the pediatric practice? To evaluate the clinical impact of PU risk scale scores in the pediatric practice we included RCTs, CCTs and before-after studies. The application of a pressure ulcer risk scale was regarded as intervention compared to the use of another or no risk scale. PU incidence (as defined by the authors) was regarded as outcome.

Further exclusion criteria were narrative reviews, opinions and studies dealing with general risk factors for PU development.

Figure 1: Identification and selection process of studies

Records identified through database searching in MEDLINE, EMBASE, CINAHL $(n=2447)$

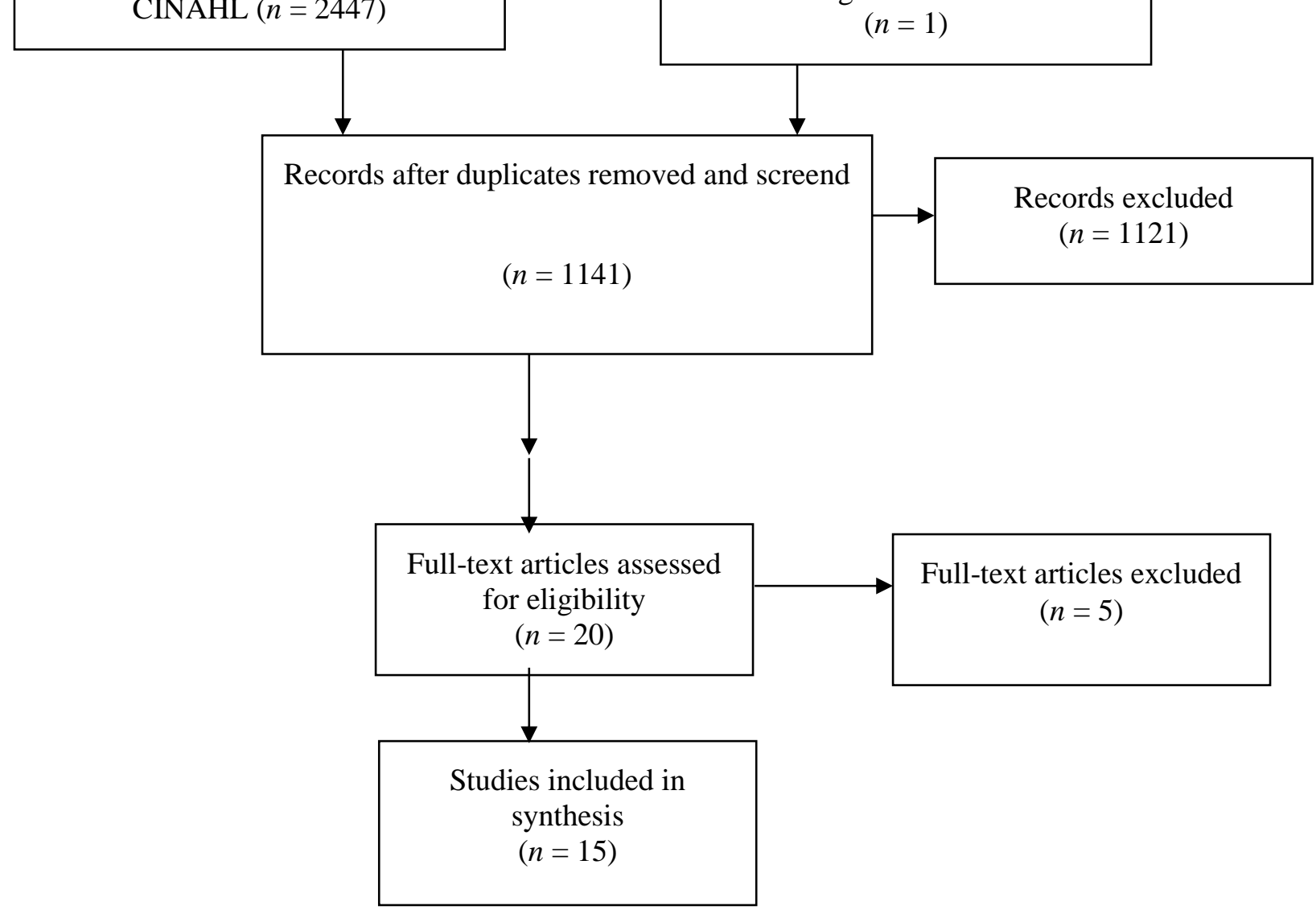

Additional records identified through other sources $(n=1)$ 


\subsubsection{Data extraction and assessment of methodological quality}

Authors, years, target groups and items of identified PU risk scales were extracted. For diagnostic accuracy a second data extraction sheet containing authors, years, instruments, setting, sample, methods, reference standard and results was used. Methodological quality of included papers was assessed by using the QUADAS tool (Whiting et al., 2003). This instrument was developed based on systematic reviews of methodological literature and three Delphi rounds with nine experts in diagnostic accuracy studies. This tool was designed to be used in systematic reviews and its use is recommended (Buntinx et al., 2009). The QUADAS checklist is also recommended for the quality assessment of studies included Cochrane Systematic Reviews of Diagnostic Test Accuracy (Reitsma et al., 2009).

Data from interrater reliability and agreement studies were gathered using a third data extraction sheet. It contained: authors, years, instrument, setting, sample of raters, sample of subjects, methods and results. The recently developed QAREL checklist (Lucas et al., 2010) was used to evaluate the methodological quality of included interrater reliability and agreement studies. In an iterative process a group of researchers with expertise in diagnostic research developed this tool for use in systematic reviews. The QAREL checklist was chosen because this seems to be the only available quality appraisal tool for reliability studies at the moment. Data extraction and methodological evaluation was conducted independently by two reviewers. Disagreements were resolved by consensus.

During the search and study selection process it became clear that there are no studies about the clinical impact of PU risk scale scores in the pediatric practice. Therefore neither a data extraction sheet nor a methodological evaluation was needed. 


\subsubsection{Data synthesis and interpretation}

Settings, populations, authors, years, and items of identified scales were summarized descriptively in one table. To enable comparisons, instruments were ordered chronologically and items were sorted according to the frequency of joint items.

Study results regarding the second and third research questions were also described and synthesized qualitatively. Due to only few eligible studies investigating different scales a meta-analysis or alternative forms of statistical pooling (e.g. reliability generalization) were impossible.

ROC curves in the original investigations were regarded as necessary for determining adequate cut-off points. These cut-off points should maximize both sensitivities and specificities. Positive likelihood ratios (LR+) above 10 and negative likelihood ratios (LR-) below 0.1 were regarded as providing convincing diagnostic evidence, whereas those above 5 and below 0.2 were regarded as giving strong diagnostic evidence (Deeks, 2001). Interrater reliability coefficients above 0.9 were regarded as the minimum for individual clinical decision-making (Nunnally and Bernstein, 1994; Polit and Beck, 2008). Results were taken from the study reports or recalculated when raw numbers were given.

\subsection{Results}

\subsubsection{Search results}

The identification and selection process is shown in Figure 1. After removal of duplicates 1141 entries were obtained. After screening and reviewing the title and/or abstract 20 full text articles were read. Five articles were excluded for the following reasons: no standardized scales were described $(n=3)$ and diagnostic accuracy was investigated in a cross sectional way $(n=2)$. No other relevant publications were found by the SCI and Scopus searches. 


\subsubsection{Pressure ulcer risk scales}

Twelve out of the 15 included publications described standardized PU scales for children (Table 1). Four instruments were developed for pediatric intensive care settings (Bedi, 1993; Garvin, 1997; Cockett, 1998; Olding and Patterson, 1998), one tool was developed for neonates (Huffines and Logsdon, 1997) and one scale was introduced for pediatric burn patients (Gordon, 2008, 2009). Pediatric patients in general were the target group for the remaining scales.

Some authors (Quigley and Curley, 1996; Huffines and Logsdon, 1997; Suddaby et al., 2005) presented modifications of the Braden scale for adults (Bergstrom et al, 1987). Taking population specific characteristics into account Quigley and Curley (1996) added the item "Tissue Perfusion and Oxygenation" to the original scale and Huffines and Logsdon (1997) replaced the items "Sensory perception" and "Friction \& shear" by "General physical condition" and "Mental state". Based on the aim to create a one-page, easy-to-use scale Suddaby et al. (2005) developed the "Starkid Skin Scale" by "...rewording and simplifying the concepts presented in the Braden Q..." (p. 134).

Pickersgill (1997) introduced a "Pediatric Risk Assessment Score" by combining items from the Medley (Williams, 1991) and Waterlow scales (Waterlow, 1985). Also Bedi (1993) modified the Waterlow scale for adults by adapting the contents in each Waterlow item to pediatrics. In subsequent stages this tool was further modified and new items were included.

Gordon (2008, 2009) used a modified Delphi technique with 15 nurses experienced in burn care to develop a new scale. Other scales were developed based on opinion and literature reviews (Garvin, 1997; Cockett, 1998; Waterlow, 1998; Barnes, 2004) and based on empirical data (Willock et al., 2007).

As shown in Table 1 there were considerable differences of included items between the scales. The item "Mobility" was part of every instrument, followed by the items "Nutrition/food intake" (included in seven scales) and "Continence" (included in six scales). 
Table 1: Suggested items for pediatric pressure ulcer risk assessment scales

\begin{tabular}{|c|c|c|c|c|c|c|c|c|c|c|c|c|c|}
\hline \multirow[b]{2}{*}{ Items } & \multicolumn{11}{|c|}{ Setting/population (Author, year) } & \multirow[b]{2}{*}{$\begin{array}{l}\text { Pediatric } \\
\text { Burn } \\
\text { Patients } \\
\text { (Gordon, } \\
\text { 2009) }\end{array}$} & \multirow[b]{2}{*}{ Total } \\
\hline & $\begin{array}{l}\text { PICU } \\
\text { (Bedi, } \\
1993)\end{array}$ & $\begin{array}{l}\text { Pediatric } \\
\text { (Quigley } \\
\text {, Curley, } \\
\text { 1996) }\end{array}$ & $\begin{array}{l}\text { PICU } \\
\text { (Garvin, } \\
1997 \text { ) }\end{array}$ & $\begin{array}{l}\text { Neonates } \\
\text { (Huffines, } \\
\text { Logsdon, } \\
1997 \text { ) }\end{array}$ & $\begin{array}{l}\text { Pediatric } \\
\text { (Pickersgill, } \\
\text { 1997) }\end{array}$ & $\begin{array}{l}\text { Pediatric } \\
\text { (Cockett, } \\
\text { 1998) }\end{array}$ & $\begin{array}{l}\text { PICU } \\
\text { (Olding, } \\
\text { Patterson, } \\
1998 \text { ) }\end{array}$ & $\begin{array}{l}\text { Pediatric } \\
\text { Waterlow } \\
\text { (1998) }\end{array}$ & $\begin{array}{l}\text { Pediatric } \\
\text { (Barnes, } \\
\text { 2004) }\end{array}$ & $\begin{array}{l}\text { Pediatric } \\
\text { (Suddaby } \\
\text { et al., } \\
\text { 2005) }\end{array}$ & $\begin{array}{l}\text { Pediatric } \\
\text { (Willock } \\
\text { et al., } \\
2008 \text { ) }\end{array}$ & & \\
\hline Gestational age & & & & $x$ & & & & & & & & & 1 \\
\hline $\begin{array}{l}\text { Weight according to } \\
\text { age }\end{array}$ & $x$ & & & & $X$ & $X$ & $x$ & & $X$ & & $X$ & & 6 \\
\hline Continence & $\mathrm{X}$ & & & & $\mathrm{X}$ & $X$ & $X$ & & $x$ & & $x$ & $x$ & 7 \\
\hline Moisture & & $x$ & $X$ & $X$ & & & & & & $x$ & & $x$ & 5 \\
\hline $\begin{array}{l}\text { Skin condition/ skin } \\
\text { damage }\end{array}$ & $X$ & & & & $X$ & $X$ & $X$ & $X$ & $X$ & & & & 6 \\
\hline Mobility & $X$ & $X$ & $X$ & $X$ & $X$ & $X$ & $X$ & $X$ & $X$ & $X$ & 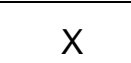 & $X$ & 12 \\
\hline Activity & & $X$ & & $X$ & & & & & & $X$ & & & 3 \\
\hline Appetite & $X$ & & & & $X$ & & & & & & & & 2 \\
\hline Nutrition/ food intake & & $X$ & $X$ & $X$ & & $X$ & $X$ & $X$ & & $X$ & $X$ & $X$ & 9 \\
\hline Age & $X$ & & & & & & & & & & & & 1 \\
\hline $\begin{array}{l}\text { Tissue perfusion/ } \\
\text { oxygenation/ } \\
\text { cyanosis }\end{array}$ & $x$ & $x$ & & & & & & & & $x$ & $X$ & & 4 \\
\hline Cachexia & $X$ & & & & & & & & & & & & 1 \\
\hline $\begin{array}{l}\text { Circulatory/ vascular } \\
\text { disease }\end{array}$ & $x$ & & & & & & & & & & & & 1 \\
\hline $\begin{array}{l}\text { Heamodynamic } \\
\text { status/inotropic }\end{array}$ & $x$ & & & & & $x$ & $x$ & & & & & $X$ & 4 \\
\hline
\end{tabular}




\begin{tabular}{|c|c|c|c|c|c|c|c|c|c|c|c|c|c|}
\hline support & & & & & & & & & & & & & \\
\hline Infection & $X$ & & & & & & & & & & & & 1 \\
\hline $\begin{array}{l}\text { Neurological/ } \\
\text { mental state/ } \\
\text { Glasgow Coma } \\
\text { Scale }\end{array}$ & $X$ & & & $x$ & & $X$ & & & $X$ & & & & 4 \\
\hline Major surgery/trauma & $x$ & & & & & $X$ & & $X$ & $X$ & & & & 4 \\
\hline Medication & $x$ & & & & $X$ & & & & & & & & 1 \\
\hline Sensory perception & & $X$ & $X$ & & & & & & $X$ & $X$ & & & 4 \\
\hline Friction \& shear & & $X$ & & & & & & & $X$ & $X$ & & & 3 \\
\hline Sedation & & & & & & $X$ & & & $X$ & & $X$ & & 3 \\
\hline $\begin{array}{l}\text { Respiratory status/ } \\
\text { ventilation }\end{array}$ & & & & & & $X$ & $X$ & $X$ & & & & & 3 \\
\hline Body temperature & & & & & & $X$ & $X$ & & & & $X$ & & 3 \\
\hline Physical disabilities & & & & & & & & $x$ & & & & & 1 \\
\hline Head injury & & & & & & & & $X$ & & & & & 1 \\
\hline Severe illness & & & & & & & & $x$ & & & & & 1 \\
\hline ICU & & & & & & & & $X$ & & & & & 1 \\
\hline Anaemia & & & & & & & & & & & $X$ & & 1 \\
\hline Albumin & & & & & & & & & & & $X$ & & 1 \\
\hline $\begin{array}{l}\text { Devices (casts, } \\
\text { splints, tubes, lines) }\end{array}$ & & & & & & $x$ & & $x$ & $x$ & $X$ & $X$ & $X$ & 6 \\
\hline Prior PU & & & & & & & & & & & & $X$ & 1 \\
\hline
\end{tabular}




\subsubsection{Diagnostic accuracy}

Three diagnostic accuracy studies using a prospective design met the inclusion criteria (Huffines and Logsdon, 1997; Curley et al, 2003; Gordon, 2009). Results of the methodological quality assessment are shown in Table 2. Studies met eight (Huffines and Logsdon, 1997) and nine (Curley et al., 2003; Gordon, 2009) of 14 quality criteria. Information regarding blinding against results of the reference standard and the index was missing in all studies. Since preventive measures were not considered in the calculation of the validity estimates it is likely that the reference standard was biased.

Table 2: Quality assessment according QUADAS

\begin{tabular}{|c|c|c|c|}
\hline Items & $\begin{array}{l}\text { Huffines } \\
\text { and } \\
\text { Logsdon } \\
(1997)\end{array}$ & $\begin{array}{l}\text { Curley et } \\
\text { al. (2003) }\end{array}$ & $\begin{array}{l}\text { Gordon } \\
(200)\end{array}$ \\
\hline $\begin{array}{l}\text { 1. Was the spectrum of patients representative of the patients } \\
\text { who will receive the test in practice? }\end{array}$ & Y & Y & $\mathrm{Y}$ \\
\hline 2. Were selection criteria clearly described? & $\mathrm{N}$ & $\mathrm{N}$ & $\mathrm{Y}$ \\
\hline $\begin{array}{l}\text { 3. Is the reference standard likely to correctly classify the } \\
\text { target condition? }\end{array}$ & $\mathrm{N}$ & $\mathrm{N}$ & $\mathrm{N}$ \\
\hline $\begin{array}{l}\text { 4. Is the time period between reference standard and index } \\
\text { test short enough to be reasonably sure that the target } \\
\text { condition did not change between the two tests? }\end{array}$ & $\mathrm{Y}$ & Y & $\mathrm{Y}$ \\
\hline $\begin{array}{l}\text { 5. Did the whole sample or a random selection of the sample } \\
\text { receive verification using a reference standard of diagnosis? }\end{array}$ & $\mathrm{Y}$ & Y & $\mathrm{Y}$ \\
\hline $\begin{array}{l}\text { 6. Did patients receive the same reference standard } \\
\text { regardless of the index test result? }\end{array}$ & Y & Y & $\mathrm{Y}$ \\
\hline $\begin{array}{l}\text { 7. Was the reference standard independent of the index test } \\
\text { (i.e. the index test did not form part of the reference } \\
\text { standard)? }\end{array}$ & $\mathrm{Y}$ & Y & $\mathrm{Y}$ \\
\hline $\begin{array}{l}\text { 8. Was the execution of the index test described in sufficient } \\
\text { detail to permit replication of the test? }\end{array}$ & Y & Y & $\mathrm{Y}$ \\
\hline $\begin{array}{l}\text { 9. Was the execution of the reference standard described in } \\
\text { sufficient detail to permit its replication? }\end{array}$ & $U$ & Y & $\mathrm{Y}$ \\
\hline $\begin{array}{l}\text { 10. Were the index test results interpreted without knowledge } \\
\text { of the results of the reference standard? }\end{array}$ & $U$ & $\mathrm{~N}$ & $U$ \\
\hline $\begin{array}{l}\text { 11. Were the reference standard results interpreted without } \\
\text { knowledge of the results of the index test? }\end{array}$ & $U$ & $\mathrm{~N}$ & $U$ \\
\hline $\begin{array}{l}\text { 12. Were the same clinical data available when test results } \\
\text { were interpreted as would be available when the test is used } \\
\text { in practice? }\end{array}$ & $\mathrm{Y}$ & Y & $\mathrm{Y}$ \\
\hline 13. Were uninterpretable/ intermediate test results reported? & $U$ & $U$ & $\mathrm{~N}$ \\
\hline 14. Were withdrawals from the study explained? & U & U & $\mathrm{N}$ \\
\hline
\end{tabular}
$\mathrm{Y}=$ yes, $\mathrm{N}=$ no, $\mathrm{U}=$ unclear. 
Study characteristics are shown in Table 3. Huffines and Logsdon (1997) scored 32 neonates according to the "Neonatal Skin Risk Assessment Scale" consisting of six items. The observation period was two month. Due to low interrater reliability of the items "Mental state", "Mobility" and "Moisture" the authors only used the sum scores of the items "General physical condition", "Activity" and "Nutrition" for validity investigation. The best balance between sensitivity (83\%) and specificity (81\%) was achieved at a cut-off of 5 with a positive likelihood ratio of 4.3 and a negative likelihood ratio of 0.2 .

Table 3: Results of prospective diagnostic accuracy studies

\begin{tabular}{|c|c|c|c|c|c|c|}
\hline Author & $\begin{array}{l}\text { Instrument } \\
\text { (score range) }\end{array}$ & $\begin{array}{l}\text { Setting/ } \\
\text { sample }\end{array}$ & Methods & $\begin{array}{l}\text { Reference } \\
\text { standard }\end{array}$ & Results & $\begin{array}{l}\text { Comments } \\
\text { (Quality Score } \\
\text { according } \\
\text { QUADAS) }\end{array}$ \\
\hline $\begin{array}{l}\text { Huffines } \\
\text { and } \\
\text { Logsdon } \\
1997\end{array}$ & $\begin{array}{l}\text { Items "general } \\
\text { physical condition", } \\
\text { "activity", "nutrition" } \\
\text { of the Neonatal } \\
\text { Skin Risk } \\
\text { Assessment Scale } \\
\text { for Predicting Skin } \\
\text { Breakdown } \\
\text { (NSRAS) (3 to 12) }\end{array}$ & $\begin{array}{l}\text { Neonatology, } \\
n=32, \\
\text { convenience, intact } \\
\text { skin, mean age } \\
33 \text { weeks' } \\
\text { gestation }\end{array}$ & $\begin{array}{l}\text { Assessment with } \\
\text { NSRAS within } 24 \mathrm{~h} \\
\text { post delivery; skin } \\
\text { assessments for } \\
\text { two months, until } \\
\text { discharge or skin } \\
\text { breakdown }\end{array}$ & Skin breakdown & $\begin{array}{l}\text { Incidence } 6 / 32 \\
(19 \%) ; \text { at cut-off } 5 \\
\text { sensitivity }=0.83, \\
\text { specificity }=0.81, \\
\text { PPV }=0.50, \text { NPV }= \\
0.95, \text { LR+ }=4.3, \\
\text { LR- }=0.2\end{array}$ & $\begin{array}{l}\text { Reference } \\
\text { standard not } \\
\text { clearly defined, } \\
\text { LRs recalculated } \\
(7 / 14)\end{array}$ \\
\hline $\begin{array}{l}\text { Curley et } \\
\text { al. } 2003\end{array}$ & Braden Q (7 to 28$)$ & $\begin{array}{l}\text { PICU, } n=322, \\
\text { convenience, intact } \\
\text { skin, mean age } \\
3 \text { years }\end{array}$ & $\begin{array}{l}\text { Assessment with } \\
\text { Braden Q and skin } \\
\text { assessments by } \\
\text { two trained nurses } \\
\text { independently until } \\
\text { discharge }\end{array}$ & $\begin{array}{l}\text { Pressure ulcers } \\
\text { Stage I to IV } \\
\text { (NPUAP 1998) }\end{array}$ & $\begin{array}{l}\text { Incidence } 86 / 322 \\
(26.7 \%) ; \text { for Stage } \\
\text { II and higher PUs } \\
\text { AUC = } 0.83 \text {, at cut- } \\
\text { off } 16 \text { sensitivity = } \\
0.88, \text { specificity = } \\
0.58, \\
\text { PPV }=0.15, \text { NPV = } \\
0.98, \text { LR+ = } 2.1 \text {, } \\
\text { LR- = } 0.2 \\
\text { Only subscales } \\
\text { "sensory } \\
\text { perception", } \\
\text { "mobility", "tissue } \\
\text { perfusion" } \\
\text { contributed greater } \\
\text { than } 0.7 \text { to AUC }\end{array}$ & $\begin{array}{l}\text { LR- recalculated } \\
(8 / 14)\end{array}$ \\
\hline $\begin{array}{l}\text { Gordon } \\
\text { (2009) }\end{array}$ & $\begin{array}{l}\text { Burn Pressure } \\
\text { Ulcer Skin Risk } \\
\text { Assessment Scale } \\
\text { (?) }\end{array}$ & $\begin{array}{l}3 \text { pediatric burn } \\
\text { intensive care } \\
\text { units, } n=163, \\
\text { convenience, } \\
\text { mean age } 7.2 \text { y ( } 2 \\
\text { months to } 18 \\
\text { years) }\end{array}$ & $\begin{array}{l}\text { Not speaking } \\
\text { English or } \\
\text { Spanish, length of } \\
\text { stay }<3 \text { days, } \\
\text { primary diagnosis } \\
\text { not acute burn } \\
\text { injury, total surface } \\
\text { aera burned }>85 \%\end{array}$ & $\begin{array}{l}\text { Risk assessment } \\
\text { on post op day } \\
\text { one, two or three; } \\
\text { daily skin } \\
\text { inspection by } \\
\text { trained nurses until } \\
\text { PU occurrence or } \\
\text { discharge }\end{array}$ & $\begin{array}{l}\text { Incidence } 44 / 163 \\
(27 \%) \text { based on } \\
\text { logistic regression } \\
\text { model comparing } \\
\text { predicted vs. } \\
\text { observed PUs } \\
\text { sensitivity = } 0.54, \\
\text { specifity }=0.95 ; \\
\text { PPV=0.80, } \\
\mathrm{NPV}=0.85, \\
\mathrm{LR+=} 11.1, \mathrm{LR}- \\
=0.48 \\
\text { Only itemas } \\
\text { "prior/current PU", } \\
\text { "precent total body } \\
\text { surface area } \\
\text { burned", "number } \\
\text { of splints" were sig. } \\
\text { predictors }\end{array}$ & $\begin{array}{l}\text { Mean age and } \\
\text { results } \\
\text { recalculated; } \\
\text { sample size } \\
\text { determenination } \\
\text { for logistic } \\
\text { regression was } \\
\text { performed; no cut- } \\
\text { off point } \\
\text { established (9/14) }\end{array}$ \\
\hline
\end{tabular}


Curley et al. (2003) used a modified version of the Braden scale to score 322 children of three pediatric intensive care units. Using newly developed stage II to IV PUs as the reference standard the best balance between sensitivity (88\%) and specificity (58\%) was achieved at a cut-off of 16 . The positive likelihood ratio was 2.1 and the negative likelihood ratio was 0.2. Performance in terms of AUC, sensitivity, specificity and likelihood ratios of a modified Braden $Q$ scale including only the items "Mobility", "Sensory perception" and "Tissue perfusion/oxygenation" was similar to the long version.

Based on a literature review and consensus of 15 burn nurses Gordon (2009) evaluated a newly developed "Burn Pressure Ulcer Skin Assessment Scale" in three pediatric burn units $(n=163)$. A logistic regression model was used to calculate the predictability of the scale items (independent variables) for the occurrence of PUs (dependent variable). Compared with the observed PU occurrence sensitivity was $54 \%$ and specificity was $95 \%(L R+=11.1, L R-=0.48)$. Due to this statistical procedure no cut-off points were established.

\subsubsection{Reliability and agreement}

Five studies provided evidence about interrater reliability and agreement (Huffines and Logsdon, 1997; Suddaby et al., 2005; Willock et al., 2008; Gordon, 2008, 2009). Results of the methodological quality assessment are displayed in Table 4. Expect one study with missing information (Gordon, 2008) authors used representative samples of raters (persons similar to intended users in clinical practice) and subjects, raters were blinded to each other's scores and the time interval between ratings was considered appropriate. On the other hand information about the assessment process and scale application (e.g. order of examination) was not stated. Willock et al. (2008) and Gordon (2008, 2009) calculated proportions of agreement, kappa and ICC coefficients that were appropriate statistical measures (Lucas et al., 2010). Huffines and Logsdon (1997) and Suddaby et al. (2005) used Persons $r$ that is inappropriate to indicate reliability (Kottner and Dassen, 2008; Lucas et al., 2010). 
Table 4: Quality assessment according QUAREL

\begin{tabular}{|c|c|c|c|c|c|}
\hline Items & $\begin{array}{l}\text { Huffines } \\
\text { and } \\
\text { Logsdon } \\
\text { (1997) }\end{array}$ & $\begin{array}{l}\text { Suddaby } \\
\text { et al. } \\
\text { (2005) }\end{array}$ & $\begin{array}{l}\text { Willock } \\
\text { et al. } \\
2008\end{array}$ & $\begin{array}{l}\text { Gordon } \\
(2008)\end{array}$ & $\begin{array}{l}\text { Gordon } \\
\text { (2008) }\end{array}$ \\
\hline $\begin{array}{l}\text { 1. Was the test evaluated in a sample of subjects who were } \\
\text { representative of those to whom the authors intended the } \\
\text { results to be applied? }\end{array}$ & $\mathrm{Y}$ & $\mathrm{Y}$ & $\mathrm{Y}$ & $\mathrm{U}$ & Y \\
\hline $\begin{array}{l}\text { 2. Was the test performed by raters who were } \\
\text { representative of those to whom the authors intended the } \\
\text { results to be applied? }\end{array}$ & $\mathrm{Y}$ & $\mathrm{Y}$ & $\mathrm{Y}$ & Y & $U$ \\
\hline $\begin{array}{l}\text { 3. Were raters blinded to the findings of other raters during } \\
\text { the study? }\end{array}$ & $\mathrm{Y}$ & $\mathrm{Y}$ & $\mathrm{Y}$ & $U$ & $U$ \\
\hline $\begin{array}{l}\text { 4. Were raters blinded to their own prior findings of the test } \\
\text { under evaluation? }\end{array}$ & $\mathrm{N} / \mathrm{A}$ & $\mathrm{N} / \mathrm{A}$ & $\mathrm{N} / \mathrm{A}$ & $\mathrm{N} / \mathrm{A}$ & $\mathrm{N} / \mathrm{A}$ \\
\hline $\begin{array}{l}\text { 5. Were raters blinded to the subjects' disease status or the } \\
\text { results of the accepted reference standard for the target } \\
\text { disorder (or variable) being evaluated? }\end{array}$ & $U$ & $U$ & $U$ & $U$ & $U$ \\
\hline $\begin{array}{l}\text { 6. Were raters blinded to clinical information that was not } \\
\text { intended to form part of the study design or testing } \\
\text { procedure? }\end{array}$ & $\mathrm{N} / \mathrm{A}$ & $\mathrm{N} / \mathrm{A}$ & $\mathrm{N} / \mathrm{A}$ & $\mathrm{N} / \mathrm{A}$ & $N / A$ \\
\hline $\begin{array}{l}\text { 7. Were raters blinded to additional cues that are not part } \\
\text { of the test? }\end{array}$ & $U$ & $\mathrm{~N}$ & $U$ & $U$ & $U$ \\
\hline 8. Was the order of examination varied? & $U$ & $U$ & $U$ & $U$ & $U$ \\
\hline $\begin{array}{l}\text { 9. Was the stability (or theoretical stability) of the variable } \\
\text { being measured taken into account when determining the } \\
\text { suitability of the time interval among repeated measures? }\end{array}$ & Y & $\mathrm{Y}$ & Y & $U$ & $\mathrm{Y}$ \\
\hline $\begin{array}{l}\text { 10. Was the test applied correctly and interpreted } \\
\text { appropriately? }\end{array}$ & $U$ & $U$ & $U$ & $U$ & $U$ \\
\hline $\begin{array}{l}\text { 11. Were appropriate statistical measures of agreement } \\
\text { used? }\end{array}$ & $\mathrm{N}$ & $\mathrm{N}$ & $Y$ & $Y$ & $Y$ \\
\hline
\end{tabular}

$\mathrm{Y}=$ yes, $\mathrm{N}=\mathrm{no}, \mathrm{U}=$ unclear, $\mathrm{N} / \mathrm{A}=$ not applicable.

Study characteristics and results are shown in Table 5. Huffines and Logsdon provided correlation coefficients for neonatal nurse rater pairs over 9 days for each item. The values for the items "General physical condition", "Activity" and "Nutrition" ranged between 0.8 and 1. Correlation among remaining items "Mental state", "Mobility" and "Moisture" was much lower ranging between -0.27 to a maximum of 0.57 . Due to the low correlations coefficients the authors decided to exclude the latter from subsequent investigations of validity.

In a strict sense Suddaby et al. (2005) did not perform a reliability study because they compared the scorings made by staff nurses with scorings made by clinical nurse specialists. The correlation for the total score was 0.85 . Most disagreements were observed for the item "Nutrition".

Willock et al. (2008) compared 15 ratings made by seven randomly selected qualified nurses with ratings made by one researcher. This design is more of a validation study than an interrater reliability study. Except one rating for the item "Inadequate nutrition" all other ratings were identical (100\% agreement). 
Gordon reported results of two interrater reliability studies comprising 21 (2008) and 20 (2009) duplicate assessments. ICC values indicate nearly perfect interrater reliability for the total score. 
Table 5: Results of interrater reliability and agreement studies

\begin{tabular}{|c|c|c|c|c|c|c|c|}
\hline Author & $\begin{array}{l}\text { Instrument } \\
\text { (score range) }\end{array}$ & Setting & Raters $(k)$ & Subjects $(n)$ & Methods & Results & $\begin{array}{l}\text { Comments } \\
\text { (Quality Score } \\
\text { according } \\
\text { QUAREL) }\end{array}$ \\
\hline $\begin{array}{l}\text { Huffines } \\
\text { and } \\
\text { Logsdon } \\
\text { (1997) }\end{array}$ & $\begin{array}{l}\text { Neonatal Skin Risk } \\
\text { Assessment Scale } \\
\text { for Predicting Skin } \\
\text { Breakdown } \\
\text { (NSRAS) (6 to 24) }\end{array}$ & Neonatology & $\begin{array}{l}\text { Nurses providing } \\
\text { care }(k \text { not stated) }\end{array}$ & $\begin{array}{l}\text { Neonates, mean } \\
\text { age } 33 \text { weeks' } \\
\text { gestation }(n=32)\end{array}$ & $\begin{array}{l}\text { Independent } \\
\text { assessment of } \\
\text { neonates by } \\
\text { researcher and the } \\
\text { nurse providing } \\
\text { care within } 9 \\
\text { subsequent } \\
\text { occasions ( } 256 \\
\text { paired ratings) }\end{array}$ & $\begin{array}{l}r=-.27 \text { to } 1.00 \\
\text { across all items } \\
\text { and rater pairs; } r= \\
0.97 \text { for "physical } \\
\text { condition", } \\
\text { "activity", } \\
\text { "nutrition" across } \\
\text { two raters }\end{array}$ & $\begin{array}{l}\text { Calculation and } \\
\text { kind of interrater } \\
\text { reliability } \\
\text { coefficients not } \\
\text { clearly described } \\
\text { (QS 4/9) }\end{array}$ \\
\hline $\begin{array}{l}\text { Suddaby } \\
\text { et al. } \\
(2005)\end{array}$ & $\begin{array}{l}\text { Starkid Skin Scale } \\
\text { (6 to } 24)\end{array}$ & Pediatric hospital & $\begin{array}{l}\text { Staff nurses }(k= \\
4), \text { clinical nurse } \\
\text { specialists }(k=3)\end{array}$ & $n=30$ & $\begin{array}{l}\text { Independent } \\
\text { assessment of } \\
\text { staff nurse and } \\
\text { clinical nurse } \\
\text { specialists on } \\
\text { same day }\end{array}$ & $\begin{array}{l}r=0.85 \text { for total } \\
\text { score; most } \\
\text { differences }(10 / 30) \\
\text { for "nutrition" }\end{array}$ & $\begin{array}{l}\text { No interrater } \\
\text { reliability study in a } \\
\text { strict sense (QS } \\
4 / 9 \text { ) }\end{array}$ \\
\hline $\begin{array}{l}\text { Willock et } \\
\text { al. (2008) }\end{array}$ & $\begin{array}{l}\text { Glamorgan scale } \\
\text { (0 to } 42)\end{array}$ & $\begin{array}{l}\text { Pediatric wards of } \\
\text { tertiary hospital }\end{array}$ & $\begin{array}{l}\text { Randomly } \\
\text { selected nurses ( } k \\
=15 \text { ) and one } \\
\text { researcher }\end{array}$ & $\begin{array}{l}\text { Not described }(n= \\
15)\end{array}$ & $\begin{array}{l}\text { Independent } \\
\text { assessment of } \\
\text { children by } \\
\text { researcher and } \\
\text { one nurse within } \\
\text { ten minutes (15 } \\
\text { paired ratings) }\end{array}$ & $\begin{array}{l}100 \% \text { agreement } \\
\text { between } \\
\text { researcher and } \\
\text { nurses rating all } \\
\text { items; one } \\
\text { disagreement for } \\
\text { rating "Inadequate } \\
\text { nutrition" }\end{array}$ & $\begin{array}{l}\text { No interrater } \\
\text { reliability study in a } \\
\text { strict sense (QS } \\
5 / 9)\end{array}$ \\
\hline $\begin{array}{l}\text { Gordon } \\
(2008)\end{array}$ & $\begin{array}{l}\text { Burn Pressure } \\
\text { Ulcer Skin } \\
\text { Assessment Scale } \\
\text { (?) }\end{array}$ & $?$ & Burn nurses $(k=5)$ & $(\mathrm{n}=21)$ & $?$ & $\begin{array}{l}\mathrm{ICC}=0.99 \text { for total } \\
\text { score }\end{array}$ & QS (2/9) \\
\hline $\begin{array}{l}\text { Gordon } \\
\text { (2009) }\end{array}$ & $\begin{array}{l}\text { Burn Pressure } \\
\text { Ulcer Skin } \\
\text { Assessment Scale } \\
\text { (?) }\end{array}$ & $\begin{array}{l}3 \text { pediatric burn } \\
\text { intensive care } \\
\text { units }\end{array}$ & Burn nurses $(k=2)$ & $(\mathrm{n}=20)$ & $\begin{array}{l}\text { Nurses rated } \\
\text { patients at the } \\
\text { same point in time }\end{array}$ & $\begin{array}{l}I C C=0.99 \text { for total } \\
\text { score; ICC for } \\
\text { items ranging form } \\
0.86 \text { tp } 1.00\end{array}$ & QS (3/9) \\
\hline
\end{tabular}




\subsection{Discussion}

This systematic review aimed at providing an overview of existing PU risk for the pediatric population and synthesizing empirical evidence about their performance. In total, 12 instruments were identified. Since many of them are modifications of PU risk scales for adults they contain many variables deemed important for PU development in the adult population as well, e.g. continence, moisture, nutrition. "Mobility" was part of every scale. Assessing the degree of mobility to determine PU risk in children seems reasonable, because the relation between mobility and PU development is well established (NPUAP \& EPUAP, 2009). On the other hand it should be noted that there are only a few studies investigating factors for PU development in the pediatric population (Cockett, 2002). Although long known to be a problem in infants and children (Okamoto et al., 1983), the risk factor "devices on the skin" is only considered in the newer scales since 1998.

Given that 12 instruments are available, the degree of validation is poor. We identified only three single validation studies: one for the Neonatal Skin Risk Assessment Scale (Huffines and Logsdon, 1997), one for the Braden Q scale (Curley et al., 2003) and one for the Burn Pressure Ulcer Skin Risk Scale (Gordon, 2009) meeting our inclusion criteria.

Huffines and Logdsdon (1997) used the items "General physical condition", "Activity" and "Nutrition" that are scored between 1 and 4 each leading to sum scores from 3 to 12. Irrespective of methodological limitations they showed that a score of 5 leads to an optimal balance between sensitivity and specificity and calculated positive and negative likelihood ratios indicate strong diagnostic evidence. Based on this result it seems that the applied items have power to discriminate between neonates with high and low PU risk.

Similarly, Curley et al. (2003) also provided a cut-off score for the Braden Q scale for discriminating between PU risks in children on the ICU. Compared to the results by Huffines and Logdsdon (1997) specificity was much lower and positive and negative likelihood ratios provide only weak diagnostic evidence. The strength 
of this study was that the authors used PU stages II to IV as reference standard. Excluding grade 1 PUs from statistical analysis enhances interrater reliability and therefore internal validity of studies (Kottner et al., 2009). Interestingly, the authors calculated nearly the same validity estimates when using the items "Sensory perception", "Mobility" and "Tissue perfusion" only. This indicates that not all PU risk scale items are equally important, a finding that is supported by numerous studies today (e.g. Fischer et al., 2004; Papanikolauo et al., 2003). Scoring the items "Sensory perception", "Mobility" and "Tissue perfusion" in the pediatric ICU population might be as good as using the whole Braden $Q$ scale.

The newly developed Burn Pressure Ulcer Skin Risk Scale (Gordon, 2009) comprises nine items but only three items were statistically significant in a multivariate logistic regression model. No cut-off points were provided and therefore the obtained validity estimates are difficult to interpret.

Although being included, the studies had severe methodological limitations. Especially the convenience sampling, the small sample size in Huffines and Logsdon's study (1997) and the missing replications limit the generalisability of results. All three investigations were conducted in PICUs and therefore results are not transferable to other pediatric settings. During our search we found more empirical studies about the development and testing of pediatric PU risks scales (Suddaby et al., 2005; Willock et al., 2008; Anthony et al., 2010) but they all used cross sectional designs that are clearly inappropriate for prognostic research (Buckley et al., 2010).

Five studies provided evidence about interrater reliability and agreement of four instruments: (1) Neonatal Skin Risk Assessment Scale (Huffines and Logsdon, 1997), (2) Starkid Skin Scale (Suddaby et al., 2005), (3) Glamorgan scale (Willock et al., 2008) and (4) Burn Pressure Ulcer Skin Risk Scale (Gordon, 2009). All investigations had methodological limitations reducing the generalisability of the findings. Furthermore, results provided by Huffines and Logsdon (1997) and Suddaby et al. (2005) are difficult to interpret, because Pearson's correlation coefficients are presented. Since they only provide information about the degree and direction of association they are inappropriate interrater reliability measures (Kottner and Dassen, 2008; Lucas et al., 2010). Willock et al. (2008) showed, that ratings made by nurses and one researcher were nearly identical. This provides 
strong evidence, that the Glamorgan scale items are easily and accurately to interpret. Findings by Gordon $(2008,2009)$ indicate that the Burn Pressure Ulcer Skin Risk Scale scores have the potential to differentiate between pediatric burn patients.

Beside the discussed validity and reliability aspects the question arises if it is feasible to develop a PU risk scale covering all the necessary aspects of the whole pediatric population. Considering the immaturity as well as the anatomical, physiological and immunological differences and vulnerability of this population's skin and tissues, especially during the neonatal period, it is clear that PU risk profiles vary across the different age group (Bahasterani, 2007, Bahasterani \& Ratliff, 2007, Schlüer et al., 2009).

We found no publication investigating the clinical impact of pediatric PU risk scales. This finding is very well comparable to the state of research in the adult population (Moore and Cowman, 2008).

\subsection{Limitations}

Due to database restrictions our results may be biased. Perhaps we missed some relevant publications or empirical findings indexed in other databases or published in the grey literature. We also not considered publication bias. Like systematic reviews of PU risk scales for adults (e.g. Pancorbo-Hidalgo et al., 2006) we focused on diagnostic accuracy in prospective studies and on reliability/agreement only. We did not review other approaches that might be also important for instruments validation (e.g. content validation). Using the occurrence of PUs (yes/no) as criterion to validate the construct "PU risk" is also limited, because being at risk does not mean getting a PU (Kottner and Balzer, 2010). Taking PU preventive measures into account may be one way to improve the precision of a validation criterion but such an approach would require very precise definitions and operationalizations of PU prevention. Finally, while rating the methodological quality based on QUADAS and QAREL we were unable to decide whether the quality criteria were unmet or not reported. 


\subsection{Conclusions}

Based on this systematic review we conclude that there is little evidence about the performance of PU risk assessment scales in the pediatric practice. Based on the sparse results no instrument can be regarded as superior to the others. Although users of the Glamorgan and the Burn Pressure Ulcer Skin Risk Scales showed excellent interrater agreement/reliability the degree of diagnostic accuracy of both tools is unclear. Whether the application of PU risk scales makes any differences to $\mathrm{PU}$ incidence is unknown. Based on this review the regular scoring of standardized PU risk scales in clinical practice is not justified. Maybe clinical judgment is as efficient as the use of standardized scales. Well-conducted RCTs might be necessary to answer the question whether pediatric patients get fewer PUs when PU risk scales are applied. 


\subsection{References}

Anthony D, Willock J, Baharestani M. (2010). A comparison of Braden Q, Garvin and Glamorgan risk assessment scales in pediatrics. Journal of Tissue Viability; 19:98-105.

Baharestani MM., 2007. An overview of neonatal and pediatric wound care knowledge and considerations.Ostomy Wound Management;53: 34-6, 38, 40.

Baharestani MM, Ratliff CR. (2007). Pressure Ulcers in Neonates and Children: An NPUAP White Paper. Advances in Skin and Wound Care; 20: 208-220.

Baharestani MM, Pope E. (2007). Chronic wounds in neonates and children. In: Krasner, D., Rodeheaver, G., Sibbald, G. (Eds.), Chronic Wound Care. HMP Communications, Malvern, PA, pp. 679-693.

Barnes S. (2004). The use of a pressure ulcer risk assessment tool for children. Nursing Times; 100: 56-58.

Bedi A. (1993). A tool to fill the gap. Developing a wound risk assessment chart for children. Professional Nurse; 9: 112-120.

Bergstrom N, Braden BJ, Laguzza A, Holman V. (1987). The Braden scale for predicting pressure sore risk. Nursing Research;36: 205- 210.

Buckley BS, Simpson CR, McLernon DJ, Hannaford PC, Murphy AW. (2010). Considerable differences exist between prevalent and incident myocardial infarction cohorts derived from the same population. Journal of Clinical Epidemiology; 63:1351-1357.

Buntinx F, Aertgeerts B, Macaskill P. (2009). Guidelines for conducting systematic reviewe of studies evaluating the accuracy of diagnostic tests. In: Knottnerus, J.A., Buntinx, F. (Eds.), The Evidence Base of Clinical Diagnosis. Blackwell, Oxford, pp. 180-212. 
Cockett A. (1998). Paeditric pressure sore risk assessment. Journal of Tissue Viability; 8: 30.

Curley MAQ, Razmus IS, Roberts KE, Wypij D. (2003). Predicting pressure ulcer risk in pediatric patients: the Braden-Q Scale. Nursing Research; 52: 22-33.

De Vet HC, Eisinga A, Riphagen II, Aertgeerts B, Pewsner, D. (2008). Chapter 7: Searching for Studies. In: Cochrane Handbook for Systematic Reviews of Diagnostic Test Accuracy Version 0.4. The Cochrane Collaboration. Available from: http://srdta.cochrane.org/.

De Vet HC, Terwee CB, Knol DL, Bouter LM. (2006). When to use agreement versus reliability measures. Journal of Clinical Epidemiology; 59: 1033-1039.

Deeks JJ. (2001). Systematic reviews in health care: Systematic reviews of evaluations of diagnostic and screening tests. British Medical Journal; 323: 157162.

Dixon M, Ratliff C. (2005).Pediatric pressure ulcer prevalence- one hospital's experience.Ostomy Wound Management; 51: 44-46 \& 48-50.

Defloor T, Grypdonck MFH. (2004). Validation of pressure ulcer risk assessment scales: a critique. Journal of Advanced Nursing; 48: 613-621.

Duncan KD. (2007). Preventing pressure ulcers: the goal is zero. The Joint Commission Journal on Quality and Patient Safety;33: 605-610.

Fischer AR, Wells G, Harrison MB. (2004). Factors associated with pressure ulcers in adults in acute care hospitals. Advances in Skin \& Wound Care; 17: 8090.

Garvin G. (1997). Wound and skin care for the PICU. Critical Care Nursing Quarterly; 20: 62-71.

Gordon MD. (2008). Development of a New Skin Risk Assessment Scale for Pediatric Burn Patients. Southern Online Journal of Nursing Research; 8:

Available at:

http://snrs.org/publications/SOJNR_articles2/Vol08Num02F_G.html\#Gordon 
Gordon MD. (2009). Psychometric evaluation of a new pressure ulcer risk assessment scale for the pediatric burn patient. The University of Texas Medical Branch. Available at: http://etd.utmb.edu/theses/available/etd-07242009104133/unrestricted/GORDONFINAL.pdf

Gray M. (2004). Which pressure ulcer risk scales are valid and reliable in a pediatric population. Journal of Wound Ostomy and Continence Nursing; 31: 157160.

Griffiths P, Murrells T. (2010). Reliability assessment and approaches to determining agreement between measurements: classic methods paper. International Journal of Nursing Studies; 47: 937-938.

Halfens RJ. (2000). Risk assessment scales for pressure ulcers: a theoretical, methodological, and clinical perspective. Ostomy Wound Management; 46: 36-44.

Huffines B, Logsdon MC. (1997). The Neonatal Skin Risk Assessment Scale for predicting skin breakdown in neonates. Issues in Comprehensive Pediatric Nursing; 20: 103-114.

Jull A, Griffiths P. (2010). Is pressure sore prevention a sensitive indicator of the quality of nursing care? A cautionary note. International Journal of Nursing Studies; 47: 531-533.

Knottnerus JA, Dinant G-J, van Schayck OP. (2009). The diagnosis before-after study to assess clinical impact. In: Knottnerus, J.A., Buntinx, F. (Eds.), The Evidence Base of Clinical Diagnosis. Blackwell, Oxford, pp. 83-95.

Kottner J, Audigé L, Brorson S, Donner A, Gajeweski BJ, Hróbjartsson A, Roberts C, Shoukri M, Streiner DL. (2011). Guidelines for reporting reliability and agreement studies (GRRAS) were proposed. Journal of Clinical Epidemiology; 64: 96-106.

Kottner J, Balzer K, Dassen T, Heinze S. (2009). Pressure ulcers: a critical review of definitions and classifications. Ostomy Wound Management; 55: 22-29.

Kottner J, Balzer K. (2010). Do pressure ulcer risk assessment scales improve clinical practice? Journal of Multidisciplinary Healthcare; 3: 103-111. 
Kottner J, DassenT. (2008). Interpreting interrater reliability coefficients of the Braden scale: a discussion paper. International Journal of Nursing Studies; 45: 1238-1246.

Kottner J. (2009). Interrater reliability and the kappa statistic: a comment on Morris et al. (2008). International Journal of Nursing Studies; 46: 140-141.

Leeflang MM, Deeks JJ, Gatsonis C, Bossuyt PM. (2008). Systematic reviews of diagnostic test accuracy. Annals of Internal medicine; 149: 889-897.

Lijmer JG, Bossuyt MM. (2009). Diagnostic testing and prognosis: the randomized controlled trial in test evaluation research. In: Knottnerus, J.A., Buntinx, F. (Eds.), The Evidence Base of Clinical Diagnosis. Blackwell, Oxford, pp.63-82.

Loman DG, (2000). Assessment of skin breakdown risk for children. Journal of Child and Family Nursing; 3: 234-238.

Lucas NP, Macaskill P, Irwig L, Bogduk N. (2010). The development of a quality appraisal tool for studies of diagnostic reliability (QAREL). Journal of Clinical Epidemiology; 63: 854-861.

Moore ZE, Cowman S. (2008). Risk assessment tools for the prevention of pressure ulcers. Cochrane Database Systematic Reviews; 16: CD006471.

National Pressure Ulcer Advisory Panel (NPUAP) and European Pressure Ulcer Advisory Panel (EPUAP). Prevention and treatment of pressure ulcers: clinical practice guideline. National Pressure Ulcer Advisory Panel, 2009, Washington DC.

Noonan C, Quigley S, Curley MAQ. (2006). Skin integrity in hospitalized infants and children. Journal of Pediatric Nursing;6: 445- 453.

Nunnally JC, Bernstein IH. (1994). Psychometric Theory. McGraw-Hill, New York. Okamoto GA, Lamers JV, Shurtleff DB. (1983). Skin breakdown in patients with myelomeningocele. Archives of Physical Medicine and Rehabilitation; 64: 20-23.

Olding L, Patterson J. (1998). Growing concern. Nursing Times; 94: 74-79. 
Papanikolaou P, Lyne P, Ratcliffe J. (2007). Using the discrete choice experimental design to investigate decision-making about pressure ulcer prevention by community nurses. Health Society Care Community;15:588-98.

Pancorbo-Hidalgo PL, Garcia-Fernandez FP, Lopez-Medina IM, Alvarez-Nieto C. (2006). Risk assessment scales for pressure ulcer prevention: a systematic review. Journal of Advanced Nursing; 54:94-110.

Pickersgill J. (1997). Taking the pressure off. Pediatric Nursing; 9: 25-27.

Polit DF, Beck C. (2008). Nursing Research. Wolters Kluwer, Philadelphia.

Quigley SM, Curley MA. (1996). Skin integrity in the pediatric population: preventing and managing pressure ulcers. Journal of the Society of Pediatric Nurses; 1: 7-18.

Reitsma JB, Rutjes AWS, Whiting P, Vlassov VV, Leeflang MMG, Deeks JJ. (2009). Chapter 9: Assessing methodological quality. In: Deeks, J.J., Bossuyt, P.M., Gatsonis, C. (Eds.), Cochrane Handbook for Systematic Reviews of Diagnostic Test Accuracy Version 1.0.0. The Cochrane Collaboration. Available from: http://srdta.cochrane.org/.

Schlüer AB, Cignacco E, Müller M, Halfens RJ. (2009). The prevalence of pressure ulcers in four pediatric institutions. Journal of Clinical Nursing;18: 32443252.

Stechmiller JK, Cowan L, Whitney JD, Phillips L, Aslam R, Barbul A, Gottrup F, Gould L, Robson MC, Rodeheaver G, Thomas D, Stotts N. (2008). Guidelines for the prevention of pressure ulcers. Wound Repair and Regeneration; 16: 151-168.

Suddaby EC, Barnett S, Facteau L. (2005). Skin breakdown in acute care pediatrics. Pediatric Nursing;31: 132-138 \& 148.

Twisk J. (2003). Applied Longitudinal Data Analysis for Epidemiology. Cambridge University Press.

Waterlow J. (1997). Pressure sore risk assessment in children. Pediatric Nursing; 9: 21-24. 
Waterlow J. (1985). Pressure sores: a risk assessment card. Nursing Times; 81: 49-55.

Whiting P, Rutjes AW, Reitsma JB, Bossuyt PM, Kleijnen J. (2003). The development of QUADAS: a tool for the quality assessment of studies of diagnostic accuracy included in systematic reviews. BMC Medical Research Methodology; 3: 25.

Williams C. (1991). Comparing Norton and Medley. Nursing Times; 87: 66-68.

Willock J, Baharestani MM, Anthony D. (2007). The development of the Glamorgan pediatric pressure ulcer risk assessment scale. Journal of Children's and Young People's Nursing;01: 211-218.

Willock J, Anthony D, Richardson J. (2008). Interrater reliability of the Glamorgan Pediatric Pressure Ulcer Risk Assessment Scale. Pediatric Nursing; 20; 1419. 



\section{Risk and associated factors of pressure ulcers in hospitalized children over 1 year of age}

Schlüer AB, Schols JMGA, Halfens, RJG. Risk and associated factors of pressure ulcers in hospitalized children over 1 year of age. Submitted to the Journal for Specialists in Pediatric Nursing, 2012 (accepted for publication, 2013). 


\section{Abstract}

Purpose: This study aimed to identify factors for the development of pressure ulcers in hospitalized patients between 1 and 18 years of age.

Design and Methods: A multicenter, descriptive, cross-sectional study in 13 hospitals was conducted in Switzerland.

Results: The prevalence of pressure ulcers in this population is $26.5 \% \%$, with $83 \%$ category 1 pressure ulcers. A third of all pressure ulcers developed along external devices. Older children developed more pressure ulcers due to ineffective positioning and limited mobility.

Practice Implications: Activity and mobility and the risk associated with the use of external devices have to be assessed for each child. 


\subsection{Introduction}

A pressure ulcer (PU) is a localized injury to the skin and/or underlying tissue as a result of pressure, or pressure in combination with shear forces (National Pressure Ulcer Advisory Panel (NPUAP) and European Pressure Ulcer Advisory Panel (EPUAP), 2009). Avoidance of pressure-related injuries and maintenance of skin and tissue integrity are important goals in the care process, and identifying individuals at risk of developing PUs by structured risk assessments is recommended as a first step for effective PU prevention (Stechmiller et al., 2008). The NPUAP and EPUAP have published an international guideline (NPUAP/ EPUAP 2009), which explicitly states that "a structured approach may be achieved through the use of a risk assessment scale" in combination with clinical judgment (NPUAP/ EPUAP 2010, p. 10).

While the problem of PUs has received a great deal of attention in adults, far less is known about PUs in children and neonates (Baharestani and Pope, 2007). Recent investigations have indicated that PUs are also common in the pediatric population: Reported PU prevalence rates including all PU categories range from approximately $2 \%$ to $28 \%$ (Kottner, Wilborn, Dassen, 2010 ) or $35 \%$ (Schlüer, Halfens, Schols, 2012). One explanation for these high rates involves the dramatically improved survival rates of both critically and chronically ill infants and children, introducing new challenges for medical and nursing care (Jones, Tweed, Marron, 2001). The skin may be affected due to external influences like increased pressure and shear forces due to the application of external devices. Particularly in patients in pediatric intensive care units (PICUs), the influence of pressure by tubes for patients on oscillation and extracorporeal membrane oxygenation as well as their decreased tissue tolerance due to their critical life condition increase the risk of skin failure, making these patients in critical life conditions most vulnerable for PUs (Baharestani and Pope, 2007, Curley, Razmus, Roberts, Wypij, 2003, Schlüer et al., 2012).

An adapted, reliable and valid PU risk assessment tool with validated cut-off points, applicable for a wide range of the population from neonates to adolescents, is still not available (Kottner, Hauss, Schlüer, Dassen, 2013, Anthony, Willock, Baharestani, 2010). Due to the different risk factors in neonates, infants and 
children it does not seem feasible to develop a risk assessment tool for PU risk assessment covering a broad range of the pediatric population (Kottner et al., 2013). Many of the available assessment tools, like the Braden- $Q$ scale are modifications of PU risk scales for adults and include variables deemed especially important for PU development in the adult population, e.g. mobility, incontinence, moisture, and nutrition. The relevance for clinical effectiveness of specifically pediatric PU risk scales has not been investigated so far (Kottner et al., 2013).

Due to the specific lack of information about factors associated with PU risk in children of different age groups, there is an urgent need for studies on pressure ulcers in the pediatric population to obtain insight into the importance of the problem and to gain knowledge about child-specific risk and associated factors. Based on such studies, assessment with a specialized and standardized risk assessment tool as well as clinical judgment may lead to an improvement of the prevention of PUs and the quality of PU-care for these patients.

\subsubsection{Research aims}

The aim of the present study was to identify factors associated with the occurrence of pressure ulcers in hospitalized pediatric patients between one and 18 years of age. Further, the aim was to identify anatomical regions associated with the highest risk of pressure ulcer occurrence and to identify risk factors of PUs in hospitalized pediatric patients. 


\section{$5.2 \quad$ Methods}

\subsubsection{Study design}

A multicenter, cross-sectional, descriptive study was conducted in all 13 pediatric hospitals in the German-speaking part of Switzerland in June 2009. These hospitals have a total of 69 wards. All hospitalized children from one year of age up to 18 years were included in the study. Children had to be hospitalized for at least one day. Exclusion criteria were a) hospitalization in psychiatric wards, b) children whose legal representatives did not allow participation, and c) children who refused to participate. The study was approved by all state ethics committees, and when necessary by the ethics board of the hospital concerned. After the patients and their legal representatives had been verbally informed about the study's content and aim, they also received the information in written form along with an informed consent form to sign. The information letter as well as the informed consent form for the legal representatives was available in eight different languages (German, French, Italian, English, Portuguese, Albanian, Serbian, and Turkish). Children of 10 years and older as well as their legal representatives were both asked to give their written consent.

\subsubsection{Measurements}

The instrument and method of data collection of the Dutch National Prevalence Measurement of Care Problems (LPZ; Halfens et al, 2010) was used to assess the prevalence, severity, location and risk factors, as well as factors associated with the occurrence of pressure ulcers. Associated factors included assessment of first occurrence of a PU and the setting in which a PU occurred. This information was taken from the patient's chart. This instrument is widely used internationally and has been assessed as reliable and valid in adult patients (Bours, Halfens, Lubbers, Haalboom, 1999). It comprises the following categories of data for assessment: (1) patient characteristics (demographic and clinical data), (2) assessment of the location and severity of pressure ulcers, (3) PU risk assessment using the Braden scale, (4) predisposing factors for PU development, 
(5) preventive interventions, as well as (6) therapeutic interventions. In addition to this instrument, we assessed all external devices on the patient's body at the time of the assessment (e.g. tubes, IV catheterizations splints/iv boards, and other devices), which might cause the occurrence of a PU in these children.

The Braden scale is part of the measurement tool and includes six subscales, five of which have four answer categories and one, only three (Bergstrom, Braden, Kemp, Champagne \& Ruby, 1998, Bergstrom, Braden, Laguzza, \& Holman, 1987). The total scores range from 6 to 23 points, with a lower score indicating a higher risk for the patient to develop a pressure ulcer. A cut-off point for patients at risk set at $\leq 20$ (Schlüer, Cignacco, Müller \& Halfens, 2009).

\subsubsection{Data collection}

The method of data collection involved a direct and systematic inspection and judgment of the skin of the patient. The NPUAP/EPUAP (NPUAP/EPUAP, 2009) pressure ulcer category system was used. Demographic and clinical data, such as date of birth, weight and size, body mass index and diagnosis, were collected from patient charts. Assessments of installations on the body site as well as other associated factors (like cloths and clothes, incorrect positioning, and cables in beds) that may lead to the development of PU were clinically assessed. The total information was gathered both by direct inspection of the patient and from the patient files.

Data were gathered by previously trained rater pairs for each patient. A total of 34 rater pairs were involved in the study. On each unit, an internal and an external rater worked together. The internal rater was from the unit itself, the external rater was from another unit or department. If the pair disagreed on their assessment, they were asked to find consensus. If no consensus could be reached, the external rater was given the right of decision. No statement about disagreement within the rater pairs can be made as this was not an objective of the study. To be selected, raters were required to have had more than two years of nursing practice with children. In all participating hospitals, nurses who worked either as wound consultants in their units or as clinical nursing specialists acted as raters. Preparatory training included methodological aspects, detailed information about 
data collection, the role and responsibilities of the raters, a detailed introduction to the measurement instruments, and special training in the grading of a pressure ulcer as well as in the Braden scale in infants and children. Pilot studies in all sites with more than two rater pairs were conducted to assess the inter-rater reliability for grading and risk assessment. The different rater pairs had to assess the same patients independently to check agreement or disagreement within the rater pairs in rating the category of PUs and use of the Braden scale. A balanced incomplete block design was chosen (Fleiss, 1981). Overall, inter-rater reliability (Kappa 0.79: $\mathrm{n}=180$ ) for the grading of pressure ulcers was sufficient. A data consistency of $95 \%$ as to whether the patient developed a pressure ulcer or not was observed.

\subsubsection{Data analysis}

Predictive Analytics Software (PASW) (version 18, formerly SPSS) was used to analyze the study data with descriptive and univariate statistical methods. Explorative statistics was used (e.g. boxplots) to describe the distribution of the Braden score in relation to departments. Distributions and frequencies were calculated. The relation between dependent variables and risk factors was distributed with cross tabs and calculated. Group differences were due to the type of data tested, with nonparametric tests for categorical (Chi-Square) and not normally distributed data (Wilcoxon). A p-value of 0.05 and lower was considered as statistically significant. 


\subsection{Results}

\subsubsection{Demographics}

The overall sample size of potential study participants who met the inclusion criteria was $268(100 \%)$. The total number of participants was $204(76 \%)$, because $64(24 \%)$ dropped out before the assessment. In 42 dropout cases (65\%), either the legal representative or the child refused participation. Seventeen patients were excluded due to unexpected discharge or because examination or operation lasted longer than the survey took place (30\%). Two children were not assessed due to an unexpected change in their condition to a critical level. Only three patients dropped out due to language problems.

In the 13 hospitals, the participation rate ranged from $43-100 \%$. Of the 204 assessed patients, $67 \%$ had been hospitalized for less than 14 days. In this subcategory, the average length of stay was five days, with a median of three days. The mean length of stay was 29 days (sd: 75.1), with a median stay of 5 days (table 1 ). 
Table 1: Demographic characteristics of the total study sample

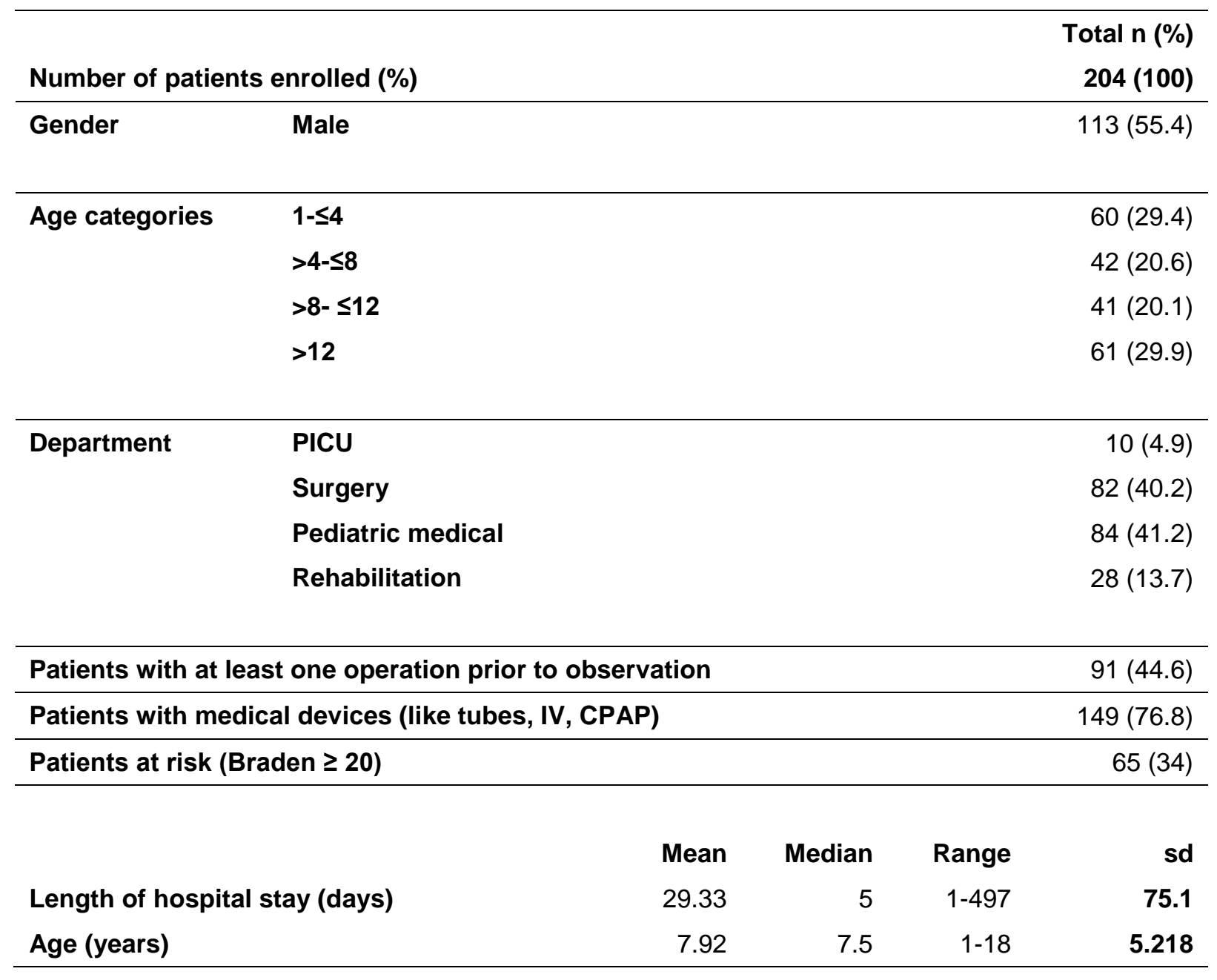

A third of all children where under the age of four, or older than 12 years of age (table 1). Nearly 80 percent of all patients were hospitalized either in the surgical or the pediatric medical department, while only five percent were hospitalized at the PICU. Ninety-one patients (including PICU cases) had at least one operation during the hospitalization before the assessment (45\%) (table 1).

\subsubsection{Pressure ulcer risk}

The mean PU risk for all patients according to the Braden scale was 20 ( $s d=3.3$ ), with a median of 22 and a range of nine to 23 . According to the Braden scale, a total of $65(32 \%)$ patients were assessed as being at risk (score of $\leq 20$ ) with a mean of 16.5 and a median of 17 (sd: 2.8), whereas patients not at risk had a mean Braden of 22 and a median of 23 (sd: 1.0) (table 2, table5). No significant differences were found between boys and girls ( $X 2$ 0.03; $d f=1 ; p=0.43$ ) whereas 
age (Wilcoxon rank sum test $Z=-13.748, P=0.000$ ) and the type of department was significantly related to being at risk (X2 25.8; $d f=4 ; p<0.001)$ (table 4).

Table 2: summary of patients showing PUs

Total patients with at least one PU (\%)

Department

PICU

\subsubsection{Subcategories of Braden scale}

In table 3 the subcategories of the Braden scale are described for all patients as well as for patients at risk and for those showing at least one PU. The highest percentage of patients were affected in the subcategory nutrition (Score 1-3) with $45.6 \%$, followed by activity with (Score 1-3) 40.7\%, mobility with (Score 1-3) $33.8 \%$, friction and shear forces with (Score 1+2) 30.9\%, moisture with (Score 1-3) $29.4 \%$. Only $19.6 \%$ of all patients were affected in their sensory perception (Score 1-3) (table 5). It is interesting to note that patients at risk (Braden score of $\leq 20$ ) as well as patients showing at least one PU had higher values in all subcategories of the Braden scale, except for nutrition and friction and shear, than patients who were not at risk or did not have a PU (table 3). 
Table 3: subcategories of the Braden scale for the whole population divided into at risk/ not at risk patients

\begin{tabular}{|c|c|c|c|c|}
\hline & & $\begin{array}{l}\text { Patients not } \\
\text { at risk } n(\%)\end{array}$ & $\begin{array}{r}\text { Patients at risk } \\
\mathrm{n}(\%)\end{array}$ & n (\%) \\
\hline \multirow{4}{*}{$\begin{array}{l}\text { sensory } \\
\text { perception }\end{array}$} & completely limited & 0 & $2(100)$ & $2(1)$ \\
\hline & very limited & 0 & $12(100)$ & $12(5.9)$ \\
\hline & slightly limited & $1(8)$ & $12(92)$ & $13(6.4)$ \\
\hline & no impairment & $125(76)$ & $39(24)$ & $164(80.4)$ \\
\hline \multirow[t]{4}{*}{ moisture } & constantly moist & 0 & 0 & 0 \\
\hline & very moist & 0 & $5(100)$ & $5(2.5)$ \\
\hline & constantly moist & $16(38)$ & $26(62)$ & $42(20.6)$ \\
\hline & rarely moist & $110(76)$ & $34(24)$ & $144(70.6)$ \\
\hline \multirow[t]{4}{*}{ activity } & bed fast & 0 & $30(100)$ & $30(14.7)$ \\
\hline & chair fast & 0 & $15(100)$ & $15(7.4)$ \\
\hline & walks occasionally & $12(48)$ & $13(52)$ & $25(12.3)$ \\
\hline & walks frequently & $114(94)$ & $7(6)$ & $121(59.3)$ \\
\hline \multirow[t]{4}{*}{ mobility } & completely immobile & 0 & $9(100)$ & $9(4.4)$ \\
\hline & very limited & 0 & $19(100)$ & $19(9.3)$ \\
\hline & slightly limited & $7(25)$ & $21(75)$ & $28(13.7)$ \\
\hline & no limitation & $119(88)$ & $16(12)$ & $135(66.2)$ \\
\hline \multirow[t]{4}{*}{ nutrition } & very poor & 0 & $8(100)$ & $8(3.9)$ \\
\hline & probably inadequate & $12(46)$ & $14(54)$ & $26(12.7)$ \\
\hline & adequate & $32(70)$ & $14(30)$ & $46(22.5)$ \\
\hline & excellent & $82(74)$ & $29(26)$ & $111(54.4)$ \\
\hline \multirow{3}{*}{$\begin{array}{l}\text { friction and } \\
\text { shear }\end{array}$} & problem & $1(7)$ & $13(93)$ & $14(6.9)$ \\
\hline & potential problem & $4(11)$ & $32(89)$ & $36(17.6)$ \\
\hline & no apparent problem & $121(86)$ & $20(14)$ & $141(69.1)$ \\
\hline
\end{tabular}

\subsubsection{PU development, localization}

A total of 54 patients showed at least one PU (26.5\%) (table 2). The most frequently assessed PU category was category 1 (83.3\%), but in one case a category 4 PU was assessed (table 3$)$. Most patients showed only one PU ( $n=33)$, 12 patients showed two PUs, five patients showed three PUs, two patients showed foru PUs and one showed five or six PUs (table 4). Most of the observed PUs had developed on the ward where the child was hospitalized during the measurement (68\%) (table 6). In addition, most of the PUs had developed in the two weeks 
before the measurement $(70.3 \%)$ (table 6$)$. The lower extremity, and, of that, the foot $(34.1 \%)$ was most often affected, followed by the upper extremity with most often the hand $(12.1 \%)$. The sacral region including the hip followed by the head area were affected less frequently (table 5). Most often PUs developed as a result of external medical devices ( $n=35,38.5 \%)$ (table 7$)$.

Table 4: PU risk assessed with the Braden scale of the total study sample and differentiated into department, sex and age categories

\begin{tabular}{llrrr} 
& & mean & median & sd \\
\hline \multicolumn{2}{l}{ Total study sample } & 20 & 22 & 3.3 \\
\hline Department & Surgery & 20 & 21 & 3.1 \\
& Rehabilitation & 20 & 23 & 3.4 \\
& Pediatric medical & 21 & 22 & 2.8 \\
& PICU & 15 & 16 & 3.3 \\
\hline Gender & Male & 20 & 21 & 3 \\
& Female & 20 & 20 & 2 \\
\hline Age categories & $\mathbf{1 - \leq 4}$ & 20 & 21 & 3.1 \\
(in years) & $>\mathbf{4 - \leq 8}$ & 21 & 22 & 2.5 \\
& $>\mathbf{4 -} \leq \mathbf{8}$ & 20 & 22 & 3.4 \\
& $>\mathbf{1 2}$ & 20 & 21 & 3.7
\end{tabular}

Table 5: Frequency of PUs according to category and patients with more than one PU

\begin{tabular}{lll}
\hline & & Total $\mathbf{n}(\%)$ \\
\hline Number of PUs & & $91(100)$ \\
Category 1 & & $45(83.3)$ \\
Category 2 & & $6(11.1)$ \\
Category 3 & & $2(3.7)$ \\
Category 4 & & $1(1.9)$ \\
\hline Patients with more than one PU & $1 \mathrm{PU}$ & $33(61.1)$ \\
& $2 \mathrm{PU}$ & $12(22.2)$ \\
& $3 \mathrm{PU}$ & $5(9.3)$ \\
& $4 \mathrm{PU}$ & $2(3.7)$ \\
& $5 \mathrm{PU}$ & $1(1.9)$ \\
& $6 \mathrm{PU}$ & $1(1.9)$ \\
\hline
\end{tabular}


Table 6: Setting in which PU occurred, point of time and localization of PU

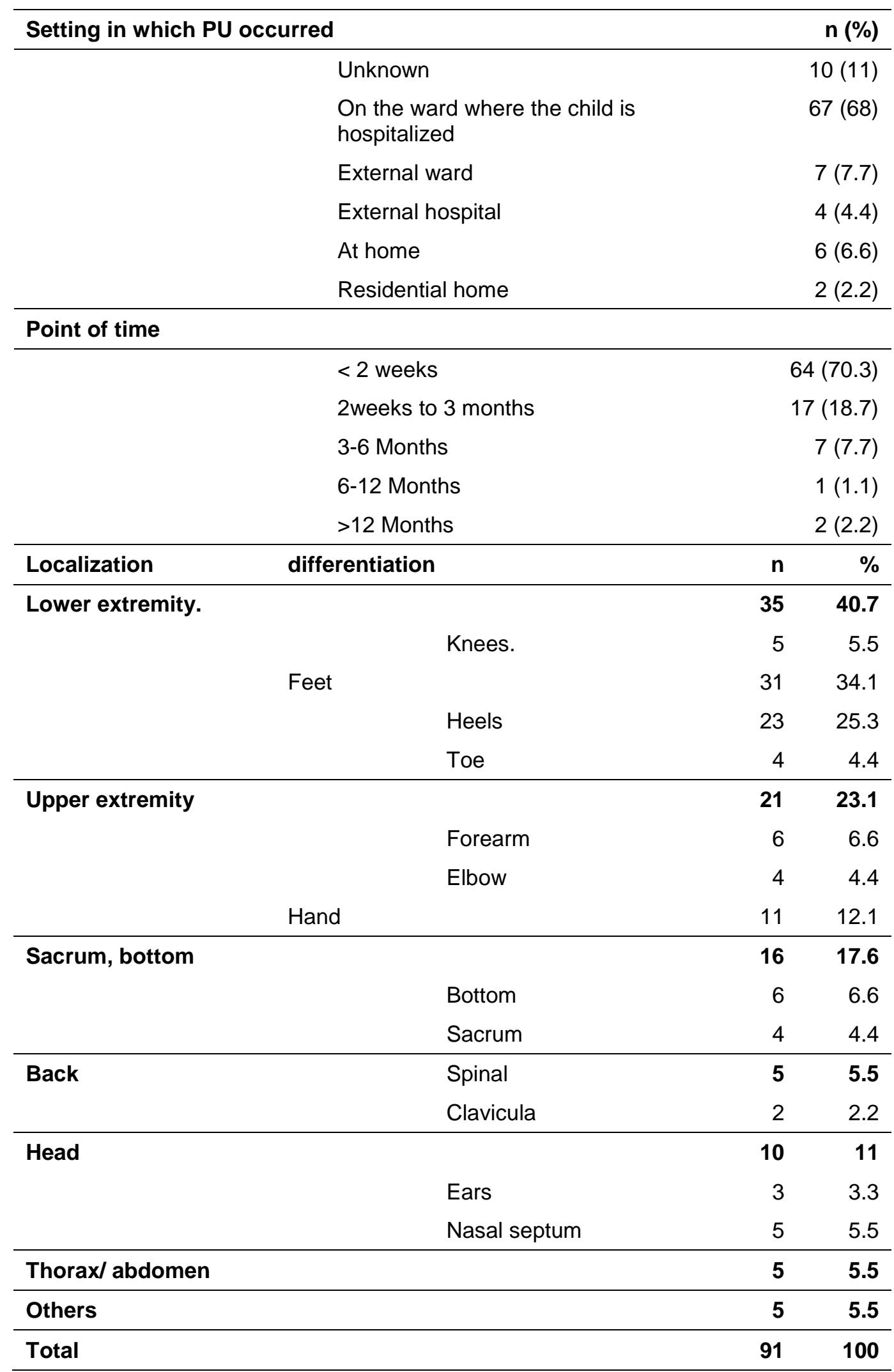


Table 7: Pressure ulcers related to the suspected cause for the development of PU

\begin{tabular}{lr}
\hline Suspected cause & $\mathbf{n}(\%)$ \\
\hline Shear or pressure & $17(18.7)$ \\
Splints due to IV catheterization* & $16(17.6)$ \\
Ineffective Positioning & $15(16.5)$ \\
Unknown & $11(12.1)$ \\
Cast $^{*}$ & $9(9.9)$ \\
Intraoperative $^{*}$ & $7(7.7)$ \\
Clothes & $4(4.4)$ \\
Tube* & $3(3.3)$ \\
Oxygenation sensor & $2(2.2)$ \\
Nasogastric tube* & $2(2.2)$ \\
Neck collar* & $2(2.2)$ \\
Cables in bed & $1(1.1)$ \\
Fixation & $1(1.1)$ \\
Nasal O2 tube* & $1(1.1)$ \\
\hline total & $91(100)$ \\
\hline
\end{tabular}

${ }^{*}$ All together summarized as external devices

\subsection{Discussion}

In this study hospitalized pediatric patients older than one year of age showed a PU prevalence rate of $26.5 \%$. These patients present with several factors that may lead to the development of a PU. First of all the presence of medical devices seems to be a particular risk factor in all age categories. Second, in these patients limited activity and mobility appeared to be particular risk factors as well. The most affected anatomical region for the development of a PU was the lower extremity especially the foot.

The PU prevalence of $26.5 \%$ in this study sample is rather high but in line with previous results reported (Schlüer et al., 2009) (28\%). Older patients over the age of 12 years showed slightly more frequent PUs (32\%) than children under the age of eight years. Patients hospitalized in the PICU setting were most often affected by a PU (40\%). Forty percent of the patients assessed as at risk (Braden scale 
$\geq 20$ ) showed a PU, whereas $32 \%$ of all patients with an external medical device showed at least one PU.

Most of the PUs assessed in this study developed due to external devices (38.5\%). This problem has long been recognized in infants and children (Okamoto, Lamers, Shurtleff, 1983). In the development of risk assessment tools for the pediatric population, the risk factor "devices on the skin" has only become part of these scales since 1998 (Kottner et al, 2013). These devices on the skin are known as the most predominant risk factors of all for PUs in children and infants (Schlüer et. al, 2012). However, the Braden scale fails to include this potential risk factor. Therefore, in this study external medical devices were additionally assessed. Young pediatric patients (under the age of five years) are, due to their developmental status, unable to differentiate pressure from other sensory perceptions of such devices properly and are therefore most vulnerable. Equipment-related risk factors, e.g. those connected with traction, tubes and IV catheterization, are therefore additional potential PU risk factors in the pediatric health care setting (Willock, Askew, Bolland, Maciver \& James, 2005, Noonan, Quigley \& Curley, 2006, Schlüer et al., 2009, Kottner et al., 2013). So far the only published and tested pediatric PU risk assessment tool for the wide range of the child population (from 1-18 years), which includes the category 'external devices on the skin' is the Glamorgan scale (Willock, Baharestani \& Anthony, 2007a, Willock, Baharestani \& Anthony, 2007b, Willock, Anthony \& Richardson, 2008). It is indispensable to include this risk factor in PU risk assessment for pediatric patients in the future (Kottner et al., 2013).

In this study risk assessment was conducted using the Braden scale. The use of the Braden scale in a pediatric population in fact needs to be reflected upon critically. The Braden Scale is one of the best-known and widely used tools for evaluating pressure ulcer risk in adults, the psychometric properties in assessing the PU risk of adults have been evaluated, still there are limited psychometric properties of that scale (Papanikolaou, Lyne, Anthony, 2007, Pancorbo-Hidalgo, Garcia-Fernandez, Lopez-Medina, Alvarez-Nieto, 2006; Moore and Cowman, 2008; Kottner, Raeder, Halfens, Dassen, 2009). Thus, additional clinical judgment by experienced nurses is recommended (Papanikolaou et al., 2007). The original Braden scale has not been validated for use in pediatric populations. Since this 
instrument is a risk scale for adults, it contains many variables deemed important for PU development in the adult population, such as incontinence, moisture and nutrition, but, as mentioned, lacks potential specific risk factors for pediatric patients. Specificity and sensitivity for PU risk assessment in pediatric patients is therefore rather weak, and many patients with no specific risk potential for PU development are categorized as 'at risk' (Schlüer et al., 2009, Schlüer et al., 2012). An adapted, reliable and valid risk assessment tool, applicable to the wide range of population from neonates to adolescents, in combination with validated cut-off points, is, however, not available for the pediatric population (Kottner et al., 2013). At the time of data collection for the present study the common pediatric risk assessment scales available, like the Braden-Q scale and the Glamorgan scale, were the best-known PU risk assessment scales for the pediatric population (Kottner et al., 2013, Curley et al., 2003, Willock et al., 2007a, Willock et al., 2007b, Willock et al., 2008). The Braden-Q, developed and introduced for immobile patients from 21 days of age, has not been validated for children more than eight years of age and no validated German version is available. There is also no validated German version of the Glamorgan scale. Due to this lack of possible alternative pediatric risk assessment tools in German and because the Braden scale is part of the instrument used (LPZ), we decided to use the Braden scale to describe potential risk factors in these pediatric patients. As stated by Kottner et al. (2013) the only indicator included in all pediatric specific risk assessment tools is mobility, which is also included in the Braden scale. Due to the knowledge that devices represent a high risk of PU development, especially in younger children, we added the assessment of devices to the original instrument as stated in the methods section (Kottner et al., 2013, Willock 2005, Willock et al., 2007a).

The most frequent localization of a pressure ulcer was the lower extremity, especially the feet $(40 \%)$. The reason for this might be the fact that the majority of pressure ulcers were developed because of splints/iv boards or cables and sensors, as well as IV catheterization. Pediatric patients in infancy often have IV catheterization on the metatarsal or the ankle, additionally fixated by splints/iv boards. These splints/iv boards related to IV catheterization are suspected of 
causing the development of a PU in $18 \%$ of all PUs. Another frequently affected area is the upper extremity, especially the hand. In line with the suspected cause of PUs in the feet, another frequently used site for insertion of an IV catheter and additional fixation with splints/iv boards in children is the hand, especially the back of the hand. From the results of this study the feet seem to be more at risk for PU development than the hand in small children. These findings require ongoing investigation to distinguish different factors that might elucidate this finding.

Up to now, the ears, the occiput, heels and ischeal tuberosities and the nose are the anatomic sites in pediatric patients found to be most likely to develop a pressure ulcer (Kottner et al., 2010, Suddaby, Barnett, Facteau, 2005, Curley et al., 2003, Schlüer et al., 2009). However, this seems especially true for children under the age of one year, who were not included in this study, where the head area was only affected in $11 \%$ of those surveyed. Patients in PICUs most frequently developed PUs on the head, especially the face. This is in line with the fact that these children need numerous medical devices such as tubes, CPAPs and nasogastric tubes, which are attached to the face area. In this study the number of patients treated in a PICU was relatively low, with 10 patients (5\%). Even the prevalence rate in PICU patients is high at $40 \%(n=4)$, but this obviously needs further investigation.

In our study, $18 \%$ of all PUs developed in the sacral region. This seems to contrast with studies of adult patients, where the sacral region is, next to the heel, most often affected (Kottner et al., 2011). These findings confirm the idea that the localization of PUs may differ between adult and pediatric patients. Further investigations along this line are needed.

Additional potential risk factors for pediatric patients mentioned in the literature are immobility and decreased skin sensitivity (Suddaby et al. 2005, Willock et al. 2005, Willock 2005). This study shows that $40 \%$ of all assessed children show a higher risk of PUs due to inactivity, immobilization and nutrition when risk assessment is done with the Braden Scale. These findings are in line with previous studies (Huffiens\& Logsdon, 1997, Kottner et al. 2013), in which mobility is the only subcategory of assessment in all so-far-published pediatric risk assessment tools (Kottner et al., 2013). In all, $40 \%$ of at risk pediatric patients (meaning patients with a Braden scale score $\leq 20$ ) show at least one PU. This is slightly lower than the 
$49 \%$ reported for the pediatric population (neonates to 18 years) by Schlüer et al. (2012). Neonates and infants need intense treatment when admitted to the hospital, often involving external devices. Therefore it seems possible that neonates and infants are due to their immature and vulnerable skin within the first 12 month of life on a general risk for PU occurrence. It therefore seems feasible that in this study were only children older than one year of age were included this rate is lower.

Nutrition was a relevant risk factor in this study as well. Nutrition is known as a relevant factor with regard to skin integrity (Rodriguez-Key, 2007) in pediatric patients. So far to our best knowledge no clinical trials conducting the influence of under- or malnutrition in pediatric patients with regard to $\mathrm{PU}$ occurrence were conducted and need further investigation.

\section{$5.5 \quad$ Limitations}

The study was conducted within 13 different pediatric hospitals; the participation rate differed between $43 \%$ and $100 \%$. Most of the dropouts where due to the fact that parents or patients refused to participate in the study $(n=42)$. According to the ethical approval necessary for this study, patients older than 10 years of age had to sign their own informed consent as did their parents or legal representative. This meant that for all these patients two informed consents were necessary.

It is important to realize that prevalence studies are always subject to daily variations. However, in general, prevalence figures over the years are relatively constant (Gunningberg, Stotts, 2008). Most of the PUs in this study were category 1. To what extent the category $1 \mathrm{PUs}$ were over- or underdiagnosed in this study remains unclear, although the inter-rater reliability between the rater pairs suggests that the scores are reliable. The results of this study were gathered on one day and provide no information about the development of PU in pediatric patients over time.

The results of this study provide insight into the risk and associated factors that lead to the development of PUs in hospitalized pediatric patients older than one 
year of age. The use of the Braden scale is of limited reliability because the original Braden scale is not validated for use in pediatric populations. Since this instrument is a risk scale for adults, it contains many variables deemed important for PU development in the adult population, it lacks potential specific risk factors for pediatric patients. Differences between adult and pediatric patients regarding the risk categories of the Braden scale require further investigation. Moreover, the question arises whether it would not be feasible and necessary to develop a PU risk scale covering all the necessary aspects for the pediatric population. With regard to this we added the assessment of medical devices in our study. In what extend these medical devices are the real cause for the PU occurrence in this study remains unclear. Due to the nature of the study, no causes of the development of Pus can be presented. Furthermore, no assumptions can be made about when the highest risk levels within a patient's hospital stay occur, or which devices represent the highest risk of PU development. In this study we only describe factors that might be associated with the occurrence of a PU in hospitalized pediatric patients older than one year of age. There is a need for longitudinal research in this population to determine at what times and within which settings pediatric patients most often develop PUs.

\subsection{Practice Implications}

PUs are a relevant care problem in children as well as in adults. This study shows that the risk factors, the anatomical localities of PU as well as the risk of PUs due to external devices differ from those in an adult population. Therefore specialized preventive interventions based on the needs of the pediatric population are mandatory. The use of risk assessment scales in pediatric health care should focus specifically on external medical devices and limited mobility and activity. Risk assessment scales for adults are not precise enough to cover pediatric risk factors. Age-related factors such as limited communication skills in children under the age of two years have not been addressed in any risk assessment tool so far. According to our findings, and in line with clinical expertise in the field of PU development in children, it is more reliable to focus on different risk populations, 
such as children hospitalized in a PICU, and also to assess equipment-related factors contributing to the development of PUs.

Clinical practice needs to be aware of the particular PU risk potential of specific populations, e.g. children, and of the importance of decreasing preventable PUs in this group.

How might this information affect nursing practice? Younger patients (under the age of five years) should be assessed carefully with regard to their inability to distinguish pressure on the skin adequately. Patients in the PICU setting seem most vulnerable to developing PUs in the face due to external devices on the skin. The risk assessment criterion 'external devices to the skin' needs to be implemented in the pediatric setting and therefore evaluated in all age categories. Hospitalized children over the age of one year have to be assessed daily for their PU risk from decreased mobility and activity and from external medical devices. It is of key importance to develop and implement pediatric specific PU prevention guidelines and highlight risk factors for this population. 


\subsection{References}

Anthony D, Willock J, Baharestani M. (2010). A comparison of Braden Q, Garvin and Glamorgan risk assessment scales in pediatrics. Journal of Tissue Viability; 19: 98-105.

Baharestani MM, Pope E. (2007). Chronic wounds in neonates and children. In: Krasner, D., Rodeheaver, G., Sibbald, G. (Eds.), Chronic Wound Care. HMP Communications, Malvern, PA, 679-693.

Bergstrom N, Braden B, Kemp M, Champagne M, Ruby E. (1998). Predicting pressure ulcer risk. A multisite study of the predictive validity of the Braden scale. Nursing Research; 47: 261- 269.

Bergstrom N, Braden BJ, Laguzza A, Holman V. (1987). The Braden scale for predicting pressure sore risk. Nursing Research; 36: 205- 210.

Bours GJJ, Halfens RJG, Lubbers M, Haalboom JRE. (1999). The development of a national registration form to measure the prevalence of pressure ulcers in the Netherlands. Ostomy Wound Management; 45: 28-40.

Curley MAQ, Razmus IS, Roberts KE, Wypij D. (2003). Predicting pressure ulcer risk in pediatric patients: the Braden-Q Scale. Nursing Research; 52: 22-33.

Fleiss J. (1981). Balanced incomplete block designs for inter-rater reliability studies. Applied psychological measurement; 5: 105-122.

Halfens R, Meijers J, Neyens J, van Nie N, Schols J, Wolters S, Rijcken S. (2010). Available at: http://www.lpz-um.eu/eng/about-Ipz, accessed 21 January 2012 Huffines B, Logsdon MC. (1997). The Neonatal Skin Risk Assessment Scale for predicting skin breakdown in neonates. Issues in Comprehensive Pediatric Nursing; 20: 103-114. 
Gunningberg L, Stotts NA. (2008). Tracking quality over time: what do pressure ulcer data show? International Journal of Quality Health Care; 20:246-53.

Jones I, Tweed C, Marron M. (2001). Pressure area care in infants and children: Nimbus pediatric system. British Journal of Nursing;11: 789-795.

Kottner J, Hauss A, Schlüer AB, Dassen T. (2013). Validation and clinical impact of pediatric pressure ulcer risk assessment scales: A systematic review. International Journal of Nursing Studies; 50: 807-818.

Kottner J, Wilborn D, Dassen T. (2010). Frequency of pressure ulcers in the pediatric population: a literature review and new empirical data. International Journal of Nursing Studies; 47: 1330-1340.

Kottner J, Balzer K, Dassen T, Heinze S. (2009). Pressure ulcers: a critical review of definitions and classifications. Ostomy Wound Management; 55: 22-29.

Kottner J, Gefen A, Lahmann N. (2011). Weight and pressure ulcer occurrence: a secondary data analysis. International Journal of Nursing Studies; 48: 1339-48.

Moore ZE, Cowman S. (2008). Risk assessment tools for the prevention of pressure ulcers. Cochrane Database Systematic Reviews; 16: CD006471.

National Pressure Ulcer Advisory Panel (NPUAP) and European Pressure Ulcer Advisory Panel (EPUAP). Prevention and treatment of pressure ulcers: clinical practice guideline. National Pressure Ulcer Advisory Panel, 2009, Washington DC.

Noonan C, Quigley S, Curley MAQ. (2006). Skin integrity in hospitalized infants and children. Journal of Pediatric Nursing; 6: 445- 453.

Okamoto GA, Lamers JV, Shurtleff DB. (1983). Skin breakdown in patients with myelomeningocele. Archives of Physical Medicine and Rehabilitation; 64: 20-23.

Papanikolaou P, Lyne P, Ratcliffe J. (2007). Using the discrete choice experimental design to investigate decision-making about pressure ulcer prevention by community nurses. Health Society Care Community; 15: 588-98. 
Pancorbo-Hidalgo PL, Garcia-Fernandez FP, Lopez-Medina IM, Alvarez-Nieto C. (2006). Risk assessment scales for pressure ulcer prevention: a systematic review. Journal of Advanced Nursing; 54:94-110.

Schlüer AB, Cignacco E, Müller M, Halfens RJ. (2009). The prevalence of pressure ulcers in four pediatric institutions. Journal of Clinical Nursing; 18: 32443252.

Schlüer AB, Halfens RJ, Schols JMGA. (2012). Pediatric Pressure Ulcer Prevalence: A Multicenter, Cross-Sectional, Point Prevalence Study in Switzerland. Ostomy Wound Management; 58:18-31.

Stechmiller JK, Cowan L, Whitney JD, Phillips L, Aslam R, Barbul A, Gottrup F, Gould L, Robson MC, Rodeheaver G, Thomas D, Stotts N. (2008). Guidelines for the prevention of pressure ulcers. Wound Repair and Regeneration; 16: 151-168.

Suddaby EC, Barnett S, Facteau L. (2005). Skin breakdown in acute care pediatrics. Pediatric Nursing; 31: 132-138 \& 148.

Willock J, Askew C, Bolland R, Maciver H, James N. (2005). Multicenter research: lessons from the field. Pediatric Nursing; 17: 31- 33.

Willock J. (2005). Identifying the characteristics of children with pressure ulcers. Nursing Times; 101: 40-43.

Willock J, Baharestani M, Anthony D. (2007a). A risk assessment sacle for pressure ulcers in children. Nursing Times; 103: 32-33.

Willock J, Baharestani MM, Anthony D. (2007b). The development of the Glamorgan pediatric pressure ulcer risk assessment scale. Journal of Children's and Young People's Nursing; 01: 211-218.

Willock J, Anthony D, Richardson J. (2008). Interrater reliability of the Glamorgan Pediatric Pressure Ulcer Risk Assessment Scale. Pediatric Nursing; 20; 1419. 



\section{Pressure ulcers in hospitalized neonates and infants; prevalence, risk factors, preventive measures}

Schlüer AB, Halfens RJG, Schols JMGA. Pressure ulcers in hospitalized neonates and infants; prevalence, risk factors, preventive measures. Submitted to the Journal Critical Care Nurse, 2013. 


\section{Abstract}

Aims and objectives: The aim of this study was first to assess the prevalence, severity and localization of pressure ulcers in hospitalized neonates and infants (< 1 years) and second to assess possible risk factors and preventive measures taken in these patients.

Background: Pressure ulcer prevalence rates in neonates and infants in the literature vary from $11 \%$ to $61.5 \%$. Different risk factors like a lower age ( $<2$ years) of patients and use of external medical devices are associated with the development of pressure ulcers, especially in neonates and infants.

Design: A multicenter, cross-sectional, descriptive study was conducted in all 14 pediatric hospitals in the German-speaking part of Switzerland in June 2009.

Methods: All hospitalized neonates and infants were included in the study. The instrument and method of data collection of the Dutch National Prevalence Measurement of Care Problems was used.

Results: The total number of patients included was 194 (72\%). The overall pressure ulcer prevalence rate in the total study sample was $45.4 \% \quad(n=88)$. Almost all pressure ulcers were category 1 ulcers (99\%). Ventilation support devices such as continuous positive airways pressure or mechanical ventilation increased the risk for pressure ulcers more than twofold. Total skin assessment $(66.5 \%)$, repositioning $(68.1 \%)$ and skin care $(50 \%)$ were conducted most frequently as preventive measures.

Conclusion: Pressure ulcer prevalence in hospitalized neonates and infants is high, but most of the pressure ulcers are category 1 . The use of ventilation support devices increased the risk for pressure ulcer occurrence more than twofold.

Relevance to clinical practice: Staff are recommended to use under-padding, careful fixation and positioning of medical devices, especially ventilation support devices, in these highly vulnerable patients to decrease the risk of pressure ulcers. 


\subsection{Introduction}

Pressure ulcers (PU) in adult patients cause considerable suffering and, in addition, higher morbidity and mortality and a substantial increase in costs of treatment (Allman et al., 1999; Anthony et al., 2004). Pressure ulcer development can be attributed to multiple factors that are fairly well studied in adults and elderly people (de Laat et al., 2006). In the last ten years greater attention has been paid to the PU problem in the pediatric population. There is greater awareness that pediatric patients in certain health care settings are at high risk of developing PUs (Kottner et al., 2010; Schlüer et al., 2012a; Noonan et al., 2011). Prevalence rates for PUs in hospitalized pediatric patients (0-18 years) range between $3 \%$ and $35 \%$ (Kottner et al., 2010; Schlüer et al., 2012a). In different care settings, such as pediatric intensive care units (PICUs) and according to different risk factors, such as medical devices, different PU prevalence rates have been published (Kottner et al., 2010; Schlüer et al., 2012a). An overview of PU prevalence rates for neonates and infants is presented in table 1.

A PU is a localized injury to the skin and/or underlying tissue as a result of pressure, or pressure in combination with shear forces. (National Pressure Ulcer Advisory Panel (NPUAP) and European Pressure Ulcer Advisory Panel (EPUAP), 2009). According to the guidelines of NPUAP and EPUAP, PUs are basically classified into four different categories, with category 1 as the least severe, and defined as "Intact skin with non-blanchable redness of a localized area usually over a bony prominence" and category 4 as the worst, defined as "Full thickness tissue loss with exposed bone, tendon or muscle" (EPUAP/NPUAP, 2009). These EPUAP/NPUAP categories are also used frequently in pediatric settings (Kottner et al., 2010; Schlüer et al., 2012a). 
Table 1: PU prevalence rates and risk factors for PU development in pediatric patients under the age of one year

\begin{tabular}{|c|c|c|c|}
\hline Author & $\begin{array}{l}\text { Setting and sample } \\
\text { characteristic }\end{array}$ & $\begin{array}{l}\text { Risk factor for PU } \\
\text { development }\end{array}$ & PU prevalence rates \\
\hline $\begin{array}{l}\text { Groenveld et } \\
\text { al. (2004) }\end{array}$ & $\begin{array}{l}97 \text { children in a pediatric } \\
\text { hospital in Canada } \\
n=41<1 \text { year of age }\end{array}$ & & Prevalence: $61.5 \%$ \\
\hline $\begin{array}{l}\text { Schlüer et al. } \\
\text { (2009) }\end{array}$ & $\begin{array}{l}4 \text { pediatric hospitals in } \\
\text { Switzerland } \\
\text { Total } 155 \text { patients } \\
n=56<1 \text { year of age }\end{array}$ & & $\begin{array}{l}\text { Prevalence: } 31.9 \% \text { for children } 0 \text { - } \\
20 \text { week } \\
22.2 \% \text { for children } 21-52 \text { week }\end{array}$ \\
\hline McLane (2004) & $\begin{array}{l}1064 \text { patients in nine US } \\
\text { pediatric hospitals including all } \\
\text { care settings } \\
113 \text { patients }<1 \text { year of age }\end{array}$ & & Prevalence: 0-3 month: $26 \%$ \\
\hline $\begin{array}{l}\text { McCord et al. } \\
\text { (2004) }\end{array}$ & $\begin{array}{l}\mathrm{n}=118 \text { PICU patients } \\
\mathrm{n}=37<1 \text { year age }\end{array}$ & $\begin{array}{l}\text { Presence of edema } \\
\text { Length of PICU stay > } \\
96 \text { hours } \\
\text { Increased positive-end } \\
\text { expiratory pressure } \\
\text { (PEEP) } \\
\text { Not turned/turned by a } \\
\text { low air bed } \\
\text { Weight loss }\end{array}$ & \\
\hline $\begin{array}{l}\text { Huffines and } \\
\text { Lodgson } \\
\text { (1997) }\end{array}$ & $\begin{array}{l}\text { Neonatal Intensive care Unit } \\
\text { (NICU) } \\
n=32(26-40 \text { weeks gestation } \\
\text { age) }\end{array}$ & & Prevalence: $19 \%$ skin breakdown \\
\hline $\begin{array}{l}\text { Schindler et al. } \\
\text { (2007) }\end{array}$ & $\begin{array}{l}\text { PICU, USA } \\
n=120<1 \text { year of age } \\
\text { assessing skin breakdown }\end{array}$ & $\begin{array}{l}\text { Age }<2 \text { year of age } \\
\text { Length of stay } 4 \text { days } \\
\text { and longer } \\
\text { Mechanical ventilation } \\
\text { Risk of mortality }\end{array}$ & \\
\hline $\begin{array}{l}\text { Escher Neidig } \\
\text { et al. (1989) }\end{array}$ & $\begin{array}{l}n=59 \text { children following open } \\
\text { heart surgery in a PICU, USA } \\
n=15<1 \text { year of age }\end{array}$ & $\begin{array}{l}\text { Younger age } \\
\text { Type of congenital heart } \\
\text { defect } \\
\text { Length of intubation } \\
\text { Duration of PICU stay }\end{array}$ & Prevalence: $40 \%$ \\
\hline $\begin{array}{l}\text { Willock et al. } \\
\text { (2000) }\end{array}$ & $\begin{array}{l}\mathrm{N}=82 \text { for incidence study } \\
\mathrm{N}=183 \text { for prevalence study } \\
\text { All pediatric care settings, UK } \\
\text { Altogether (incidence and } \\
\text { prevalence study) } 18 \text { patients } \\
\text { showed PU }\end{array}$ & & $\begin{array}{l}\text { Total of } 7 \text { neonates and infants } \\
\text { showed PU (combined data } \\
\text { incidence and prevalence) }=38 \%\end{array}$ \\
\hline $\begin{array}{l}\text { Waterlow } \\
\text { (1997) }\end{array}$ & $\begin{array}{l}302 \text { pediatric patients in UK } \\
\text { pediatric hospitals } \\
n=54 \text { in NICU }\end{array}$ & $\begin{array}{l}\text { Immature skin in } \\
\text { neonates } \\
\text { Epidermal stripping }\end{array}$ & Prevalence: $11 \%$ for NICU patients \\
\hline $\begin{array}{l}\text { Curley et al., } \\
\text { (2003) }\end{array}$ & $\begin{array}{l}\mathrm{n}=322 \text { form } 21 \text { days of age } \\
\text { up to } 8 \text { years of age in three } \\
\text { PICU, USA } \\
n=98<1 \text { year of age }\end{array}$ & $\begin{array}{l}\text { Younger age } \\
\text { Mechanical ventilation } \\
\text { hypotension }\end{array}$ & \\
\hline
\end{tabular}




\subsubsection{Background}

A neonate is defined as a child from birth up to and including 28 days of life, whereas an infant is defined as a child from 4 weeks of life up to its first birthday (The World Health Organization (WHO), 2005; the American Academy of Pediatrics (AAP), 2002). Neonates born before 40 weeks of gestation are defined as preterm neonates (Hack et al., 1996). Preterm neonates of lower gestation age are at great risk for skin breakdown due to the fact that their skin is immature (Nikolovski, et al., 2008; Stamatas et al., 2010; Blume-Peytavi, 2011). Within their first days of life, children undergo various adaptation processes needed to accommodate the transition from the wet uterine environment to the dry environment. During the first months and years of life the skin constitutes to develop and evolve its structure and function (Nikolovski, et al., 2008; Stamatas et al., 2010; Blume-Peytavi, 2011). In neonates the stratum corneum is underdeveloped until about 32 weeks of gestation age. Skin surface pH changes and the trans epidermal water loss (TEWL) are high in very low term neonates (Nikolovski, et al., 2008). In the first four weeks of life skin surface pH changes continuously (Garvin, 1997).

PU prevalence rates in neonates and infants vary from $11 \%$ to $61.5 \%$ (table 1 ) (Groneveld et al., 2004; Schlüer et al., 2009; McLane 2004; McCord et al., 2004; Huffines and Lodgson, 1997; Escher-Neidig et al., 1989; Willock et al., 2000; Waterlow 1997; Curley et al., 2003). Different risk factors are associated with the development of PUs, especially in neonates and infants (Baharestani and Ratliff, 2007). Younger patient age, especially the age period under 2 years, has been described as a risk factor for PU development in pediatrics (Schindler et al., 2007; Escher-Neidig et al., 1989; Waterlow, 1997; Curley et al., 2003). Therefore it is of great importance to pay attention to infants and neonates according to their specific risks for developing a PU.

Risk factors for hospitalized neonates and infants are shown in table 1. A PICU stay leads to a higher risk of PU occurrence and the risk increases the longer this PICU stay lasts (McCord et al., 2004; Schindler et al, 2004; Escher Neidig et al., 1989). Length of stay and increased positive-end-expiratory-pressure (PEEP) and mechanical ventilation are described as risk factors as well (McCord et al., 2004; 
Schindler et al., 2007). Thus, critically ill patients of younger age are at very high risk of developing PUs (Baharestani and Ratliff, 2007; Curley et al., 2003) (table 1).

Most of the PUs in pediatric patients appears to be preventable (Schlüer et al., 2009; Schlüer et al., 2012a; Brandeis et al., 2001). Two mayor steps in preventing PUs have to be taken: (1) identifying patients at risk and, (2) implementing reliable prevention strategies for all patients identified as being at risk (Association of Womens Health, Obstetrics and neonatal nurses (AWHONN) \& National Association of neonatal nurses (NANN) (2001)). Several specific pediatric risk assessment tools are implemented nowadays like the Braden $Q$ scale (Noonan et al., 2011), the Glamorgan scale (Willock et al., 2008; Anthony et al, 2010; Kottner et al., 2011) and the Neonatal Risk Assessment Scale (Huffines and Lodgson, 1997). Only limited evidence is available yet to support a specific risk assessment tool in the pediatric care setting (Kottner el al, 2011; Anthony et al., 2010).

Baharestani and Ratliff (2007) highlighted the importance of developing agerelated preventive strategies for PUs. However, the prevention of PUs in neonates and infants has not been thoroughly studied so far. Timely skin assessment is recommended but no frequency is prescribed (AWHONN/NANN, 2001). Repositioning is recommended but not for haemodynamically unstable pediatric patients and no specifications for infants and neonates are made (Butler, 2007). The same is seen for pressure relief support surfaces: no research-based recommendations for infants and neonates can be found. Due to the risk of pressure ulcer development in infants with tracheostomies, Boesch and colleges (2012) implemented a prevention program, including frequent whole-body skin and device assessment at least every 24 hours, with a further device-related skin assessment every 8 hours. They created a moisture-reducing device interface (including a foam-layer between skin and device) and pressure-free device interface (Boesch et al., 2012) with a significant decrease - from $8.1 \%$ to $0.3 \%$ - in tracheostomy-related pressure ulcers in young children. Most of these tracheostomy-related PUs occurred in children of 2 years and younger, but no information about infants under the age of one can be found.

Because of this lack of knowledge, it is not only of great importance to assess prevalence, severity and localizations, but also risk factors and preventive 
measures taken in hospitalized neonates and infants in different care settings according to PU occurrence.

The aims of this study therefore were:

(1) to assess the prevalence, severity as well as most frequent localizations of PUs in hospitalized neonates and infants in different pediatric hospital departments;

(2) to explore risk factors of neonates and infants with PUs;

(3) to assess which preventive measures for PUs were taken in these patients.

\subsection{Material and Methods}

\subsubsection{Study design}

A multicenter, cross-sectional, descriptive study was conducted in all 14 pediatric hospitals in the German-speaking part of Switzerland in June 2009. These hospitals have a total of 70 wards. All hospitalized neonates and infants from 1 day old up to their first birthday were included in the study. Children had to have been hospitalized for at least one day. Exclusion criteria were children whose legal representatives did not permit participation and healthy new-borns hospitalized after birth in a maternity ward/department.

\subsubsection{Ethical approval}

The study was approved by all cantonal ethics committees, and when necessary by the ethics boards of the hospitals themselves. After the parents or legal representative had been verbally informed about the study's content and aim, they also received written information along with an informed consent document to sign. After parents or a legal representative signed the informed consent form, neonates or infants meeting the inclusion criteria were included in the study. 


\subsubsection{Measurements}

The instrument and data collection method of the Dutch National Prevalence Measurement of Care Problems (LPZ) (Halfens et al, 2010) was used in this study to assess the prevalence, severity, location, prevention, as well as risk factors for the occurrence of pressure ulcers. This instrument is widely used internationally (Halfens et al., 2010), and comprises amongst others the following categories of data for assessment: (1) patient characteristics (demographic and clinical data), (2) assessment of the location and severity of pressure ulcers, (3) risk factors for PU development, and (4) use of preventive measures. In addition to this instrument, we assessed all external devices on the patient's body at the time of the assessment (e.g. tubes, IV catheterizations, Continuous Positive Airways Pressure (CPAP), splints, and other devices), which might cause the occurrence of a PU.

\subsubsection{Data collection}

The method of data collection involved a direct and systematic inspection and judgment of the skin of the patient. Here, the NPUAP/EPUAP (NPUAP/EPUAP, 2009) pressure ulcer category system was used. Demographic and clinical data, such as date of birth, weight and size, body mass index and diagnosis, were collected from patient charts. Assessments of installations on the body site as well as other risk factors (like cloths and clothes, incorrect positioning, and cables in beds), which can lead to the development of PUs, as well as preventive measures taken, were assessed by direct inspection. This information was gathered both by a direct inspection of the patient and from the patient files.

Previously trained rater pairs gathered data for each patient. A total of 35 rater pairs were involved in the study. All raters were trained nurses with at least two years' experience in working with neonates and infants. Preparatory training, given by the first author, included methodological aspects, detailed information about the data collection, the role and responsibilities of the raters, a detailed introduction to the measurement instruments, and special training in the grading of a pressure ulcer in infants and children (Schlüer et al., 2012a). For each hospital unit, an 
internal and an external rater worked together. The internal rater was from the unit itself, while the external rater was from another unit or department. If the pair disagreed on their assessment, they were asked to find consensus. If no consensus could be reached, the external rater was given the right to decide. No statement about disagreement within the rater pairs can be made, as this was not an objective of the study.

\subsubsection{Data analysis}

Predictive Analytics Software (PASW) (version 18) was used to analyse the data. Frequencies and cross tables were calculated. Group differences were due to the type of data tested, with nonparametric tests for categorical data (Chi-Square). The relationship between pressure ulcers and possible influencing and conflicting factors was studied by logistic regression. To find the most suitable model for the logistic regression, the following variables were applied to the model: age, lower gestation age, department, medical devices overall, certain types of medical devices (categorized into ventilation support devices, feeding devices such as a nasogastric tubes, IV catheterization devices and monitoring sensors), gender, whether the child had undergo an operation in the two weeks prior to the study assessment and length of stay. The data were entered into the model followed by a forward stepwise selection of the important variables according to the use of likelihood quotients. The entry and removal probabilities were 0.05 and 0.10 . A pvalue of 0.05 and lower was considered to be statistically significant. 


\subsection{Results}

The overall sample size of potential study participants who met the inclusion criteria was $270(100 \%)$. In the 14 hospitals, the participation rate ranged from 65$100 \%$. The total number of participants was $194(72 \%)$. Of the76 (28\%) dropouts, parents/legal representatives refused participation in 26 cases $(34 \%)$. Fourteen were excluded due to unexpected discharge or because an examination or operation lasted longer than the survey did (18\%). In eight cases the parents were not available for informed consent (11\%) or could not be asked for other reasons $(n=9,12 \%)$. Three (4\%) children were not assessed due to an unexpected change in their condition to a critical level. Three patients dropped out due to language problems of the parents/legal representative.

The demographic characteristics of the study sample are shown in table 2. The mean age of the study population was 5.7 weeks, with a median age of 3 weeks. Among patients, 107 were neonates (55\%) of which $75(70 \%)$ had a gestational age of 24 to 32 weeks (very pre-term neonate) and 41 (30\%) a gestational age of 32 to 37 weeks (pre-term neonate). Sixty percent of all patients were under the age of 28 days. The average length of stay of a patient was 15 days with a median of 12 days. Most of the patients had been in hospital for less than 30 days (83\%) before the study assessment was conducted.

Table 2: Demographics of total study sample

Total study sample

$\mathrm{N}(\%)$

$194(100)$

\begin{tabular}{lll}
\hline Gender & Male & $105(54.1)$ \\
& Female & $88(45.4)$ \\
& Unknown & $1(0.5)$ \\
\hline Department & Surgery & \\
& Rehabilitation & $13(6.7)$ \\
& Pediatric medical & $2(1)$ \\
& PICU & $46(23.7)$ \\
& NICU/neonatal unit & $26(13.4)$ \\
& $107(55.2)$ \\
\hline
\end{tabular}




\begin{tabular}{|c|c|c|c|c|c|}
\hline \multirow[t]{5}{*}{ Age categories } & \multicolumn{4}{|c|}{$1-\leq 7$ days } & $46(23.7)$ \\
\hline & \multicolumn{4}{|c|}{$8-\leq 30$ days } & $74(38.1)$ \\
\hline & \multicolumn{4}{|c|}{$31-\leq 90$ days } & $52(36.8)$ \\
\hline & \multicolumn{4}{|c|}{91 days $-\leq 6$ months } & $14(7.2)$ \\
\hline & \multicolumn{4}{|c|}{$>7$ months } & $8(4.1)$ \\
\hline \multirow{2}{*}{$\begin{array}{l}\text { Gestational age in } \\
\text { neonates }\end{array}$} & \multicolumn{4}{|c|}{$24-\leq 31$ weeks gestation age } & $75(70)$ \\
\hline & \multicolumn{4}{|c|}{$32-\leq 36$ weeks gestation age } & $41(30)$ \\
\hline \multirow[t]{4}{*}{ Length of stay } & \multicolumn{4}{|c|}{$\leq 14$ days } & $115(59.3)$ \\
\hline & \multicolumn{4}{|c|}{$15-\leq 30$ days } & $48(24.7)$ \\
\hline & \multicolumn{4}{|c|}{$31-\leq 60$ days } & $24(12.4)$ \\
\hline & \multicolumn{4}{|c|}{$>61$ days } & $7(3.6)$ \\
\hline \multicolumn{5}{|l|}{ Patient with external devices } & $176(91)$ \\
\hline \multicolumn{5}{|c|}{ Patients with operation within 2 weeks before study assessment } & $28(14.5)$ \\
\hline \multirow{2}{*}{$\begin{array}{l}\text { Age distribution over all in } \\
\text { days }\end{array}$} & mean & Median & sd & Range & \\
\hline & 43.6 & 23 & 63.56 & $1-300$ & \\
\hline Length of stay in days & 15.2 & 12 & 33.07 & $1-134$ & \\
\hline
\end{tabular}

6.3.1 PU prevalence rates and localization of PUs

The overall PU prevalence rate in the total study sample was $45.4 \%(n=88)$. The PU prevalence rate for more severe PUs (category 2 to 4$)$ was $0.5 \%(n=1)$. PU prevalence rates for different characteristics and patient groups were calculated and are presented in table 3; they vary between $28.6 \%$ (infants of 91 days up to and including 6 months of age) and $62.5 \%$ (infants older than 7 month of age) (table 3). 
Table 3: PU prevalence rates in different settings and number of PU per patient

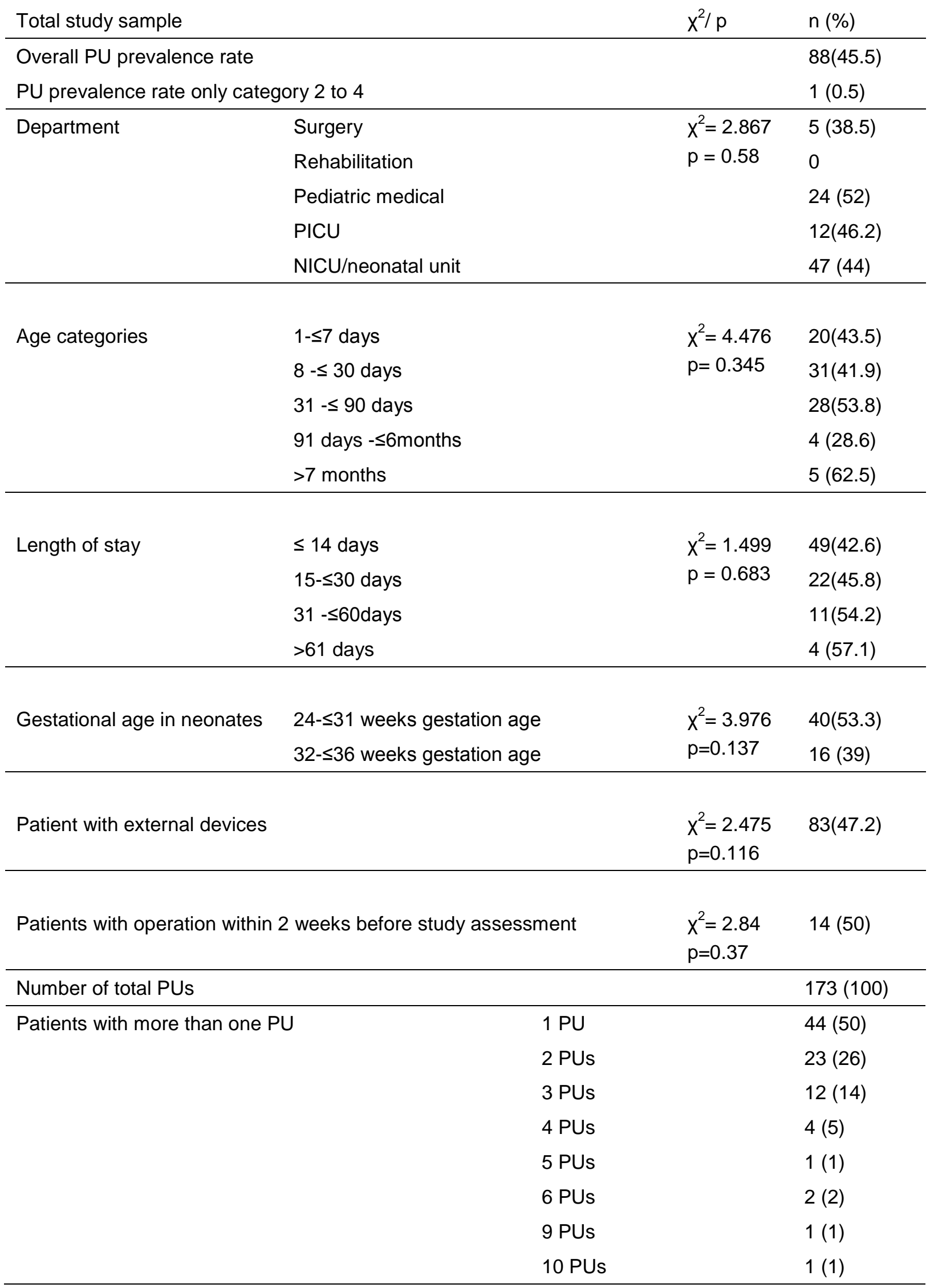


Except for one case, all PUs were category 1 ulcers (99\%). Fifty percent of all patients had one PU, whereas one patient had nine and another ten PUs (table 3). The most affected areas for PU occurrence were on a patient's feet $(n=36)$, followed by the nose $(n=28)$ and the bottom $(n=16)$ (table 4). Most of these PUs ( $n=165,95 \%$ ) occurred in the setting where the patient was hospitalized and lasted for at least 2 weeks prior to the inquiry $(n=166, p=96 \%)$ (table 4 ).

Table 4 Localization, point of time and point of occurrence of PUs

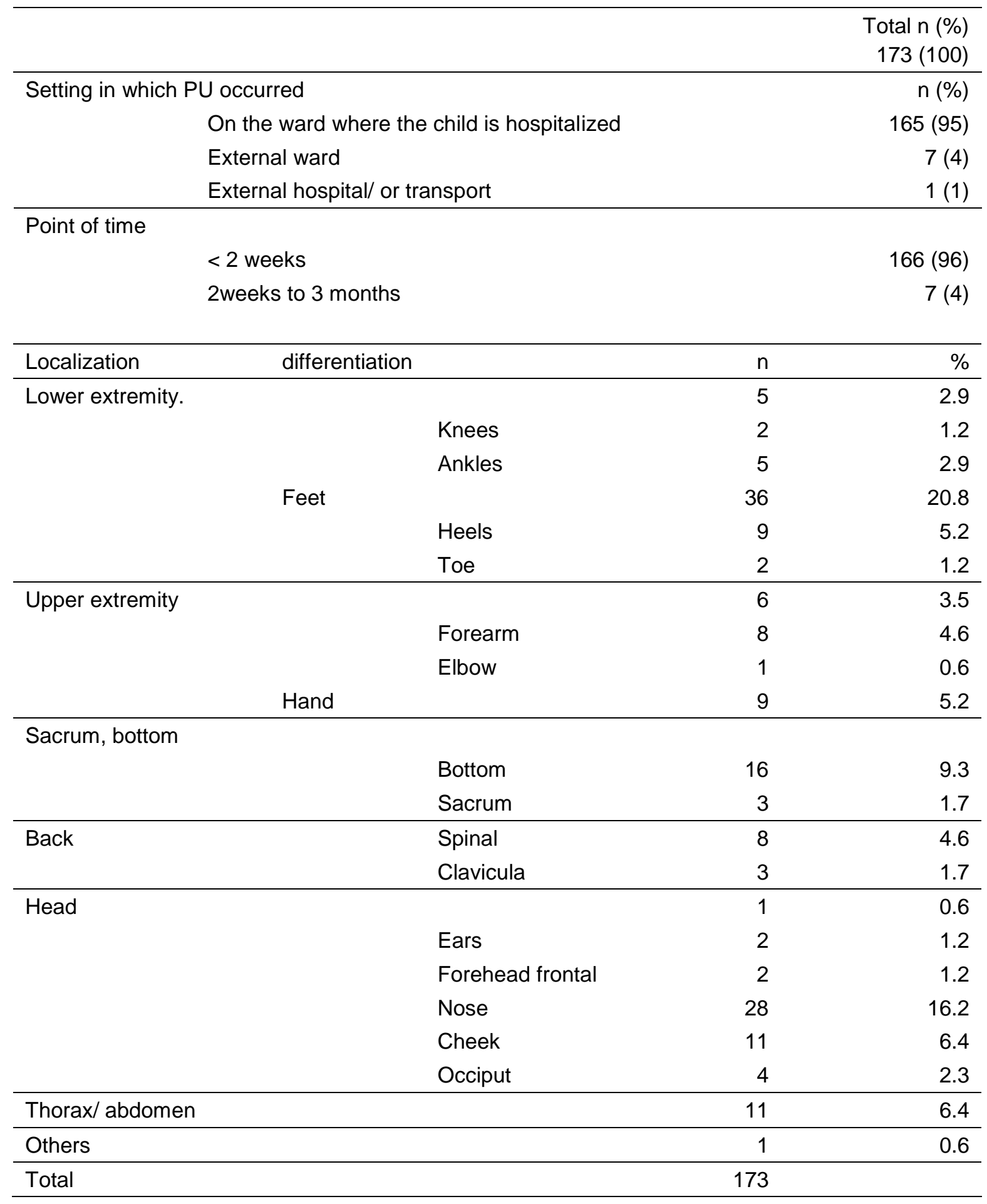




\subsubsection{Risk factors and preventive measures}

All potential risk factors measured, namely age, gender, lower gestation age, department, medical devices overall, certain types of medical devices (categorized into ventilation support devices, feeding devices such as a nasogastric tubes and IV catheterization devices), whether the child had had an operation in the two weeks prior to the study assessment and length of stay where calculated separately with the chi square test. All risk factors mentioned were put into a logistic regression model. Only ventilation support of the patient $(p=0.015)$ was statistically significant related to the existence of a PU (table 5). The odds ratios and associated confidence intervals of the variables in the final model are presented in table 5. The Hosmer- Lemeshow-test for the goodness of fit for this model was $p=0.025$; Nagelkerke $R 2=0.054$.

Table 5: Odds ratios for PU occurrence with $95 \%$ confidence interval

\begin{tabular}{|c|c|c|c|c|}
\hline & \multirow[t]{2}{*}{ Odds ratio } & \multicolumn{2}{|c|}{ 95\% Confidence interval } & \multirow[t]{2}{*}{ Sig } \\
\hline & & Lower level & Upper level & \\
\hline Ventilation support device & 2.598 & 1.201 & 5.623 & 0.015 \\
\hline Monitoring devices & 0.877 & 0.329 & 2.340 & 0.793 \\
\hline Feeding tubes & 1.196 & 0.577 & 2.481 & 0.630 \\
\hline Peripheral or central venous catheter & 0.937 & 0.486 & 1.806 & 0.846 \\
\hline
\end{tabular}

Table 6 shows the preventive measures collected in the total study sample. Most of these measures were conducted at least once during the 24 hours before the assessment and included total skin assessment (66.5\%), repositioning (68.1\%) and skin care $(50 \%)$. Next to these interventions, repositioning of monitoring devices was performed in $71.3 \%$ of cases; details are shown in table 5 . 
Table 6: Preventive measures conducted in the total study sample

\begin{tabular}{|c|c|c|}
\hline \multicolumn{2}{|l|}{ Preventive measures } & \multirow{2}{*}{$\begin{array}{r}\text { Total } \\
188(100) \\
188(100)\end{array}$} \\
\hline Intervention within last 24 hours & & \\
\hline \multirow[t]{4}{*}{ Regular repositioning } & & $128(68.1)$ \\
\hline & Every 3 hours & $15(8)$ \\
\hline & Every 4 hours & $52(27.7)$ \\
\hline & Every 6 hours & $56(29.8)$ \\
\hline Rehydration & & $40(21.3)$ \\
\hline $\begin{array}{l}\text { Instruction of parents for PU } \\
\text { prevention }\end{array}$ & & $15(8)$ \\
\hline Skin care & & $95(50.0)$ \\
\hline Daily skin inspection & & $125(66.5)$ \\
\hline Use of skin barrier cream & & $32(17.0)$ \\
\hline $\begin{array}{l}\text { Padding of tubes/CPAP, ventilation } \\
\text { devices }\end{array}$ & & $44(23.4)$ \\
\hline Padding of splints and iv cannulas & & $30(16.1)$ \\
\hline \multirow{8}{*}{$\begin{array}{l}\text { Reposition of monitoring cables, } \\
\text { sensors }\end{array}$} & & $134(71.3)$ \\
\hline & Never & $53(28.3)$ \\
\hline & Every 2 hours & $2(1.1)$ \\
\hline & Every 3 hours & $14(7.5)$ \\
\hline & Every 4 hours & $62(33.2)$ \\
\hline & Every 6 hours & $55(29.4)$ \\
\hline & Every 8 hours & $1(0.5)$ \\
\hline & Every 24 hours & $1(0.5)$ \\
\hline Relieving of exposed body site & & 0 \\
\hline Cloth diaper for positioning & & $113(60.1)$ \\
\hline Gel ring for head & & $9(4.8)$ \\
\hline Pressure relieving surfaces (foam) & & $73(38.8)$ \\
\hline Incubator & & $36(19.1)$ \\
\hline Artificial skin & & $28(14.9)$ \\
\hline $\begin{array}{l}\text { Repositioning not possible due to } \\
\text { unstable life condition }\end{array}$ & & $5(2.7)$ \\
\hline
\end{tabular}




\subsection{Discussion}

In this study the PU prevalence rate (categories 1-4) in neonates and infants was high, with an overall prevalence of $45.5 \%$; yet the PU prevalence rate for more severe PUs (categories $2-4$ ) was low at $0.5 \%$. Ventilation support devices such as CPAP or mechanical ventilation increased the risk of pressure ulcers more than twofold. Total skin assessment $(66.5 \%)$, repositioning (68.1\%) and skin care (50\%) were conducted most frequently as preventive measures. For the first time PU prevalence rates for this patient group are presented and classified with regard to different departments and age categories as well as risk factors like patients with external devices.

The overall PU prevalence rate is in line with previously published PU prevalence rates in hospitalized neonates and infants (table 1). Because of the high prevalence rate of category 1 PUs the question as to whether the measurement of PU category 1 was performed correctly arises. However all rater pairs were previous trained, and all raters had at least two years of experience working with neonates and infants. The training of the raters included specific training in the assessment and diagnosis of PUs, especially category 1 PUs, with special attention to their diagnosis in preterm neonates and infants. The raters were supervized by the first author and if they were unsure about the diagnosis of a PU they could obtain advice from the first author.

In the literature (Baharestani et al, 2009) it is suggested that a category $1 \mathrm{PU}$ can serve as an indication of being at risk for a category 2 to $4 \mathrm{PU}$. When a category 1 PU occurs, preventive measurements are necessary. In our study only one infant developed a higher category PU than category 1 , which makes it questionable whether a category $1 \mathrm{PU}$ is a good indication of additional risk in this population. It is remarkable insofar as in clinical practice category 2 to 4 PUs are seen regularly in hospitalized neonates and infants, especially due to CPAP or other mechanical ventilation support devices (Schlüer et al., 2012b; Hoegeling et al.2011; Boesch et al, 2012; Curley et al., 2003; Neidig-Escher, 1989; McCord et al., 2004). To what extent the nonresponse patients were affected by a severe PU is unknown, but it is important to note that $4 \%$ of the dropouts were infants or neonates who were not assessed because their condition had changed to a critical level. We can assume 
that these patients underwent intense treatment to stabilize their condition. With respect to the knowledge that a PICU stay (McCord et al., 2004; Escher-Neidig et al., 1989) as well as mechanical ventilation (Curley et al., 2003; Schindler et al., 2007) (which are both intense treatments) increase the risk of severe PUs, we can assume that neonates and infants in critical condition are at high risk for severe PUs. Besides this methodological deficit it is of interest that in this study ventilation support devices were the only factors associated with the occurrence of PUs. According to the localization of the PUs, the feet and nose were the most commonly affected areas in this study sample. Feet, especially ankles or heels and toes, were also frequently affected areas in the study of Curley and colleagues (2003) as well as the occiput and ear. A possible explanation for this is that in neonates and infants monitoring devices like oxygenation sensors and IV catheters are fixed to the feet of the child, and therefore this localization can also be affected by medical device related PUs (Schlüer et al., 2012b). PUs in the area of the nose are often caused by a nasogastric feeding tube, ventilation tube or by a CPAP mask with Prongs. It is therefore of great importance to pay special attention to the careful application of ventilation support devices, and to the careful fixation and regular repositioning of any devices in neonates and infants in order to decrease the PU risk.

Very pre-term neonates and infants with a longer stay in hospital are known to be patients at risk for PU development (Schindler et al., 2007; Cignacco, 2009; Curley et al., 2003). Due to their immaturity, hospitalized neonates are commonly provided with several monitoring and medical devices such as IV catheterization, ventilation support devices and nasogastric tubes. In this study population nearly 95\% of all children had devices like these. Since these are major PU risk factors for this patient group, the high prevalence rate in this study population seems feasible. Why infants of 31 to 90 days as well as 7 to 12 months of age are affected most in this study population remains unclear. One factor that might have led to this finding is the heterogeneity of the relatively small subgroup in these different age categories.

Repositioning and turning of the patient was found to be frequent, although timely intervals varied between 3 and 6 hours and were most frequently conducted at 4and 6-hour intervals. The current recommendation calls for a 1 - to 3- hour time 
interval in turning patients but cautions carers to weigh the benefit against the stress for the patients, especially for very low-term neonates (AWHONN/NANN, 2001; Scott et al., 2011). Despite these recommendations, no guidelines with special attention to this population and its unique risk factors in terms of PU occurrence are available so far.

There are also some limitations of this study that need to be mentioned. One is the fact that a cross-sectional design was used, which does not allow making causal interpretations. Further, the participation rate of $72 \%$ is sufficient, although the parental refusal rate involving $34 \%$ of non-participants is rather high, and needs further investigation of how to better inform parents about the need for such studies. One possible explanation is that many studies of these patients are conducted and parents may not have wanted to stress their child with another study.

Further studies drawing attention to the increased risk of PU development are needed in this group to guide a trajectory towards an adapted and truly patientoriented prevention. To what extent ventilation support devices lead to more severe PUs and which patients are therefore at highest risk needs to be studied further in clinical trials with incidence measurements.

\subsection{Conclusion}

This study shows that the overall PU prevalence rate of hospitalized neonates and infants is $45.5 \%$ with even higher rates in certain patient groups. Patients with a longer of stay in hospital, very pre term neonates (24 to 32 weeks of gestation age) and infants between 31 and 90 days of age as well as infants between 7 and 12 months of age show the highest PU prevalence rates.

The prevention of PUs in this patient group must start early to avoid any further harm to their highly vulnerable skin. Therefore these children need evidence based and appropriate preventive measures to decrease their PU risk. At least daily head-to-toe-skin assessment of neonates and infants at risk of PUs should be performed. Monitoring and regular repositioning of any monitoring sensors and 
cables should be conducted as well. Under-padding, careful fixation and positioning of medical devices, especially ventilation support devices, in these highly vulnerable patients are mandatory to decrease the risk of pressure ulcers.

\subsubsection{Impact}

What is known about the topic: Neonates and infants are at high risk of pressure ulcer development. Appropriate and evidence based preventive measures need to be implemented for these vulnerable patients.

What this paper adds: Category 1 pressure ulcers are a major nursing care issue in neonates and infants and require appropriate preventive measures to avoid any further harm to the vulnerable skin of these patients. Ventilation support devices increase the risk of PUs in neonates and infants most. Effective PU prevention with device related under-padding and careful positioning and fixation of such devices is mandatory. Special attention should be paid to the fact that repositioning the patient must be weighed against the stress that such an intervention can cause, especially in low- and very low-term neonates and critically ill infants. So far the ideal time interval for turning and repositioning patients in this age group is unknown. 


\subsection{References}

American Academy of Pediatrics (AAP). (2002). Newborns, Infants, and Toddlers, http://patiented. aap.org/categoryBrowse.aspx?catID=5001 Accessed 24 April 2013.

Anthony D, Reynolds T, Russell L. (2004). The role of hospital acquired pressure ulcer in length of stay. Clinical Effectivness Nursing; 8: 4-10.

Anthony D, Willock J, Baharestani M. (2010). A comparison of Braden Q, Garvin and Glamorgan risk assessment scales in pediatrics. Journal of Tissue Viability; 19: 98-105.

Association of Women's Health, Obstetrics and neonatal nurses (AWHONN) \& National Association of Neonatal Nurses (NANN). Neonatal skin care: evidencebased clinical practice guideline. Journal of obstetric, gynecologic, and neonatal nursing; 30: 41-51.

Allmann RM, Goode PS, Burst N, Bartolucci AA, Thomas DR. (1999). Pressure Ulcers, Hospitals Complications and Disease Severity: Impact on Hospital Costs and Length of Stay. Advances in Wound Care; 12: 22-30.

Baharestani MM, Black J M, Carville K, Clark M, Cuddigan JE, Dealey C, Defloor T, Harding KG, Lahmann NA, Lubbers MJ, Lyder CH, Ohura T, Orsted HL, Reger SI, Romanelli M, Sanada H. (2009). Dilemmas in measuring and using pressure ulcer prevalence and incidence: an international consensus. International Wound Journal; 6: 97-104.

Baharestani MM, Ratliff CR. (2007). Pressure Ulcers in Neonates and Children: An NPUAP White Paper. Advances in Skin and Wound Care; 20: 208-220.

Blume-Peytavi U, Hauser M, Stamatas GN, Pathirana D, Garcia Bartels N. (2012). Skin care practices for newborn and infants: review of the clinical evidence for best practices. Pediatric Dermatolgy; 29: 1-14. 
Boesch RP, Myers C, Garrett T, Nie A, Thomas N, Chima A, McPhail GL, Ednick M, Rutter MJ, Dressman K. (2012). Prevention of tracheostomy-related pressure ulcers in children. Pediatrics; 129: e792-e797.

Brandeis GH, Berlowita DR, Katz P. (2001). Are pressure ulcers preventable? A survey of experts. Advances in skin and wound care; 14: 244-248.

Butler, CT. (2007). Pediatric skin care: Guidelines for assessment, prevention and treatment. Dermatology Nursing; 19: 471-485.

Cignacco E. (2009). Kinder mit chronischen Erkrankungen - Die vergessene Kindheit. Pflege; 22: 325 - 328.

Curley MA, Quigley SM, Lin M. (2003). Pressure ulcers in pediatric intensive care: Incidence and associated factors. Pediatric Critical Care Medicine; 4: 284-290.

deLaat E, Schoonhoven L, Pickkers P, Verbeek, A, Van Achterberg T. (2006). Epidemiology, risk and prevention of pressure ulcers in critically ill patients: a literature review. Journal of Wound Care; 15: 269-275.

Escher Neidig JR, Kleiber C, Oppliger RA. (1989). Risk factors associated with pressure ulcers in the Pediatric Patient following open-heart surgery. Progress in Cardiovascular Nursing; 4: 99-106.

Garvin G. (1997). Wound and skin Care for the PICU. Critical Care Nrusing Quaterly; 20: 62-71.

Groeneveld A, Anderson M, Allen S, Bressmer S, Golberg M, Magee B. (2004). The prevalence of pressure ulcers in a tertiary care pediatric and adult hospital. Journal of Wound Ostomy Continence; 31: 108-122.

Huffines B, Logsdon MC. (1997). The Neonatal Skin Risk Assessment Scale for predicting skin breakdown in neonates. Issues in Comprehensive Pediatric Nursing; 20: 103-114.

Hack M, Friedman H, Fanaroff AA. (1996). Outcomes of extremely low birth weight infants. Pediatrics; 98: 931- 937. 
Halfens R, Meijers J, Neyens J. et al (2010). Available at:http://www.lpzum.eu/eng/about-Ipz. Accessed 12 April 2013.

Hoegeling M, Fardin SR, Frieden IJ, Wargon O. (2011). Forehead pressure necrosis in neonates following continuous positive airway pressure. Pediatric Dermatology; 29: 45-48.

Kottner J, Hauss A, Schlüer AB, Dassen T. (2011). Validation and clinical impact of pediatric pressure ulcer risk assessment scales: A systematic review. International Journal of Nursing Studies.4.Epub ahead of print.

Kottner J, Wilborn D, Dassen T. (2010). Frequency of pressure ulcers in the pediatric population: a literature review and new empirical data. International Journal of Nursing Studies; 47: 1330-1340.

McLane KM, Bookout K, McCord S, McCain J, Jefferson LS. (2004). The 2003 national pediatric pressure ulcer and skin breakdown prevalence survey. Journal of Wound Ostomy Continence; 31: 168-178.

McCord S, McElvain V, Sachdeva R, Schartz P, Jefferson LS. (2004). Risk factors associated with pressure ulcers in the pediatric intensive care unit. Journal of Wound Ostomy Continence; 31: 179-183.

National Pressure Ulcer Advisory Panel (NPUAP) and European Pressure Ulcer Advisory Panel (EPUAP). Prevention and treatment of pressure ulcers: clinical practice guideline. National Pressure Ulcer Advisory Panel, 2009, Washington DC.

Nikolovski J, Stamatas GN, Kollias N, Wiegand BC. (2008). Barrier function and water-holding and transport properties of infant stratum corneum are different from adult and continue to develop through the first year of life. Journal of Investigation in Dermatology; 128: 1728-36.

Noonan C, Quigley S, Curley MA. (2011). Using the Braden Q Scale to Predict Pressure Ulcer Risk in pediatric patients. Journal Pediatric Nursing; 26: 566-575.

Schlüer AB, Halfens RJ, Schols JMGA. (2012a). Pediatric Pressure Ulcer Prevalence: A Multicenter, Cross-Sectional, Point Prevalence Study in Switzerland. Ostomy Wound Management; 58: 18-31. 
Schlüer AB, Hauss A, Birr K. (2012b). Dekubitusprophylaxe in der pädiatrischen Pflege. In: Schröder G, Kottner J. (eds), Dekubitus und Dekubitusprophylaxe. 1 Edition. Berne: Hans Huber.

Schlüer AB, Cignacco E, Müller M, Halfens R. (2009). The Prevalence of Pressure Ulcers in Four Pediatric Institutions. Journal of Clinical Nursing; 18: 3244-3252.

Schindler CA, Mikhailov TA, Fischer K, Lukasiewicz G, Kuhn EM, Duncan L. (2007). Skin integrity in critically ill and injured children. American Journal of Critical Care; 16: 568-574.

Scott M, Pasek TA, Lancas A, Duke A, Vetterly C. (2011). Skin care Oktoberfest: A creative approach to pressure ulcer prevention education in a pediatric intensive care unit. Critical Care Nurse; 31: 74-76.

Stamatas GN, Nikolovski J, Luedtke MA, Kollias N, Wiegand BC. (2010). Infant skin microstructure assessed in vivo differs from adult skin in organization and at the cellular level. Pediatric Dermatology; 27: 125-31.

Stone McCord S, Levy ML. (2006). Practical guide to pediatric wound care.

Seminars in plastic surgery; 20: 192-199.

Waterlow J. (1997). Pressure sore risk assessment in children. Pediatric Nursing; 9: 21-24.

The World Health Organization (WHO). The World Health Report 2005 - make every mother and child count, Accessed 23 April 2013.

Willock J, Hughes J, Tickle S, Rossiter G, Johnson C, Pye H. (2000). Pressure sores in children- the acute hospital perspective. Journal of Tissue Viability; 10: 59-62.

Willock J, Anthony D, Richardson J. (2008). Interrater reliability of the Glamorgan Pediatric Pressure Ulcer Risk Assessment Scale. Pediatric Nursing; 20: 14-19. 



\section{Pressure ulcer treatment in pediatric patients}

Schlüer AB, Schols JMGA, Halfens, RJG. Pressure ulcer treatment in pediatric patients. Submitted to the Journal Advances in Skin \& Wound Care, 2013 (accepted for publication). 


\section{Abstract}

Objective: To assess pressure ulcer treatment in Swiss hospitalized pediatric patients and to determine whether there are differences in pressure ulcer treatment according to demographic characteristics of the patients.

Design: A descriptive multicenter point prevalence study was conducted in June 2009 in all German-speaking pediatric hospitals in Switzerland.

Setting: All hospitalized patients from birth up to $\leq 17$ years of age in fourteen Swiss pediatric hospitals, including all pediatric departments were assessed.

Patients: A total of 412 patients participated in this study.

Main Outcome Measures: The instrument and method of the Dutch National Prevalence Measurement of Care Problems was used.

Main results: Thirty five percent of the patients had a pressure ulcer. Almost all of these PU's (94.1\%) were of category 1. The most severe pressure ulcers occurred in patients older than eight years of age. Age of the patient and department where the only characteristics, which significantly influenced the occurrence of pressure ulcers category 2 to 4 . Pressure ulcers category 2 to 4 were mostly covered with hydrocolloid or polyurethane foam dressings. No pediatric specific guideline according pressure ulcer treatment is used in the involved hospitals.

Conclusion: Most of all patients had pressure ulcers of category 1, so appropriate prevention to decrease any further trauma in these patients is necessary. Severe pressure ulcers (category 2-4) are mostly limited to older pediatric (over the age of eight years) patients with chronic condition or after surgery intervention. A pressure ulcer treatment guideline adapted for pediatric needs is recommended. 


\subsection{Introduction}

A pressure ulcer (PU) is a localized injury to the skin and/or underlying tissue as a result of pressure, or pressure in combination with shear forces (National Pressure Ulcer Advisory Panel (NPUAP)/ European Pressure Ulcer Advisory Panel (EPUAP), 2009). Although PUs have gained a great deal of attention in adults, far less is known about PUs in children and neonates (Baharestani and Ratliff, 2007). Recent investigations indicate that PUs are also common in hospitalized infants and children: reported PU prevalence rates in children including all PU categories range from approximately $3 \%$ to $35 \%$ in hospitals (Kottner, Wilborn, Dassen, 2010, Schlüer, Halfens, Schols, 2012). In some departments and pediatric care settings, such as neonate departments and Pediatric Intensive Care Units (PICU), the PU prevalence rate may rise to even $50 \%$ (Schlüer et al., 2012). While it is well known that the costs for PU treatment in adult patients are extensive (Xakelis and Frantz, 1996, Anthony, Reynolds, Russell, 2004, Bennet, Dealy, Posnett, 2004, Allmann, Goode, Burst, Bartolucci, Thomas, 1999), only vague suggestions have mentioned that the costs for the pediatric population are comparable to those for adult patients (Pickersgill, 1997, Singh, Bartlett, Low, Kirschner, 2002, Butler, 2007, Gabriel et al., 2009).

There are several guidelines for wound treatment in adult patients regarding both the treatment of PUs as well as wounds in general (Fan, Tang, Escandon, Kirsner, 2011, Adams, Sabesan, Easley, 2012, Henzel, Bohie, Guihan, Ho, 2011, Warriner III and Carter, 2010, McGinnis and Stubbs, 2011, Mclnnes, Jammali-Blasi, BellSyer, Dumville, Cullum, 2012). To our best knowledge no specific guideline for wound treatment in pediatric pressure ulcer wounds is available today.

Epidemiological studies and empirical evidence state that the most common wound types in pediatric patients include epidermal stripping, extravasation injuries, surgical wounds, incontinence associated dermatitis, chemical and thermal injuries, wounds secondary to congenital abnormalities and pressure ulcers (Baharestani and Ratliff, 2007, Baharestani, 2007a). Wound care in pediatric patients needs to take account of several relevant differences between child and adult patients (Baharestani and Ratliff, 2007, Singh et al., 2002, Gabriel et al., 2009, Baharestani et al., 2009b, Stone McCord and Levy, 2006) which 
render the management of acute and chronic wounds of various etiologies in the pediatric population a challenge (Baharestani et al., 2009b). Due to their small body sites, especially in newborns, neonates and infants, pediatric patients present difficulties for finding an appropriate wound treatment (Baharestani and Ratliff, 2007). The skin of infants, newborns and children is morphologically and functionally different from that of adults (Nikolovskis, Stamatas, Kollias, Wiegand, 2008, Stamatas, Nikolovski, Luedtke, Kollias, Wiegand, 2010). Appropriate pain management, age-appropriate communications strategies according to wound treatment and early mobility and activity especially in infants and toddlers all add a greater aspect of complexity in wound care (Gabriel et al., 2009, Baharestani et al., 2009a). Small sized dressings that are easy to apply even to the small fingers and toes of very low term neonates with adequate adhesion, but which do not stick to the skin are for instance necessary to meet specific pediatric needs (Baharestani et al., 2009b).

Only a few research publications about the treatment of pediatric PUs could be found. In the study of Cisler-Cahill (2006) a total of 48 wounds of all types were treated with amorphous hydrogel and healed without surgical intervention. PU related wounds were included, but no information on the number, severity or localization of the PUs, or on the explicit treatment and duration of a wound was given. In three case reports on forehead pressure necrosis wounds in neonates following continuous positive airway pressure (CPAP), these PUs were treated with hydrocolloids for an unknown time period. The PUs were not categorized but described as pressure necrosis. In all three cases a slight but visible scarring remained after an 18-month follow up period (Hoegeling, Fardin, Frieden, Wargon, 2011). In a study of Stasikelis et al. (1999), out of 79 children with cerebral palsy undergoing osteotomies, 5 developed a PU (not categorized) after cast removal. The wound treatment was conducted with undefined local wound treatment without interfering with the planned rehabilitation program. All 5 PUs healed within 2-8 weeks (Stasikelis et al., 1999).

In a study on the surgical treatment of PUs, the successful technique of specific muscle flap operations in pediatric patients with ischial pressure ulcer category three and four is described (Ahluwalia, Martin, Mahoney, 2010). In another study the long-term outcome of surgical reconstruction of pediatric PUs is described 
(Singh et al., 2002). In this study a total of 19 paraplegic patients between 9 and 16 years of age with 20 PUs localized as sacral $(n=7)$, ischial $(n=9)$, trochanteric $(n=3)$ and iliac crest $(n=1)$ were treated surgically with myocutaneous flaps. The overall PU recurrence rate after treatment was 1 out of 20 (5\%). The long-term follow up over a five year time period showed that the treatment was successful and provided long-term skin integrity (Singh et al., 2002).

In three studies the use of negative pressure wound therapy (NPWT) for PU related pediatric wounds were studied (Gabriel et al., 2009, Baharestani et al., 2009b, Baharestani 2007b). In the study of Bahasterani (2007b) three PUs were treated with NPWT, with a total closure of the wound in two and an $80 \%$ closing of the wound in one case. In the study of Gabriel et al. (2009) five patients all showed category 3 and 4 PUs (child 3 to 12 years of age $n=2$, adolescent 13 to 21 years of age $n=3)$. After a 15 day NPWT treatment in these patients, two PUs were closed completely $(40 \%)$ and three wounds needed further treatment. No further references to age or treatment are made (Gabriel et al., 2009). In the clinical review of Bahasterani et al. (2009a) the recommendation was made that NPWT should be used in PUs category 3 and 4. However, category 3 and 4 PUs were not further described in this study (Baharestani 2007a).

Up to now, there has been a lack of knowledge and research to guide clinical practice in the field of PU treatment in pediatric patients (Baharestani et al., 2009a, Stone McCord and Levy, 2006, Butler, 2007, Cisler-Cahill, 2006).

\subsubsection{Study purpose}

Because of this lack of knowledge the following research questions were formulated for this study:

(1) Which pediatric patients show severe PUs of category 2, 3 and 4 compared with patients at risk (patients with category $1 \mathrm{PU}$ )?

(2) What is the current PU treatment in Swiss pediatric hospitals?

(3) Are there any differences in the treatment of severe PUs (category 2 to4) according to demographic characteristics of patients? 


\subsection{Methods}

In 2009 a multicenter, cross-sectional, point prevalence study was conducted in all 14 pediatric hospitals in the German-speaking part of Switzerland on one day in June (Schlüer et al., 2012). These 14 hospitals had a total of 70 wards. All pediatric departments at the participating sites were included.

\subsubsection{Patients}

Children in all departments, including PICUs, neonatal intensive care units (NICUs), all surgical units, all pediatric medical units as well as the departments for pediatric rehabilitation care, were invited to participate if they met the inclusion criteria. Inclusion criteria were an age of 24 hours up to and including 17 years, and being hospitalized for at least one day in the respective institutions. Exclusion criteria were a) hospitalization in psychiatric units, b) children whose legal representatives did not allow participation, and c) children who refused to participate; this included no informed consent form from children 10 years and older as well as younger children who verbally refused to participation (Schlüer et al., 2012).

\subsubsection{Ethical approval}

The ethics board of each hospital and all cantonal ethics committees approved the study. All patients and their families were verbally informed about the study and also received the same information in written form. The information letter, as well as the informed consent form, was available in eight different languages. Children 10 years of age and older were asked to give their own written consent; in other cases the parents or legal representatives were asked to do this (Schlüer et al., 2012). 


\subsubsection{Measurements}

The instrument and method of data collection of the Dutch National Prevalence Measurement of Care Problems (LPZ) (Halfens et al., 2010) was used to assess the treatment of pressure ulcers. This instrument is widely used in Europe and elsewhere, and has been shown to be reliable and valid (Halfens et al., 2010). It collects among other things the following categories of data on patient level: (1) patient characteristics (demographic and clinical data), (2) assessment of the severity of pressure ulcers, as well as (3) prevention and treatment interventions. Furthermore a few questions were asked about the policy of the hospital and ward about PU, as if they have a guideline for PU.

To differentiate risk factors for the development of more severe PUs (category 2 to 4) patients with a PU category 1 were defined as patients at risk. This is in line with Bahasterani et al. (2009b) and with recommendations from pediatric specific PU research findings (Curley, Razmus, Roberts, Wypij, 2003) whereas PUs category one seem to be the most important risk factor for pediatric patients to develop severe PUs.

The method of data collection related to PUs involved a direct and systematic inspection and judgment of the skin of the patient. The EPUAP (2009) pressure ulcer category system consisting of four categories was used (NPUAP/ EPUAP, 2009). Demographic and clinical data, such as date of birth, weight and size, body mass index and diagnosis, were collected from the patient charts. The wound treatment applied was assessed by direct inspection as well as by analyzing the patients' charts and wound documentation.

\subsubsection{Procedure}

Previously trained rater pairs gathered data from each patient. Each rater pair consisted of a health care worker who worked on the ward surveyed, and a health care worker who did not work on that ward. A total of 35 rater pairs were involved in the study. In all participating hospitals, nurses who worked either as wound consultants in their units or as clinical nurse specialists acted as raters. Preparatory training included methodological aspects, detailed information about 
data collection, the role and responsibilities of the raters, a detailed introduction to the measurement instruments, and special training in the grading of a pressure ulcer.

\subsubsection{Data analysis}

Predictive Analytics Software (PASW) (version 18, formerly SPSS) was used to analyze the study data with descriptive methods. Distributions and frequencies were calculated and tested with the Chi square test (categorical data) and one Way-ANOVA.

\subsection{Results}

The overall sample size of potential study participants who met the inclusion criteria was 560 . The total number of participants was $412(74 \%)$ because 148 (26\%) dropped out before the assessment. In 67 cases (12\%), either the parents or the child refused to participate. Sixty patients were excluded due to unexpected discharge or because examination or operations lasted longer than the survey $(11 \%)$. Four patients were not assessed due to an unexpected change in their condition to a critical level. Five patients dropped out due to language problems of the parents, for 12 patients the reasons were unknown.

\subsubsection{Demographic characteristics}

As presented elsewhere (Schlüer et al., 2012), the participation rate in the 14 clinics ranged from 6-97 patients (43-100\%). The length of stay showed an average of 25 days and a median of 7 days. Of the 412 assessed patients, $67 \%$ $(n=275)$ had been hospitalized for less than 14 days. Patients with an oncology diagnosis, acute gastroenteritis, pneumonia or cardiology diagnosis represented the largest group with $33 \%(n=135)$ and were classified as pediatric medical department patients, followed by neonates $(n=109,27 \%)$, and patients in the surgery departments (including, plastic and burn surgery, visceral surgery, 
neurosurgery and orthopedic and trauma patients) ( $\mathrm{n}=99,24 \%)$. The patient population in the PICU consisted of 36 children (9\%). Furthermore, 33 patients (8\%) were hospitalized for rehabilitation care (table 1).

Eleven of the 14 hospitals (78\%) had a guideline for PU treatment, but none specific for pediatrics, and19 wards of the 61 (31\%) wards didn't work according to a PU treatment guideline. Eight of the 14 hospitals (57\%) organized in the last two years an extra training on prevention and treatment of PU but only based on the prevention and treatment of PUs of adult patients.

Table 1: Demographic characteristics of the study sample

\begin{tabular}{|c|c|c|c|c|c|}
\hline & & Mean & Median & SD & n (\%) \\
\hline \multirow[t]{2}{*}{ Sex } & Female & & & & $181(44)$ \\
\hline & Male & & & & $231(56)$ \\
\hline Age (years) & & 4 & 1 & 5.4 & \\
\hline Age (months) & & 52 & 14 & 66.7 & \\
\hline $\begin{array}{l}\text { Age group }<1 \\
\text { year of age } \\
\text { (weeks) }\end{array}$ & & 6 & 3 & 9 & $203(49)$ \\
\hline \multirow[t]{5}{*}{ Age category } & $<1$ year & & & & $203(49.3)$ \\
\hline & $1-4$ & & & & $61(14.8)$ \\
\hline & $4-8$ & & & & $44(10.7)$ \\
\hline & $8-12$ & & & & $43(10.4)$ \\
\hline & $>12$ & & & & $61(14.8)$ \\
\hline \multicolumn{6}{|c|}{ Duration of stay (days) related to divisions } \\
\hline & Surgery & 9.13 & 4 & 16.6 & $99(24)$ \\
\hline & Pediatric medical & 17 & 4.5 & 44.8 & $135(33)$ \\
\hline & Rehabilitation & 110.4 & 64 & 137.9 & $33(8)$ \\
\hline & Neonatology & 19.9 & 14 & 20.9 & $109(27)$ \\
\hline & PICU & 14.8 & 7 & 16.2 & $36(9)$ \\
\hline
\end{tabular}

\subsubsection{Prevalence of PU}

Of the 412 patients taking part in this study, a total of 142 showed one or more pressure ulcers on the day of inquiry, which involved a PU prevalence rate of 35 \%. Of these 142 patients, 77 (54\%) showed one, 35 (25\%) two, 17 (12\%) three, 6 four $(4 \%), 2$ five $(2 \%), 3$ six $(1 \%), 1$ nine and one patient showed 10 pressure 
ulcers. This resulted in a total number of 269 PUs. Almost all of these PU's (94.1\%)were of category 1 , which we defined as at risk of PU (table 2).

Table 2: Wound dressings used in the 142 patients with a total of 269 PUs categories 1 to 4

\begin{tabular}{|c|c|c|c|c|c|}
\hline Wound dressing & Cat. 1 & Cat. 2 & Cat. 3 & Cat. 4 & $\mathrm{n}(\%)$ \\
\hline No dressing & 205 & 7 & & & $212(78.8)$ \\
\hline Ointment & 20 & & & & $20(7.3)$ \\
\hline Hydrocolloid & 6 & 2 & & & $8(3)$ \\
\hline Paraffin gauze dressing & 3 & & & 1 & $4(1.5)$ \\
\hline Polyurethane foam dressings & 1 & 2 & 1 & & $4(1.5)$ \\
\hline Drying out /air dry & 3 & & & & $3(1.2)$ \\
\hline Alginate & 1 & & 1 & & $2(0.7)$ \\
\hline Oil & 1 & & & & $1(0.4)$ \\
\hline Dressing containing silver & 1 & & & & $1(0.4)$ \\
\hline Film dressing & 1 & & & & $1(0.4)$ \\
\hline Others & 11 & & 1 & $1^{*}$ & $13(4.8)$ \\
\hline Totaln(\%) & $253(94)$ & $11(4)$ & $3(1)$ & $2(1)$ & $269(100)$ \\
\hline
\end{tabular}

${ }^{*}$ Negative pressure wound therapy (NPWT)

Age of the patient and the department where the patient was hospitalized were the only factors, which significantly influenced the occurrence of category 2 to 4 PUs in comparison to patients with category 1 PUs, whereas gender, body mass index, whether the hospital had a guideline according to PU prevention and/or treatment, or had an extra training, or worked according an PU guideline at the ward were not statistically significant. Patients in a pediatric medical department or a surgery department $(X 2=12.005, P=0.017)$, or who are older (over the age of eight years) showed more severe PUs $(p=0.000, F=12.269)$.

\subsubsection{Treatment}

Tables 2 and 3 list the wound treatments/wound dressings applied in PUs according to category. In nearly $80 \%$ of all pressure ulcers belonging to category 1 no dressings at all were used $(n=205)$. The use of ointment with a high level of lipid was common in 7\% of category 1 PUs. Hydrocolloid dressings were used in 6 patients $(2.3 \%)$ as well as paraffin gauze dressings in 3 patients (1.2\%). In more than half of all the pressure ulcer cases of category 2 , no dressing was used $(n=7$, 64\%) (table 2). Category 3 and 4 PUs were treated with different dressings and 
treatments, including the use of NPWT in one case (table 2). Of all possible wound dressings known, at the 14 clinics involved in the study, only ointment $(7 \%)$ and hydrocolloid (3\%) were used more frequently (table 2).

'Other dressings' (5\%) included all the different dressings that were used for pressure ulcer treatment. In category 1 PUs these included the use of a special biosynthetic skin substitute, the use of an antifungal solution and the use of creams brought by the family of the patient. The one category $3 \mathrm{PU}$ (treatments score 'other') was disinfected and not covered, and the pressure ulcer rated as category 4 was treated with an NPWT (table 2). 
Table 3: Differentiation of patients with category 2 to 4 PUs according to treatment and patient characteristics

\begin{tabular}{|c|c|c|c|c|c|c|c|c|}
\hline & Localization & $\begin{array}{l}\text { Length of time } \\
\text { since PU } \\
\text { occurrence }\end{array}$ & $\begin{array}{l}\text { Wound } \\
\text { treatment }\end{array}$ & $\begin{array}{l}\text { Age of } \\
\text { patient }\end{array}$ & $\begin{array}{l}\text { Division/subdivision/ } \\
\text { medical } \\
\text { treatment/medical } \\
\text { diagnosis }\end{array}$ & $\begin{array}{l}\text { Suspected cause } \\
\text { for the PU } \\
\text { development }\end{array}$ & $\begin{array}{l}\text { Duration of } \\
\text { patient } \\
\text { stay }\end{array}$ & $\begin{array}{l}\text { Further } \\
\text { comments }\end{array}$ \\
\hline \multicolumn{9}{|c|}{ Category 2} \\
\hline $1^{+}$ & heel & 2-4 weeks & hydrocolloid & 11 years & $\begin{array}{l}\text { Surgery/ Orthopedic, } \\
\text { spinal cord, }\end{array}$ & cast & 99 days & $\begin{array}{l}\text { First description } \\
\text { of PU after cast } \\
\text { removal }\end{array}$ \\
\hline $2^{+}$ & heel & 2-4 weeks & hydrocolloid & 11 years & $\begin{array}{l}\text { Surgery/ Orthopedic, } \\
\text { spinal cord, }\end{array}$ & cast & 99 days & $\begin{array}{l}\text { First description } \\
\text { of PU after cast } \\
\text { removal }\end{array}$ \\
\hline $3^{*}$ & hip & 2-4 weeks & no & 8 years & $\begin{array}{l}\text { Surgery/ Neuroorthopedic } \\
\text { Cerebral palsy }\end{array}$ & Post operative & 15 days & \\
\hline $4^{*}$ & hip & 2-4 weeks & no & 8 years & $\begin{array}{l}\text { Surgery/ Neuroorthopedic } \\
\text { Cerebral palsy }\end{array}$ & Post operative & 15 days & \\
\hline $5^{\circ}$ & heel & 3-6 months & no & 11 years & $\begin{array}{l}\text { Pediatric medical juvenile } \\
\text { arthritis }\end{array}$ & shoes & 10 days & \\
\hline $6^{\circ}$ & heel & 3-6 months & no & 11 years & $\begin{array}{l}\text { Pediatric medical juvenile } \\
\text { arthritis }\end{array}$ & shoes & 10 days & $\begin{array}{l}\text { First occurrence } \\
\text { of the PU at home }\end{array}$ \\
\hline 7 & hand & $<2$ weeks & no & 8 years & $\begin{array}{l}\text { Pediatric medical/ diabetes } \\
\text { type I }\end{array}$ & $\begin{array}{l}\text { Splint of peripheral } \\
\text { iv }\end{array}$ & 5 days & \\
\hline 8 & heel & $<2$ weeks & no & 15 years & $\begin{array}{l}\text { Surgery/ orthopedic } \\
\text { Cerebral palsy }\end{array}$ & $\begin{array}{l}\text { Positioning } \\
\text { postoperative }\end{array}$ & 6 days & \\
\hline $9^{a}$ & heel & 3-6 months & $\begin{array}{l}\text { Polyurethane } \\
\text { foam }\end{array}$ & 16 years & $\begin{array}{l}\text { Pediatric medical/ } \\
\text { oncology } \\
\text { sarcoma }\end{array}$ & positioning & 1 day & $\begin{array}{l}\text { Decreased } \\
\text { sensitivity, after } \\
\text { tumor excision }\end{array}$ \\
\hline $10^{a}$ & heel & 3-6 months & $\begin{array}{l}\text { Polyurethane } \\
\text { foam }\end{array}$ & 16 years & $\begin{array}{l}\text { Pediatric medical/ } \\
\text { oncology } \\
\text { sarcoma }\end{array}$ & positioning & 1 day & $\begin{array}{l}\text { Decreased } \\
\text { sensitivity, after } \\
\text { tumor excision }\end{array}$ \\
\hline
\end{tabular}




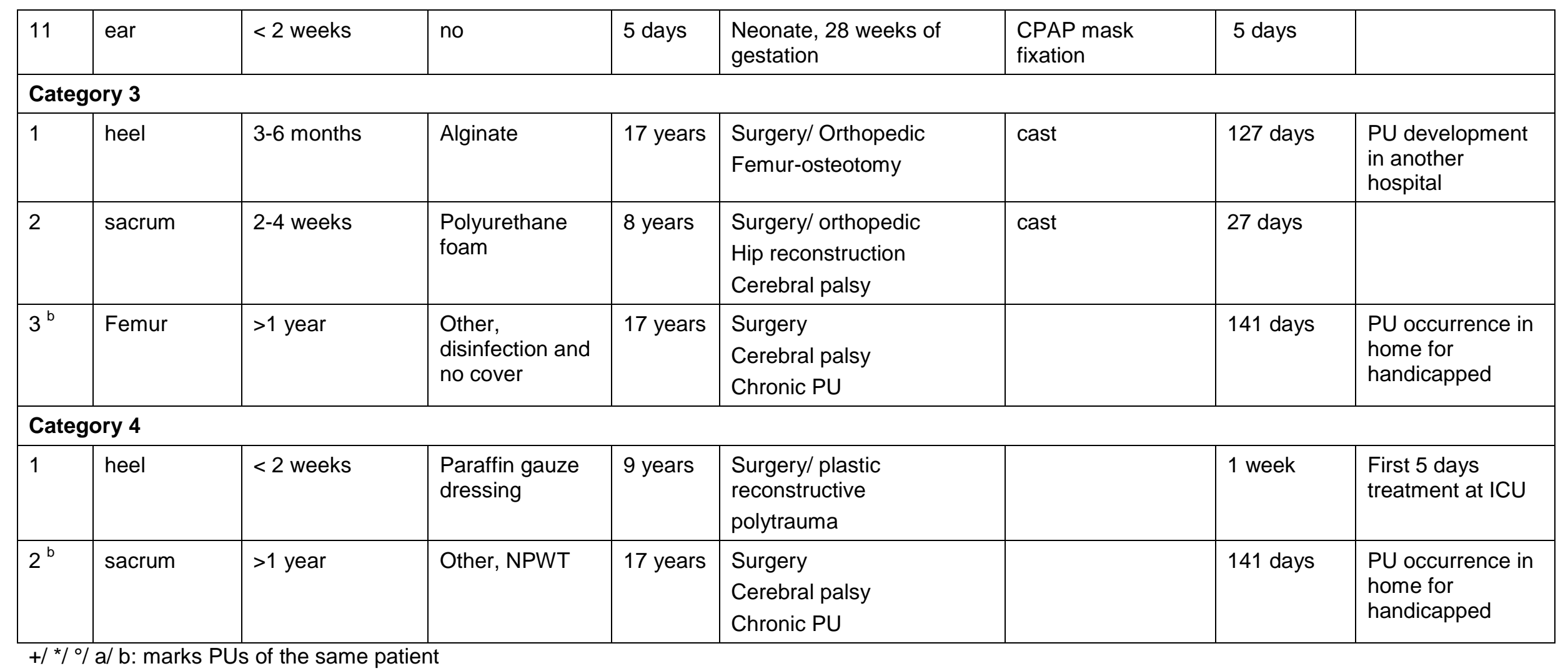




\subsection{Discussion}

This study was set out to survey the treatment for PUs in pediatric wards in German-speaking Switzerland. The results revealed a range of different treatments primarily related to differences in severity and location. In discussing the results a distinction will be made between category 1 and category 2 to 4 PUs.

It seems reasonable that most of the category 1 PUs are not treated with a wound dressing, since in category 1 PUs the skin is still intact (NPUAP/ EPUAP, 2009). The nonuse of any dressing in category 1 PUs makes it possible to recognize any changes in these ulcers quickly and easily. In addition, it is very important to carry out appropriate preventive interventions in pediatric patients with a category $1 \mathrm{PU}$ to avoid any further trauma to the skin (Baharestani and Ratliff, 2007). Regular risk assessment, daily skin assessment, repositioning and pressure relief are all components of effective PU prevention (Parnham, 2012).

These preventive interventions need to be adapted to pediatric patients with regard to the varying needs in different age groups, e.g., neonates and infants, as well as in settings like the PICU (Parnham, 2012).

With regard to the use of hydrocolloid and polyurethane foam dressings in $3 \%$ of all category 1PUs, this might also mainly have been done for preventive reasons to protect an affected or vulnerable skin area from further trauma (Butler, 2007, Quigley and Curley, 1996). One should be aware that hydrocolloid dressings for the prevention of PUs as well as for the protection of further trauma of PU sites are more common in daily practice with pediatric patients if devices like splints or tubes are used. No literature according to that practice is found, but to the knowledge of the authors this is often conducted in daily practice.

The use of ointment $(7 \%)$ as well as oil $(n=1)$ in category 1 PUs might also be judged as a preventive intervention. However, the use of ointment, oil or antifungal solutions or creams brought by the family for patients with a category $1 \mathrm{PU}$ is not in line with recommendations in the literature (Butler, 2007, Stone McCord and Levy, 2006, Baharestani, 2007b, Quigley and Curley, 1996, Lund, 1999). Such use 
may of course be related to normal skin care but it is not clear whether this was the case here. Nevertheless, this finding needs critical reflection, especially in neonates and children below 5 years of age. Routine use of any ointments, oil, etc. is not recommended for skin care in pediatric patients of these ages, especially in children below the age of five years (Butler, 2007, Lund, 1999, Blume-Peytavi, Hauser, Stamatas, Pathirana, Garcia Bartels, 2012, Malloy and Perez-Woods, 1991, Irving, 2001, Pasek et al., 2008). Therefore, this is an area for further research.

The use of paraffin gauze, alginate and silver dressings for the treatment of category 1 PUs also calls for critical reflection. One may assume that there is no primary treatment indication for these dressings in category 1 PUs (which still imply intact skin) and what is more, that all these dressings need a second covering layer or dressing, thus making the PU invisible. This means that a category $1 \mathrm{PU}$ cannot be assessed easily without changing or removing the dressings, and thus rendering children more sensitive. Finally, due to cost related factors, this strategy should not be advised either (Hollinworth, 2005, Meulemeire, 2009).

The use of any dressing in pediatric patients must rely on a clear goal for the intended treatment, with consideration of potential critical aspects like further harm or trauma. In addition, any dressing use in pediatric patients must protect the skin from further harm, like epidermal stripping (Butler, 2007, Baharestani 2007b, Meulemeire, 2009).

Regarding the treatment of category 2 to 4 PUs, the use and type of dressings found in this study seem reasonable. The use of polyurethane foam dressings as well as of hydrocolloid dressings is in line with recommendations for the pediatric population (Butler, 2007, Baharestani 2007b, Meulemeire, 2009). Why 7 (64\%) category 2 PUs, which were not covered with any dressing, we can only surmise. If these category 2 PUs involved blisters with still intact skin, then this strategy can be understood. Any change in the category $2 \mathrm{PU}$ can be assessed easily then and unnecessary wound dressing changes can be avoided. Of course, appropriate preventive interventions to avoid further trauma of blisters is of great importance and yet, if the blister breaks, an appropriate dressing subsequently needs to be chosen (Meulemeire, 2009). 
The use of alginate in a category 3 PU seems reasonable as well. Pediatric wounds classified for the use of an alginate dressing mostly show partial and full thickness skin loss (Stone McCord and Levy, 2006). The control of bleeding from a wound, using alginate has been studied in adult patients but not in children (Baharestani 2007a). In fact, the use of calcium alginate in neonates is not recommended due to the unknown absorption of calcium in these patients (Baharestani, 2007a). However, in this study the patient with alginate treatment of his category $3 \mathrm{PU}$ was 17 years of age.

NPWT for PU treatment is highly recommended in some studies in pediatric patients with, for example, PU wounds as well as acute and chronic wounds with partial and full thickness skin loss and considerable exudation (Baharestani, 2007a, Gabriel et al., 2009, Baharestani et al., 2009a). The advantages of the use of NPWT in pediatric patients are well described in those studies. In the present study, NPWT was used in only one case of a category $4 \mathrm{PU}$.

As described in the literature (Singh et al., 2002, Gabriel et al., 2009, Baharestani, 2007a, Stasikelis et al., 1999, El-Sabbagh, 2011), a comparatively high proportion of surgical patients, especially patients after orthopedic treatment or patients with cerebral palsy and spinal cord lesions showed category 3 and 4 PUs and were older than 8 years of age in this study. This leads to the assumption that especially older pediatric patients with chronic conditions may be affected by more severe PUs.

On hospital as well as on ward level, in more than half of all institutions surveyed, a PU treatment guideline was available but none of these was adapted to the needs of pediatric patients.

\subsection{Limitations of this study and implications for further research}

Prevalence studies are always subject to daily variations when small samples are used. The results presented here include all pediatric hospitals, and therefore the overall prevalence rate as the treatment of the patients will give a good indication of the situation in Switzerland. 
Data are gathered by nurses of the hospital itself, which could have given a bias. However for participants it was clear that this study was not used to evaluate their work, or their institution, so there were no positive or negative incentives to make the results positive or negative.

This study shows that severe PUs occur especially in older pediatric patients (over the age of eight years) with chronicle condition and/or after surgical interventions. It is of great importance to assess these patients carefully for their risk of PU development and that health care professionals are aware of these high-risk patients.

For pediatric patients no research based wound care guidelines are available and wound dressings are often not tested in different pediatric populations, such as neonates, infants and children. Only several earlier studies about NPWT use and surgical techniques in pediatric patients provide some research-based information about PU treatment in pediatric patients. As already noted, specific wound care guidance with regard to different age groups in pediatric patients is of great importance. Further research in this area is therefore crucial, as well as research to obtain more evidence for the different types of wound dressings in children with PUs.

\subsubsection{Conclusions and implications for clinical practice}

To our best knowledge for the first time data on the treatment of PUs in pediatric patients are presented. Most of the PUs in these hospitalized pediatric patients are category 1. Therefore appropriate preventive interventions to avoid any further trauma or worsening of these patients' PUs are mandatory. Severe PUs of category 2, 3 and 4 are mostly limited to older pediatric (over the age of eight years) patients especially with chronic conditions or after surgical, especially orthopedic interventions.

In addition, there is an explicit need for an evidence-based pediatric specific guideline about the treatment of PUs.

It is a clinical challenge to use dressings, which are both appropriate to the goal that has to be achieved in wound healing as well as to specific pediatric needs. In 
addition, the choice of a dressing in children with PUs should be balanced and well documented as well as regularly evaluated. Pediatric patients are not small adults, and this is also true for wound care. 


\subsection{References}

Adams SB, Sabesan VJ, Easley ME. (2012). Wound healing agents. Critical Care Nursing Clinics North America; 24: 255-260.

Ahluwalia R, Martin D, Mahoney JL. (2010). The operative treatment of pressure wounds: a 10-years' experience in flap selection. International Wound Journal; 7: 103-106.

Allmann RM, Goode PS, Burst N, Bartolucci AA, Thomas DR. (1999). Pressure Ulcers, Hospitals Complications and Disease Severity: Impact on Hospital Costs and Length of Stay. Advances in Wound Care; 12: 22-30.

Anthony D, Reynolds T, Russell L. (2004). The role of hospital acquired pressure ulcer in length of stay. Clinical Effective Nursing; 8: 4-10.

Baharestani MM, Black J M, Carville K, Clark M, Cuddigan JE, Dealey C, Defloor T, Harding KG, Lahmann NA, Lubbers MJ, Lyder CH, Ohura T, Orsted HL, Reger SI, Romanelli M, Sanada H. (2009a). Dilemmas in measuring and using pressure ulcer prevalence and incidence: an international consensus. International Wound Journal; 6: 97-104.

Bahasterani MM, Amjad I, Bookout K, et al. (2009b) V.A.C. Therapy in the management of pediatric wounds: clinical review and experience. International Wound Journal; 6: 1-26.

Bahasterani MM. (2007a). Use of negative pressure wound therapy in the treatment of neonatal and pediatric wounds: a retrospective examination of clinical outcomes. Ostomy Wound Management; 53: 75-85.

Baharestani MM. (2007b). An overview of neonatal and pediatric wound care knowledge and considerations. Ostomy Wound Management; 53: 34-6, 38, 40.

Baharestani MM, Ratliff CR. (2007). Pressure Ulcers in Neonates and Children: An NPUAP White Paper. Advances in Skin and Wound Care; 20: 208-220.

Bennett G, Dealy C, Posnett J. (2004). The cost of pressure ulcers in the UK. Age and Ageing; 33: 230-235. 
Blume-Peytavi U, Hauser M, Stamatas GN, Pathirana D, Garcia Bartels N. (2012). Skin care practices for newborn and infants: review of the clinical evidence for best practices. Pediatric Dermatolgy; 29: 1-14.

Butler CT. (2007). Pediatric Skin Care: Guidelines for Assessment, Prevention and Treatment. Dermatology Nursing; 19: 471-486.

Cisler-Cahill L. (2006). A protocol for the use of amorphous hydrogel to support wound healing in neonatal patients: An adjunct to nursing skin care. Neonatal Network; 25: 267- 273.

Curley MAQ, Razmus IS, Roberts KE, Wypij D. (2003b). Predicting pressure ulcer risk in pediatric patients: the Braden-Q Scale. Nursing Research; 52: 22-33.

El-Sabbagh A. (2011). The accordion gracils muscle flap: a new design for coverage of recurrent and complicated ischial pressure sores. International Wound Journal; 8: 447-453.

Fan K, Tang J, Escandon J, Kirsner RS. (2011). State of the art in topical wound healing products. Plastic Reconstructive Surgery; 127(Supl): 44S-59S.

Gabriel A, Heinrich C, Shores J, et al. (2009). Outcomes of vacuum-assisted closure for the treatment of wounds in a pediatric population: case series of 58 patients. Journal Plastic Reconstructive Aesthetic Surgery; 62: 1428-1436.

Goldberg SR, Diegelmann RF. (2012). WoundHealing Primer. Critical Care Nursing Clinics North America; 24: 165-178.

Halfens R, Meijers J, Neyens J. et al (2010). Available at:http://www.lpzum.eu/eng/about-lpz. Accessed 12 April 2013.

Henzel K, Bogie KM, Guihan M, Ho CH. (2011). Pressure ulcer management and research priorities for patients with spinal cord injury: Consensus opinion from $\mathrm{SCl}$ QUERI Expert Panel on Pressure ulcer research implementation. Journal Rehabiltation Research Device; 48: xi-xxxii.

Hoegeling M, Fardin SR, Frieden IJ, Wargon O. (2011). Forehead pressure necrosis in neonates following continuous positive airway pressure. Pediatric Dermatology; 29: 45-48. 
Hollinworth H. (2005). The management of patients' pain in wound care. Nursing Standard; 20: 65-6, 68, 70.

Irving V. (2001). Caring for and protecting the skin of pre-term neonates. Journal Wound Care; 10: 253-256.

Kottner J, Wilborn D, Dassen T. (2010). Frequency of pressure ulcers in the pediatric population: a literature review and new empirical data. International Journal of Nursing Studies; 47: 1330-1340.

Lund C. (1999). Prevention and management of infant skin breakdown. Nursing Clinics North America; 34: 907-920.

Malloy MB, Perez-Woods RC. (1991). Neonatal skin care: prevention of skin breakdown. Pediatric Nursing; 17: 41-48.

McGinnis E, Stubbs N. Pressure-relieving devices for treating heel pressure ulcers (Review). (2011). The Cochrane Library; Issue 9.

McInnes E, Jammali-Blasi A, Bell-Syer S, Dumville J, Cullum N. (2012).

Preventing pressure ulcers- are pressure redistributing support surfaces effective? A Cochrance systematic review and meta-analysis. International Journal of Nursing Studies; 49: 345-359.

Meulemeire F. (2009). A case study evaluation of safetec dressings used for pediatric wounds. Wounds; 5: 12-19.

National Pressure Ulcer Advisory Panel (NPUAP) and European Pressure Ulcer Advisory Panel (EPUAP). Prevention and treatment of pressure ulcers: clinical practice guideline. National Pressure Ulcer Advisory Panel, 2009, Washington DC.

Nikolovski J, Stamatas GN, Kollias N, Wiegand BC. (2008). Barrier function and water-holding and transport properties of infant stratum corneum are different from adult and continue to develop through the first year of life. Journal Investigation in Dermatology; 128: 1728-36.

Parnham A. (2012). Pressure ulcer risk assessment and prevention in children. Nursing Children and Young People; 24: 24-29. 
Pasek TA,Geyser A,Sidoni M, et al. (2008). Skin care team in the pediatric intensive care unit: a model for excellence. Critical Care Nurse; 28:125-35.

Pickersgill J. (1997). Taking the Pressure off. Paediatric Nursing; 9: 25-27.

Quigley SM, Curley MAQ. (1996). Skin integrity in the pediatric population: preventing and managing pressure ulcers. Journal for Specialists in Pediatric Nursing; 1: 7-18.

Schlüer AB, Halfens RJ, Schols JMGA. (2012). Pediatric Pressure Ulcer Prevalence: A Multicenter, Cross-Sectional, Point Prevalence Study in Switzerland. Ostomy Wound Management; 58: 18-31.

Singh DJ, Bartlett SP, Low DW, Kirschner RE. (2002). Surgical Reconstruction of Pediatric Pressure Sores: Long-Term Outcome. Journal Plastic Reconstructive Aesthetic Surgery; 109: 265-269.

Stamatas GN, Nikolovski J, Luedtke MA, Kollias N, Wiegand BC. (2010). Infant skin microstructure assessed in vivo differs from adult skin in organization and at the cellular level. Pediatric Dermatology; 27: 125-31.

Stasikelis PJ, LeeDD, Sullivan CM. (1999). Complications of osteotomies in severe cerebral palsy. Neuromuscular; 19: 207-210.

Stone McCord S, Levy ML. (2006). Practical guide to pediatric wound care. Seminars in plastic surgery; 20: 192-199.

Warriner III RA, Carter MJ. (2010). The current state of evidence-based protocols in wound care. Plastic Reconstructive Surgery; 127 (Suppl): 144S-153S.

Xakelis GC, Frantz R. (1996). The Cost of Healing Pressure Ulcers Across Multiple Health Care Settings. Advances in Wound Care; 9: 18-22. 
8 General discussion 


\subsection{General discussion and future directions}

The aims of this thesis were to obtain more information about the prevalence, risk factors and characteristics of pediatric patients with a pressure ulcer (PU), as well as information on risk assessment scales for the pediatric population. In addition, another aim was to address the prevention and treatment of pressure ulcers (PUs) in different pediatric patient populations.

\subsubsection{Main results}

This dissertation shows that the prevalence of PUs in pediatric patients is high. However pediatric patients are mainly affected by category 1 PUs. Severe PUs of category 2, 3 and 4 are limited to a few groups of pediatric patients, such as older children (over the age of 8 years) with chronic diseases and after orthopedic interventions.

There is an overall PU prevalence rate of $35 \%$ for the total population in Swiss pediatric hospitals. Neonates and infants, especially those in critical life conditions who are hospitalized in a PICU or NICU setting are highly affected by category 1 PUs, with a prevalence rate of $44 \%$ (NICU) and $46 \%$ (PICU), respectively. Hospitalized pediatric patients older than one year of age showed a PU prevalence rate of $26.5 \%$.

With regard to patient characteristics, children with a longer stay in hospital, very pre term neonates (24 to 32 weeks of gestation age) and infants between 31 and 90 days of age as well as infants between 7 and 12 months of age show the highest PU prevalence rates.

With regard to the localization of PUs in pediatric patients, the feet are the most common site, with $34 \%$ in children older than 1 year and $21 \%$ in neonates and infants. The nose is also a frequent localization in neonates and infants (16.2\%), whereas the area around any medical devices (like, tubes, iv boards/splints) in pediatric patients older than 1 year $(38.5 \%)$ is most frequent. 
Ventilation support devices more than double the risk of PUs in neonates and infants treated in a PICU, whereas limited mobility and activity and external devices are relevant risk factors in children older than 1 year.

Prevention of PUs starts with a risk assessment. Several PU risk assessment tools, mostly adapted from adult PU risk assessment are available for the pediatric setting. However, a systematic literature review revealed that no pediatric specific risk assessment tool can be recommended today. It is of great importance that risk assessment tools for the pediatric population should focus on specific pediatric risk factors like external devices, younger age (under the age of 5 years) and limited mobility.

Effective PU preventive measures in pediatric patients need to focus on the specific risk factors as well as on the localizations of PUs, which differ from those seen in adult patients. The preventive measures include regular head to toe skin assessment, including extra attention to the specific localizations of PUs in pediatric patients, regular repositioning of the patients, application of specific preventive measures like under-padding of devices and the regular as well as careful check whether a younger child ( $<5$ years) is not lying on a device or other object which may cause pressure on the skin.

With regard to category 1-4 PUs, a variety of wound care treatments are used in pediatric patients, with hydrocolloid dressings and ointments being used most frequently. No evidence based wound treatment guideline, meeting the unique needs of pediatric patients is available so far.

\subsubsection{Discussion of the main results with reliance to the literature}

\subsubsection{Prevalence of PUs}

The rather high prevalence of PUs in children makes it a relevant care problem for this target population. The overall prevalence figure of $35 \%$ is higher than figures already reported in the literature, which varied from 3\% (Dixon and Ratliff, 2005, McLane et al., 2004) to 28\% (Kottner et al., 2010). 
Pediatric patients hospitalized in the PICU setting were most often affected by a PU (44\%). This is in line with a prior study of Escher-Neidig et al. (1989), which assessed a PU prevalence of $40 \%$ in PICU patients after heart surgery. The prevalence rate in neonates and infants was $45.5 \%$. Prevalence rates for neonates and infants appear to vary between 26\% (McLane et al., 2004) and 61.5\% (Groeneveld et al., 2004).

Most pediatric patients are affected by a category $1 \mathrm{PU}$ and severe PUs are limited to older pediatric patients. Most category 1 PUs are reversible (Kottner 2011). Several authors have therefore recommended defining pressure ulcer prevalence by starting the category system at category 2 (Halfens et al., 2001, Defloor 1999), and to consider a category $1 \mathrm{PU}$ as the most important risk factor for developing a higher category of PUs (Defloor 1999, Noonan et al. 2011, Coleman et al., 2013). Following this line of reasoning would implicate that many pediatric patients are in fact at high risk.

Yet, the overall prevalence rate of category 2 and higher was only $3 \%$. This is lower than the prevalence of severe pressure ulcers in the study of Suddaby et al. 2003 and Groeneveld et al. 2004 (both 5.1\%) and also lower than the PU prevalence in the pilot study of Schlüer et al. (2009) (4.5\%) (Chapter 2). This means that the progression to a higher category PU in fact seems to occur rather infrequently.

Nevertheless the diagnosis of a category $1 \mathrm{PU}$ requires appropriate preventive intervention.

\subsubsection{Risk factors, localizations of PU, characteristics of patients showing a PU and risk assessment tools for the pediatric population}

The studies in this thesis have shown that the risk factors and the anatomical localizations of PUs, as well as the risk of PUs due to external devices, differ from those in an adult population.

Medical devices on the skin are the predominant risk factor for PU occurrence in pediatric patients. This finding is in line with prior studies (Willock et al., 2005, Escher-Neidig et a., 1989, Waterlow, 1997, Curley et al., 2003), where external 
devices were also the major risk factor in pediatric patients. With regard to neonates and infants, in whom mechanical ventilation support devices have shown to be the major risk factor, this was also reported in the studies of Schindler et al. (2007), Curley et al. (2003) and Boesch et al. (2012).

Younger age can also be considered as major PU risk factor in pediatric patients. In our studies neonates born at 24 to 31 weeks of gestation age, as well as neonates 1 to 7 days old and infants older than 7 months were mostly affected by PUs (Chapter 6). Pediatric patients of under the age of 2 years are also described as a risk group in the studies of Curley et al., (2003), Schindler et al., (2007); McCord et al., (2004), and Escher-Neidig et al., (1989). Due to their developmental status, young pediatric patients (under the age of five years) are, unable to differentiate pressure from other sensory perceptions of such devices properly and therefore are most vulnerable.

In pediatric patients older than 1 year PU risk assessment was carried out using the Braden scale (Schlüer et al., 2012, Schlüer et al., 2013b). Nutrition and activity were the subcategories, which were limited most in patients showing a PU. This had not been established in previous studies. With regard to activity, it seems logical that pediatric patients, who cannot actively change their position, are at risk for PU development. Nutrition is also known as a relevant factor with regard to skin integrity (Rodriguez-Key, 2007) in pediatric patients. No clinical trials investigating the influence of malnutrition in pediatric patients with regard to PU occurrence could be found. With regard to the fact that there is not a single risk factor, which can explain a PU risk in adult patients (Coleman et al., 2013), this seems also true for pediatric patients.

Regarding the localization of PUs, the feet and nose were the most commonly affected areas in pediatric patients. The feet, especially ankles or heels and toes, were also frequently affected areas in the study of Curley and colleagues (2003), as were the occiput and ear. A possible explanation for this is that in neonates and infants monitoring devices like oxygenation sensors and IV catheters are fixed to the feet of the child (Schlüer et al., 2009; Schlüer et al., 2012). PUs in the area of the nose are often caused by a nasogastric feeding tube, ventilation tube or by a CPAP mask with prongs (Schlüer et al., 2013c). 
Based on our systematic review we conclude that there is little evidence about the performance of PU risk assessment scales in pediatric practice (Kottner et al., 2013). On the basis of these sparse results and according to the findings of Anthony et al. (2010). Whether the application of PU risk scales makes any difference to PU occurrence in pediatric patients is unknown as well.

With regard to the risk factors established in this thesis, medical devices, especially mechanical ventilation support devices, a PICU stay, younger age and limited nutrition and activity were the major risk factors. In the development of risk assessment tools for the pediatric population, the risk factor "devices on the skin" has only become part of such scales since 1998 (Kottner et al, 2013). PICU stay and younger age as risk factors are not part of a pediatric risk assessment scale. We can conclude that the use of risk assessment scales in pediatric health care should focus specifically on external medical devices and on limited mobility and activity. Risk assessment scales for adults are not precise enough to cover all relevant pediatric risk factors. According to our findings, and in line with clinical expertise in the field of PU development in children, it is more reliable to focus on different pediatric risk populations, and also to assess device related factors contributing to the development of PUs.

\subsubsection{Prevention}

Preventive measures targeting medical devices are most frequently performed in pediatric patients to decrease the risk of PU occurrence (Schlüer et al., 2013c). This is in line with the fact that these devices are THE major risk factor for PU occurrence in pediatric patients and that pediatric patients treated in PICUs are a high-risk group.

To the best of our knowledge no study assessing preventive measures to decrease PU risk and prevalence in the pediatric population is available today.

Total skin assessment, repositioning and skin care were conducted frequently as preventive measures in our studies (Schlüer et al., 2013c). With regard to different skin condition in different age groups, like the immature skin of neonates (especially preterm neonates), regular head to toe skin assessment and 
appropriate skin care seem important as preventive measures to decrease PU risk in pediatric patients.

The use of pressure related surfaces is not very common in pediatric patients. Devices especially adapted to pediatric needs, like small sizes for lower weight, are not widely available (Parnham, 2012, Law, 2002).

Finally, no guidelines for effective PU preventive measures with special attention to the pediatric population and their unique risk factors in terms of PU occurrence are available so far.

\subsubsection{Treatment}

Data on the treatment of PUs in pediatric patients are presented in chapter seven. Severe PUs of category 2, 3 and 4 were mostly limited to older (over the age of eight years) pediatric patients, especially those with chronic conditions or after surgical interventions, especially orthopedic surgery.

Only a few research publications on the treatment of pediatric PUs could be found (Cisler-Cahill, 2006; Hoegeling et al, 2011). The use of any dressing in pediatric patients must rely on a clear goal for the intended treatment, with consideration of potential critical aspects like further harm or trauma. It remains a clinical challenge to use dressings which are both appropriate to the goal that has to be achieved in wound healing as well as to the specific pediatric needs, such as the different skin condition in different age categories, small body sites and active patients (Baharestani and Ratliff, 2007).

\subsection{Methodological aspects}

The methodological aspects of each study are discussed in the respective chapters. In general, the cross sectional design must be regarded as a limitation. Consequently, no causal relationships can be established related to PU 
development. This is important insofar as most of the PUs were assumed to develop due to external devices.

Yet, besides this overall limitation, the strengths of this thesis are connected with the careful planning of how the studies were conducted in all hospitals, the training of the raters by the principal investigator at all study sites and the careful and intense recruitment of the pediatric patients and their parents. The participation rate varied from sufficient $(43 \%)$ to excellent $(100 \%)$ and thus may be considered to reflect the population of pediatric patients in the German speaking part of Switzerland. The results are transferable to pediatric patients treated in hospitals with comparable standards of care and they establish the importance of PU prevention in daily pediatric care.

\subsubsection{The study sample}

The study sample involved all hospitalized children meeting the inclusion criteria on the day of the respective study measurements. All pediatric departments at the participating sites were included, involving children from departments like PICU, $\mathrm{NICU}$, all surgical disciplines, all pediatric medical disciplines as well as the departments for pediatric rehabilitation care.

About $70 \%$ of all participating patients were under the age of five years and $50 \%$ were younger than one year. This is representative for the population of pediatric patients in Switzerland (Kind \& Spital, 2011).

The recruitment of the study participants was mostly performed on the day prior to when the study was carried out by trained nurses, who also acted as raters. Study participation varied between $43 \%$ and $100 \%$ in the hospitals. Most drop-outs were due to parents/legal guardian and/or or children themselves refusing to participate (12\%). The participation rate in the PICU and NICU setting as well as in the neonatology departments was over $80 \%$. It can therefore be assumed that the information procedure by the nurses was adequate enough for the parents to decide on the participation of their child in the study. The information letter as well as the informed consent form for parents was available in eight different languages 
(German, French, Italian, English, Portuguese, Albanian, Serbian, Turkish). The drop-out rate due to language problems was only $0.5 \%$.

\subsubsection{Clinical research with children as participants}

Clinical research with children as participants involves several challenges and needs to protect the right of children of all ages as well as their right to independent decision-making (Knox and Burkhart, 2007, American Academy of Paediatrics (AAP), 1995). Informed consent must be obtained from the parent or guardian and also from the child who is able to read and understand an adapted version of the study information provided. In Switzerland this is defined as children older than 10 years of age (Schubiger et al., 2009). The recruitment of preterm neonates is even more challenging, due to the unexpected birth of a preterm neonate and due to the possibility that the baby needs special medical attention, because of a critical life condition after birth, and that the mother is not available for an information and informed consent (Pickler and Martin, 2010). To what extent this was a limitation in the study presented in chapter six remains unclear.

\subsubsection{Measurements tool}

To assess the prevalence, severity, as well as predisposing factors of pressure ulcers and to explore the prevention and treatment of PUs, the instrument and methodology of data collection of the Dutch National Prevalence Measurement Care Problems (LPZ) (Halfens et al., 2010) were used in this study. This instrument is widely used in Europe and has been shown to be reliable and valid. In addition to the original instrument, we also assessed all installations on the patient's body at the time of the assessment (e.g. tubes, IV catheterizations, continuous positive airways pressure (CPAP), splints). This was done, based on the findings of our earlier pilot study (Chapter 2) (Schlüer et al., 2009). 


\subsection{Implications for future research}

When researching PU related factors in the pediatric population our studies have revealed that (Schlüer et al., 2009, chapter 2, Schlüer et al., 2012, chapter 3) it is of great importance to use an adapted overall measurement tool (risk factors, preventive measures, prevalence and treatment) addressing the specific characteristics and needs of the pediatric population (Baharestani and Ratliff, 2007, Baharestani, 2007).

Therefore, based on the results and experiences of our studies, an adapted pediatric version of the LPZ PU measurement tool has been developed that will be tested for the first time in Switzerland in November 2013, when a nationwide pressure ulcer prevalence measurement will be conducted in all pediatric hospitals (Nationaler Verein zur Qualitätssicherung in Spitälern und Kliniken (ANQ) and Berner Fachhochschule (BFH), 2013).

Furthermore there is a need for more longitudinal research in this population to determine when, why and within which settings pediatric patients most often develop PUs. Future studies are also necessary to guide a trajectory towards an adapted and truly pediatric patient-oriented PU prevention and treatment. This will require adequately randomized controlled trials on the effect and process of tailored preventive interventions, including the use of appropriate risk assessment scales, and also on relevant PU treatment modalities, among which studies on the effect of different types of wound dressings.

\subsection{Implications for clinical practice}

Pediatric patients are vulnerable to PU development. It is vital that pediatric nurses are trained to recognize the early stages of pressure ulcers. Category 1 PUs are a major nursing care issue in neonates and infants, and require appropriate preventive measures to avoid any further harm to the vulnerable skin. Ventilation support devices greatly increase the risk of PUs in neonates and infants. Effective PU prevention includes device related under-padding and careful positioning and 
fixation of such devices. At least daily head-to-toe-skin assessment of neonates and infants at risk of PUs should be performed. Monitoring and regular repositioning of any monitoring sensors and cables should be conducted as well. Special attention should be paid to the fact that repositioning of the pediatric patient must be weighed against the stress that such an intervention can cause, especially in low- and very low-term neonates and critically ill infants.

This thesis shows that the risk factors, the anatomical localities of PUs as well as the risk of PUs due to external devices differ from those in an adult population. Therefore, specialized preventive interventions based on the specific needs of the pediatric population are mandatory, including a careful assessment of younger patients (under the age of five years) with regard to their inability to distinguish and sense pressure on the skin adequately.

Based on the systematic review of pediatric pressure ulcer risk assessment tools, no instrument can be regarded yet as superior to others. According to our findings, it is important to focus on different risk populations, such as children hospitalized in a PICU and very low term neonates.

Regarding the treatment of already present PUs, it remains a clinical challenge to use dressings which are both appropriate to the goal to be achieved in wound healing as well as to specific pediatric needs (e.g. being easy to apply and fitting small body sites like fingers and toes even in low term neonates). In addition, the choice of a dressing in children with PUs should be balanced and well documented as well as regularly evaluated.

Finally, there is an explicit need for evidence based pediatric specific guidelines on the prevention and treatment of PUs. 


\subsection{References}

American Academy of Pediatrics, Committee on Drugs. (1995). Guidelines for the ethical conduct of studies to evaluate drugs in pediatric populations. Pediatrics; 95 : 286- 294.

Anthony D, Willock J, Baharestani M. (2010). A comparison of Braden Q, Garvin and Glamorgan risk assessment scales in pediatrics. Journal of Tissue Viability; 19:98-105.

Baharestani MM. , 2007. An overview of neonatal and pediatric wound care knowledge and considerations. Ostomy Wound Management; 53: 34-6, 38, 40.

Baharestani MM, Ratliff CR. (2007). Pressure Ulcers in Neonates and Children: An NPUAP White Paper. Advances in Skin and Wound Care; 20: 208-220.

Boesch RP, Myers C, Garrett T, Nie A, Thomas N, Chima A, McPhail GL, Ednick M, Rutter MJ, Dressman K. (2012). Prevention of tracheostomy-related pressure ulcers in children. Pediatrics; 129: e792-e797.

Cisler-Cahill L. (2006). A protocol for the use of amorphous hydrogel to support wound healing in neonatal patients: An adjunct to nursing skin care. Neonatal Network; 25: 267- 273.

Coleman S, Gorecki C, Nelson EA, Closs SJ, Defloor T, Halfens R, Farrin A, Brown J, Schoonhoven L, Nixon J. (2013). Patient risk factors for pressure ulcer development: Systematic review. International Journal of Nursing Studies; 50 : 974-1003.

Curley MA, Quigley SM, Lin M. (2003). Pressure ulcers in pediatric intensive care: Incidence and associated factors. Pediatric Critical Care Medicine; 4: 284-290.

Dixon M, Ratliff C. (2005). Pediatric pressure ulcer prevalence- one hospital's experience. Ostomy Wound Management; 51: 44-46 \& 48-50.

Defloor T. (1999). The risk of pressure ulcer sores: a conceptual scheme. Journal of Clinical Nursing; 8: 206-216. 
Escher Neidig JR, Kleiber C, Oppliger RA. (1989). Risk factors associated with pressure ulcers in the Pediatric Patient following open-heart surgery. Progress in Cardiovascular Nursing; 4: 99-106.

Groeneveld A, Anderson M, Allen S, Bressmer S, Golberg M, Magee B. (2004). The prevalence of pressure ulcers in a tertiary care pediatric and adult hospital. Journal of Wound Ostomy Continence; 31: 108-122.

Halfens R, Meijers J, Neyens J. et al (2010). Available at:http://www.lpzum.eu/eng/about-lpz. Accessed 12 April 2013.

Halfens RJ, Bours GJ, Bronner CM. (2001). The impact of assessing the prevalence of pressure ulcers on the willingness of health care institutions to plan and implement activities to reduce the prevalence. Journal of Advanced Nursing; 36: 617-625.

Hoegeling M, Fardin SR, Frieden IJ, Wargon O. (2011). Forehead pressure necrosis in neonates following continuous positive airway pressure. Pediatric Dermatology; 29: 45-48.

Law J. (2002). Transair Paediatric Mattress replacement system evaluation. British Journal of Nursing; 11: 343-346.

Kind \& Spital (2010). Positionspapier zur Einführung von Swiss DRG. Available at: www.kindundspital.ch, accessed 12.05.2013.

Knox CA, Burkhardt PV. (2007). Issues Related to Children Participating in Clinical Research. Journal of Pediatric Nursing; 22: 310-318.

Kottner J, Hauss A, Schlüer AB, Dassen T. (2013). Validation and clinical impact of pediatric pressure ulcer risk assessment scales: A systematic review. International Journal of Nursing Studies; 50: 807-818.

Kottner J. (2012). Was sind Dekubitus? in Schröder G, Kottner J. (2012). Dekubitus und Dekubitusprophylaxe. Hans Huber, Bern.

Kottner J, Wilborn D, Dassen T. (2010). Frequency of pressure ulcers in the pediatric population: a literature review and new empirical data. International Journal of Nursing Studies; 47: 1330-1340. 
McLane KM, Bookout K, McCord S, McCain J, Jefferson LS. (2004). The 2003 national pediatric pressure ulcer and skin breakdown prevalence survey. Journal of Wound Ostomy Continence; 31: 168-178.

McCord S, McElvain V, Sachdeva R, Schartz P, Jefferson LS. (2004). Risk factors associated with pressure ulcers in the pediatric intensive care unit. Journal of Wound Ostomy Continence; 31: 179-183.

National Pressure Ulcer Advisory Panel (NPUAP) and European Pressure Ulcer Advisory Panel (EPUAP). Prevention and treatment of pressure ulcers: clinical practice guideline. National Pressure Ulcer Advisory Panel, 2009, Washington DC.

Nationaler Verein zur Qualitätssicherung in Spitälern und Kliniken (ANQ), Berner Fachhochschule (BFH). Nationale Prävalenzmessung Sturz und Dekubitus vom 5. November 2013 (2013). Available at: www.anq.ch. Accessed: 30.5.2013.

Noonan C, Quigley S, Curley MA. (2011). Using the Braden Q Scale to Predict Pressure Ulcer Risk in pediatric patients. Journal Pediatric Nursing; 26: 566-575.

Parnham A. (2012). Pressure ulcer risk assessment and prevention in children. Nursing Children and Young People; 24: 24-29.

Pickler RH, Martin AT. (2010). Protection of children in research. Journal of Pediatric Health Care; 24: 66-68.

Rodriguez-Key M, Alonzi A. (2007). Nutrition, skin integrity and pressure ulcer healing in chronically ill children: An overview. Ostomy Wound Management; 53: 56-66.

Schindler CA, Mikhailov TA, Fischer K, Lukasiewicz G, Kuhn EM, Duncan L. (2007). Skin integrity in critically ill and injured children. American Journal of Critical Care; 16: 568-574.

Schlüer AB, Schols JMGA, Halfens RJ. (2013b). Risk and associated factors of pressure ulcers in hospitalized children over 1 year of age. Submitted to the Journal for Specialists in Pediatric Nursing. 
Schlüer AB, Halfens RJ, Schols JMGA. (2013c). Pressure ulcers in hospitalized neonates and infants; prevalence, risk factors, preventive measures. Submitted to the Journal Nursing in Critical Care.

Schlüer AB, Halfens RJ, Schols JMGA. (2012). Pediatric Pressure Ulcer Prevalence: A Multicenter, Cross-Sectional, Point Prevalence Study in Switzerland. Ostomy Wound Management; 58: 18-31.

Schlüer AB, Cignacco E, Müller M, Halfens R. (2009). The Prevalence of Pressure Ulcers in Four Pediatric Institutions. Journal of Clinical Nursing; 18: 3244-3252.

Schubiger G, Salathé M, Pfiffner D. (2009). Forschung an und mit Kindern und Jugendlichen $<18$ Jahren. Available at:

http://www.swissethics.ch/doc/templates/AGEK_KinderChecklliste_Ver4.1_d.pdf, accessed: 30.5.2013.

Waterlow J. (1997). Pressure sore risk assessment in children. Pediatric Nursing; 9: 21-24.

Willock J, Askew C, Bolland R, Maciver H, James N. (2005). Multicenter research: lessons from the field. Pediatric Nursing; 17: 31- 33. 



\section{Summary}

Pressure ulcers are a common and highly relevant nursing care problem in hospitals. They are associated with psychological and physical suffering, increased morbidity and mortality rates and higher costs for health care worldwide. Pressure ulcer development can be attributed to multiple factors that are fairly well-studied in adults and elderly people. While the problem of pressure ulcers in adults has received a great deal of attention, far less is known about pressure ulcers in children and neonates. With regard to pediatric care settings, some challenges remain. The overall health status of hospitalized children is generally better and multi-morbidity is limited to a small percentage of patients, such as very low term neonates (born before 32 weeks of gestation age), newborns with congenital abnormalities and children with chronic conditions. Survival rates of both critically and chronically ill neonates, infants and children have improved dramatically in recent years. This fact introduces new challenges for medical and nursing care for these patients.

Children's skin undergoes several changes throughout the first 18 years of life. Within the first days of life neonates undergo various adaptation processes needed to accommodate to the transition from the wet intrauterine environment to the dry outside environment. During the first months and years the skin continues to develop and evolve its structure and functions. It is known that any skin breakdown, especially in critically ill neonates and infants, increases the risk of septicemia as well as related severe complications and higher mortality. Pressure ulcers also cause an increase in pain, infection and calorie expenditure in pediatric patients, and therefore it is of great importance to avoid any damage to the fragile skin of pediatric patients.

With regard to pressure ulcer risk factors in pediatric patients, immobility and decreased skin sensitivity are known. Sick children in general and - due to their limited communication skills - neonates, infants and toddlers, disabled and neurologically impaired children in particular, seem to be at high risk of developing pressure ulcers. Despite the known risk factors, a reliable and valid pressure ulcer risk assessment tool with validated cut-off points, applicable to a wide range of the juvenile population from neonates to adolescents, is not available. 
Pressure ulcer prevention is multifaceted and requires skills, knowledge and consistency in nursing practice. Risk assessment, skin assessment, repositioning and pressure relief are integral components of effective prevention of pressure ulcers in children. The preventive measures taken for children are often those recommended for adult patients. However, several authors have highlighted the importance of specific age-related preventive strategies. Preventive measures should meet the individual needs of each child, and special attention must be paid to neonates and infants. The same is true when it comes to pressure ulcer treatment. No specific guideline for wound treatment of pediatric pressure ulcer wounds is available today.

There is a considerable lack of knowledge with regard to the problem of pressure ulcers in pediatric patients. This thesis, entitled "Pressure ulcers in pediatric patients: a challenge!" presents different aspects of the problem of pressure ulcers in pediatric patients.

The introduction in Chapter one presents the scope of the topic. It first provides insight into the topic of pressure ulcers and highlights the unique needs of pediatric patients of all ages with regard to this issue.

Chapter two presents the results of the first pilot study on pressure ulcer prevalence in four Swiss pediatric hospitals. This study reveals a high prevalence rate of $27.7 \%$. The prevalence of pressure ulcers category 2 and higher accounts for only $4.5 \%$. Although not all pressure ulcers are preventable, the high prevalence rates indicate a need to improve preventive actions as well as risk assessment and to start raising staff's awareness of the pressure ulcer issue in the pediatric health care setting. This study marks an important first step in recognizing the relevance of the pressure ulcer issue in the pediatric health care setting.

In Chapter three the results of a multicenter point prevalence pressure ulcer study conducted in all pediatric hospitals of the German speaking part of Switzerland are described. The study reveals a very high pressure ulcer prevalence rate of $35 \%$ in the 14 Swiss pediatric hospitals. However the prevalence rate of category 2 and higher is only $3 \%$. Especially the age of the patients, the Braden risk score for pressure ulcer development as well as the institution in which the patients were 
hospitalized appear to be related to the development of pressure ulcers. The most frequently affected patient group in this study involved very young patients in the Pediatric Intensive Care Unit setting showing mostly category 1 pressure ulcers. The pressure ulcer prevalence of nearly $45 \%$ in this patient group and the figure of $60 \%$ being at risk is disconcerting and needs special attention. Patients in the Neonatal Intensive Care Unit setting also show an overall prevalence of nearly $45 \%$. Children treated in a Neonatal Intensive Care Unit or/and Pediatric Intensive Care Unit care setting are mostly vulnerable due to several factors like the immaturity of the skin in very young neonates and newborns and also because of anatomical, physiological and immunological differences. In general these children are in a critical clinical condition and often undergo lifesaving treatments. If one takes into consideration that in these patients often many external medical devices are applied which might affect the skin, the high vulnerability to getting a pressure ulcer seems feasible. In view of this and the findings presented in this study, the question arises whether in the pediatric population a prevalence rate for children with and without external medical devices like tubes and fixation devices might be an important marker. Further, it highlights the importance of evidence based pressure ulcer prevention in these patients.

Chapter four presents a systematic review in which the validation and clinical impact of pressure ulcer risk assessment tools used in pediatric care settings is explored. Over the last five decades more than 30 standardized pressure ulcer risk scales for adults have been developed, tested and modified. A total of 12 pediatric specific risk assessment tools were identified. Many of them are modifications of pressure ulcer risk scales for adults and contain variables deemed especially important for pressure ulcer development in the adult population, e.g. continence, moisture, nutrition. "Mobility" was part of every scale. Assessing the degree of mobility to determine pressure ulcer risk in children seems reasonable, because the relation between mobility and pressure ulcer development is well established. On the other hand, it should be noted that there are only a few studies investigating specific factors for pressure ulcer development in the pediatric population. Although long known to be a problem in infants and children, the risk factor "devices on the skin" has only been considered in the newer scales since 1998. The degree of validation of these risk assessment tools is poor. Five studies provided evidence about interrater reliability and the agreement of four 
instruments. Besides the discussed validity and reliability aspects, the question arises if it is feasible to develop a pressure ulcer risk scale covering all the necessary aspects of the whole pediatric population. Considering the immaturity as well as the anatomical, physiological and immunological differences and vulnerability of this population's skin and tissues, especially during the neonatal period, it is clear that pressure ulcer risk profiles vary across the different age groups.

Chapter five focuses on certain risk factors and prevalence among hospitalized pediatric patients over one year of age. In this study hospitalized pediatric patients older than one year showed a pressure ulcer prevalence rate of $26.5 \%$. These patients present with several factors that may lead to the development of a pressure ulcer. First of all the presence of medical devices seems to be a particular risk factor in all age categories. Second, in these patients limited activity and mobility appeared to be particular risk factors as well. The most affected anatomical region for the development of a pressure ulcer was the lower extremity especially the foot. Older patients over the age of 12 years showed slightly more frequent pressure ulcers (32\%) than children under the age of eight years. Patients hospitalized in the Pediatric Intensive Care Unit setting were most often affected by a pressure ulcer (40\%).

Most of the pressure ulcers assessed in this study developed due to external devices (38.5\%). Young pediatric patients (under the age of five years) are, due to their developmental status, unable to differentiate pressure from other sensory perceptions of such devices properly and are therefore mostly vulnerable. Equipment-related risk factors, e.g. those connected with traction, tubes and IV catheterization, are therefore additional potential pressure ulcer risk factors in the pediatric health care setting. This is also in line with the fact that the most frequent localization of a pressure ulcer was the lower extremities, especially the feet $(40 \%)$. The reason for this might be the fact that the majority of pressure ulcers were developed because of splints/iv boards or cables and sensors, as well as IV catheterization used at this anatomic site.

In Chapter six the prevalence, risk factors and preventive measures in hospitalized neonates and infants in all 14 hospitals of the German speaking part of Switzerland are presented. In this study the pressure ulcer prevalence rate 
(categories 1-4) in neonates and infants was high, with an overall prevalence of $45.5 \%$; yet the pressure ulcer prevalence rate for more severe pressure ulcers (categories 2-4) was low, at $0.5 \%$. Ventilation support devices such as Continuous Positive Airways Pressure or mechanical ventilation increased the risk of pressure ulcers more than twofold. Total skin assessment (66.5\%), repositioning (68.1\%) and skin care $(50 \%)$ were conducted most frequently as preventive measures. In the literature it is suggested that a category 1 pressure ulcer can serve as an indication of being at risk for a category 2 to 4 pressure ulcers. When a category 1 pressure ulcer occurs, preventive measures are necessary. In our study only one infant developed a pressure ulcer higher than category 1, which makes it questionable whether a category 1 pressure ulcer is a good indication of additional risk in this population. According to the localization of the pressure ulcers, the feet and nose were the most commonly affected areas in this study sample. Regarding the feet, especially the ankles, heels and toes, were frequently affected areas and regarding the head, next to the nose also the occiput and ear. A possible explanation for this is that in neonates and infants monitoring devices like oxygenation sensors and IV catheters are fixed to the feet of the child, and therefore this localization can also be affected by medical device related pressure ulcers. Pressure ulcers in the area of the nose are often caused by a nasogastric feeding tube, ventilation tube or by a Continuous Positive Airways Pressure mask with Prongs. It is therefore of great importance to pay special attention to the careful application of ventilation support devices, and to the careful fixation and regular repositioning of any devices in neonates and infants in order to decrease the pressure ulcer risk.

In Chapter seven pediatric specific topics with regard to pressure ulcer wound treatment are highlighted. The results revealed a range of different treatments primarily related to differences in severity and location. Most of the category 1 pressure ulcers are not treated with a wound dressing, since in category 1 pressure ulcers the skin is still intact. The nonuse of any dressing in category 1 pressure ulcers makes it possible to recognize any changes in these ulcers quickly and easily. In addition, it is very important to carry out appropriate preventive interventions in pediatric patients with a category 1 pressure ulcer to avoid any further trauma to the skin. The use of any dressing in pediatric patients with higher categories of pressure ulcers must rely on a clear goal for the intended treatment. 
In addition, any dressing use in pediatric patients must protect the skin from further harm, like epidermal stripping.

In Chapter eight the main findings of all studies conducted are presented. The core of this chapter encompasses the general discussion of the study results as well as their consequences for clinical practice and further research in this field. Furthermore it highlights methodological aspects, including the ethical topic of clinical research in which children are participants.

Pediatric patients of all ages are beyond doubt at risk of developing a pressure ulcer. Evidence based guidelines for effective pressure ulcer prevention and treatment in pediatric patients are mandatory, taking into account their unique needs. Health care staff has to be aware of pediatric specific risk factors for pressure ulcer development, like the application of external devices. In addition, adequate preventive and treatment measures have to be taken and monitored regularly. 


\section{Samenvatting}

Decubitus is een algemeen voorkomend en uiterst relevant verpleegkundig probleem in ziekenhuizen. Het wordt geassocieerd met psychisch en fysiek lijden, een grotere morbiditeit, hogere mortaliteitscijfers en wereldwijd hogere uitgaven voor gezondheidszorg. Het ontstaan van decubitus kan worden toegeschreven aan meerdere factoren die zowel bij volwassenen als ouderen redelijk goed zijn onderzocht. Echter, terwijl het probleem van decubitus bij volwassenen veel aandacht heeft gekregen, is beduidend minder bekend over decubitus bij kinderen en pasgeborenen. Wat betreft de pediatrische zorg resten er derhalve nog wel enige uitdagingen. De algehele gezondheid van gehospitaliseerde kinderen is in het algemeen goed, maar de multi-morbiditeit is beperkt tot een klein percentage van de patiënten, zoals zeer vroeg geborenen (vroeger dan 32 weken in de zwangerschapsperiode), pasgeborenen met congenitale afwijkingen en kinderen met chronische aandoeningen. De overlevingscijfers van zowel kritieke als chronisch zieke pasgeborenen, zuigelingen en kinderen zijn de laatste jaren sterk toegenomen. Dit brengt echter nieuwe uitdagingen met zich mee bij de medische en verpleegkundige zorg voor deze patiënten.

De kinderhuid ondergaat meerdere veranderingen gedurende de eerste 18 levensjaren. De eerste levensdagen maken pasgeborenen verschillende processen door om zich aan te passen aan de overgang van de vochtige intrauterine naar de droge omgeving daarbuiten. Gedurende de eerste maanden blijft de huid zich vervolgens qua structuur en functies ontwikkelen. Het is bekend dat elk huidprobleem, vooral bij pasgeborenen en zuigelingen in kritieke toestand, het risico op sepsis, bijkomende ernstige complicaties en een hogere mortaliteit kan vergroten. Ook decubitus veroorzaakt pijn, infecties en hoger calorieverbruik bij pediatrische patiënten en derhalve is het van groot belang om enigerlei beschadiging van de fragiele huid bij deze patiënten te voorkomen.

Wat betreft de risicofactoren van decubitus bij pediatrische patiënten zijn immobiliteit en verminderde sensitiviteit van de huid goed bekend. Zieke kinderen in het algemeen en pasgeborenen, zuigelingen, peuters alsmede (neurologisch) gehandicapten in het bijzonder, lijken door hun beperkte 
communicatievaardigheden een grote kans op het ontwikkelen van decubitus te hebben.

Echter, ondanks de bekende risicofactoren is een betrouwbaar en geldig decubitus-risico assessment instrument met vastgestelde grenswaarden, dat toepasbaar is bij jongeren, variërend van pasgeborenen tot adolescenten, niet beschikbaar.

Decubituspreventie heeft vele facetten en vereist vaardigheid en kennis bij de verpleging. Een goede risicoanalyse, regelmatige inspectie van de huid, wisselligging en verminderen van druk zijn ook onderdelen van decubituspreventie bij kinderen. Deze preventieve maatregelen die bij kinderen worden genomen, zijn vaak dezelfde als die welke worden aanbevolen bij volwassen patiënten. Verschillende auteurs hebben ook het belang van specifieke, leeftijdsgerelateerde preventiestrategieën belicht. Preventieve maatregelen dienen daarbij tegemoet te komen aan de individuele behoeften van elk kind en bijzondere aandacht moet uitgaan naar pasgeborenen en zuigelingen. Hetzelfde geldt voor de behandeling van decubitus. $\mathrm{Er}$ is momenteel nog geen specifieke richtlijn voor de decubitusbehandeling bij kinderen.

Er bestaat ook nog een groot gebrek aan kennis over decubitus bij pediatrische patiënten. Dit proefschrift, getiteld "Decubitus bij pediatrische patiënten: een uitdaging!" toont verschillende aspecten van het decubitusprobleem bij pediatrische patiënten.

De inleiding in Hoofdstuk 1 beschrijft het onderzoeksterrein. Inzicht wordt geboden in het onderwerp decubitus en in de unieke behoeften van pediatrische patiënten van alle leeftijden met betrekking tot dit zorgprobleem.

Hoofdstuk 2 presenteert de resultaten van het eerste vooronderzoek over de prevalentie van decubitus in vier Zwitserse pediatrische ziekenhuizen. Deze studie laat een hoge prevalentiegraad van $27,7 \%$ zien. De prevalentie van decubituswonden categorie 2 en hoger is echter slechts $4,5 \%$. Ofschoon niet alle decubitus valt te voorkomen, is het prevalentiecijfer van $27,5 \%$ toch een aanwijzing voor het feit dat de decubituspreventie beter kan. Deze begint met de bewustmaking bij het personeel in de pediatrische verpleging. Deze studie 
markeert ook een eerste belangrijke stap in de erkenning van het belang van het onderwerp decubitus in de pediatrische verpleegkunde.

In Hoofdstuk 3 worden de resultaten van een multicenter prevalentiestudie getoond, die in alle pediatrische ziekenhuizen van het Duitstalige deel van Zwitserland is uitgevoerd. De studie laat een zeer hoge decubitusprevalentiegraad van $35 \%$ in de veertien deelnemende Zwitserse pediatrische ziekenhuizen zien. De prevalentie van decubitus categorie 2 en hoger is opnieuw laag met $3 \%$. De leeftijd van de pediatrische patiënten, de Braden risicoscorelijst voor het ontwikkelen van decubitus en de instelling waar de patiënten zijn opgenomen lijken met name gerelateerd te zijn aan het ontwikkelen van decubitus. De meest getroffen patiëntengroep in deze studie betrof de zeer jonge patiënten in pediatrische intensive care units, die overigens overwegend decubituswonden categorie 1 vertoonden. De prevalentie van decubitus van bijna $45 \%$ in deze patiëntengroep alsmede het percentage van $60 \%$ dat een risico op decubitus heeft is verontrustend en vraagt om extra aandacht. Onder patiënten in neonatale intensive care units is de decubitusprevalentie ook bijna $45 \%$. Kinderen die worden behandeld in neonatale en/of pediatrische intensive care units zijn inderdaad bijzonder kwetsbaar door verschillende factoren, zoals de immaturiteit van hun huid en andere anatomische, fysiologische en immunologische verschillen. Bovendien verkeren deze kinderen vaak in een kritieke klinische toestand en zijn niet zelden levensreddende behandelingen aangewezen. Als men dan in ogenschouw neemt dat bij deze patiënten vaak veel externe medische hulpmiddelen en apparatuur wordt toegepast, waarmee zij via draden, slangen etc. verbonden zijn, die vanwege hun directe fixatie aan de huid tot huidletsel kunnen leiden, is de grote kwetsbaarheid voor het krijgen van decubitus plausibel. Door dit aspect en de resultaten van deze studie rijst de vraag of we specifiek bij de pediatrische populatie moeten kijken naar de decubitusprevalentie bij kinderen met en zonder externe medische hulpmiddelen met gebruik van, draden, slangen en andere fixatiemiddelen. Verder benadrukt een en ander het belang van doelgerichte decubitus-preventie bij deze patiënten.

Hoofdstuk 4 beschrijft een review over de validatie en klinische invloed van decubitusrisicoscorelijsten in de pediatrische zorg. Gedurende de laatste vijf decennia zijn meer dan 30 gestandaardiseerde risicoschalen voor decubitus bij 
volwassenen ontwikkeld, getest en aangepast. In totaal zijn er 12 specifieke pediatrische risicoscorelijsten vastgesteld. Vele hiervan zijn modificaties van decubitusrisicoscorelijsten voor volwassenen en bevatten variabelen die vooral van belang zijn bij de ontwikkeling van decubitus bij volwassenen, bijvoorbeeld incontinentie, vochtigheid en voeding. Het item "mobiliteit" maakt deel uit van elke schaal. Het vaststellen van de mate van mobiliteit om de kans op decubitus bij kinderen te meten, lijkt overigens redelijk, omdat de relatie tussen mobiliteit en het ontwikkelen van decubitus algemeen aanvaard is. Aan de andere kant moet worden opgemerkt dat er slechts enkele studies bestaan die de specifieke factoren voor het ontwikkelen van decubitus bij kinderen onderzoeken. Ofschoon het een bekend probleem bij zuigelingen en kinderen is, wordt de risicofactor "medisch materiaal dat contact maakt met de huid" slechts in de nieuwere schalen vanaf 1998 meegenomen. De mate van validatie van deze risicoscorelijsten is nog gering. Vijf studies toonden de inter-rater betrouwbaarheid en overeenstemming bij vier instrumenten aan. Naast de besproken validiteits- en betrouwbaarheidsaspecten doet zich ook de vraag voor of het haalbaar is om een decubitusrisicoschaal te ontwikkelen die alle daartoe benodigde aspecten van de gehele pediatrische populatie omvat. Gezien de immaturiteit, de anatomische, fysiologische en immunologische verschillen en ook de kwetsbaarheid van de huid en de weefsels bij deze populatie tijdens met name de neonatale periode, is het duidelijk dat decubitusrisicoprofielen voor de verschillende leeftijdsgroepen pediatrische patiënten uiteenlopen.

Hoofdstuk $\mathbf{5}$ is gericht op de risicofactoren en de prevalentie van decubitus bij gehospitaliseerde pediatrische patiënten ouder dan één jaar. In deze studie vertoonden gehospitaliseerde pediatrische patiënten boven één jaar een decubitus-prevalentie van $26,5 \%$. Bij deze patiënten zijn er verschillende factoren die tot de ontwikkeling van decubitus kunnen leiden. Allereerst lijkt de aanwezigheid van medische hulpmiddelen opnieuw een bijzondere risicofactor te zijn. Ten tweede blijken bij deze patiënten de beperkte activiteit en mobiliteit eveneens relevante risicofactoren te zijn. De meest aangedane anatomische zone waren de lagere extremiteiten, in het bijzonder de voet. Patiënten ouder dan 12 jaar vertoonden iets vaker decubitus (32\%) dan kinderen onder de acht jaar. Patiënten die gehospitaliseerd waren in pediatrische intensive care units hadden het meest te maken met decubitus (40\%). 
De vastgestelde decubitus had zich overwegend door externe invloeden ontwikkeld (38,5\%). Jonge pediatrische patiënten (onder de vijf jaar) zijn door hun ontwikkelingsstatus niet goed in staat om druk van andere sensorische waarnemingen te onderscheiden en daardoor extra kwetsbaar. Hulpmiddelgerelateerde risicofactoren, waaronder tractie, gebruik van slangen en IVkatheterisatie, zijn zodoende extra potentiële risicofactoren voor decubitus in de pediatrische zorg voor deze groep. Dit sluit ook aan bij het feit dat de meest voorkomende locatie van decubitus de lagere extremiteiten zijn, in het bijzonder de voeten (40\%). De meerderheid van de decubitus-gevallen deed zich voor door splints/IV-boards of snoeren en sensoren, evenals IV-katheterisatie die op deze anatomische plaats worden toegepast.

In Hoofdstuk 6 worden de prevalentie van decubitus en de gerelateerde risicofactoren en preventieve maatregelen bij gehospitaliseerde pasgeborenen en zuigelingen gepresenteerd van alle 14 ziekenhuizen van het Duitssprekende deel van Zwitserland. In deze studie was de decubitusprevalentie (categorie 1-4) bij pasgeborenen en zuigelingen hoog, met een gemiddelde prevalentie van 45,5\%. Niettemin was de prevalentie van de ernstigere vormen van decubitus (categorie 2-4) laag met $0,5 \%$. Beademingsapparatuur zoals Continuous Positive Airways Pressure (CPAP) apparatuur of mechanische beademing verdubbelden het risico op decubitus ruim. Regelmatige huidinspectie $(66,5 \%)$, wisselligging $(68,1 \%)$ en huidverzorging $(50 \%)$ werden het vaakst uitgevoerd als preventieve maatregelen. In de literatuur wordt gesuggereerd dat categorie 1 decubitus een indicator kan zijn voor het risico op een categorie 2 tot 4 decubitus. Als zich een categorie 1 decubitus voordoet, zijn preventieve maatregelen derhalve noodzakelijk. In onze studie ontwikkelde echter slechts één zuigeling een decubitus hoger dan categorie 1 , hetgeen het twijfelachtig maakt of een categorie 1 decubitus een goede indicator is van een extra risico bij deze populatie. Ten aanzien van de lokalisatie van decubitus bleken de voeten en neus de meest aangedane lichaamsdelen. Wat de voeten betreft waren vooral enkels of hielen en tenen vaak aangedaan; wat betreft het hoofd vooral, naast de neus vooral ook het achterhoofd en oor. Een mogelijke verklaring is dat bij pasgeborenen en zuigelingen allerlei bewakingsapparatuur zoals oxygenatie-sensoren en IV-catheters aan de voeten worden bevestigd. Het is dus van groot belang om bijzondere aandacht te besteden aan de zorgvuldige toepassing van beademing ondersteunende 
apparaten alsmede te zorgen voor een voorzichtige fixatie en het regelmatig repositioneren van hulpmiddelen bij pasgeborenen en zuigelingen teneinde de kans op decubitus te verkleinen.

In Hoofdstuk 7 worden specifieke pediatrische aspecten belicht inzake de behandeling van decubituswonden. De resultaten laten een reeks verschillende behandelingen zien, vooral gerelateerd aan de ernst of de locatie van de decubitus. Categorie 1 decubitus wordt meestal niet behandeld met een wondverband, omdat in categorie 1 decubitus de huid nog intact is. Het achterwege laten van een verband bij een categorie 1 decubitus maakt het goed mogelijk om verdere veranderingen in de huid snel en makkelijk te herkennen. Daarnaast is het uiterst belangrijk om bij deze wonden passende preventieve maatregelen te nemen om verder trauma van de huid te vermijden. Het gebruik van wondverbanden bij pediatrische patiënten met hogere decubitus-categorieën hangt af van het gespecificeerde doel bij de voorgenomen behandeling. Tevens moet het gebruik van een wondverband bij pediatrische patiënten de huid beschermen tegen verdere verwonding.

In Hoofdstuk 8 worden de voornaamste resultaten van alle uitgevoerde studies gepresenteerd. De kern van dit hoofdstuk omvat de algemene bespreking van de studieresultaten evenals hun consequenties voor klinische toepassing en verder (veld) onderzoek. Tevens belicht het hoofdstuk de methodologische aspecten inclusief het ethische vraagstuk van klinisch onderzoek waarin kinderen participeren.

Duidelijk is geworden dat pediatrische patiënten van alle leeftijden een risico lopen om decubitus te ontwikkelen. Goede richtlijnen voor effectieve decubituspreventie en behandeling bij pediatrische patiënten zijn nodig, gezien hun unieke behoeften. Verpleegkundig personeel dient zich bewust te zijn van de pediatrisch-specifieke risicofactoren voor de ontwikkeling van decubitus, waaronder met name het gebruik van externe hulpmiddelen. Daarnaast moeten uiteraard relevante en kindvriendelijke preventieve en curatieve maatregelen genomen worden met secundaire monitoring van hun effect. 


\section{Acknowledgement}

I would like to thank, with my deepest gratitude, the many people and institutions that have supported this project and helped me in researching and writing this dissertation. In the first place I would like to thank all the pediatric patients and their families. Without their active participation, this study would not have been possible.

Fritz, right at the beginning of our relationship I started my academic nursing career. You as an advanced student in this field inspired me to go on with this study. Since then we have shared a lot of experiences, academic and nonacademic; we have achieved the balance of work and life. We spend evenings and nights in front of computers, always knowing that the other one is here. My most important thanks is for you, for the years of our relationship, for all the human and scientific support, for the personal encouragement and your faith in my competences and skills.

Paula Sofia, Emilia Mathilda, Juliana Margeritha and Olivia Theodora, you are the most beautiful daughters I could ever imagine. Over all this time all of you brought me immediately back to the relevant aspects of daily life. Spending time with you is a pleasure, a gift and a preventive, too. I thank you all for your smiles, thoughts and ideas, you surely make my life rich and unique.

Jos MGA Schols and Ruud JG Halfens, you are both wonderful promoters and copromoters. You have supported the process of my work and studies and also cared for me as a person and for my family. Your consulting on my studies, methodological aspects and the manuscript was always very quick, very profound and enriched my work. You both always brought new ideas and insights to discuss and to clarify. Thank you for all the time you spent with me or on me and for my thesis, and for both being the most reliable persons I can imagine in such a process. Thank you for all your emails from wherever in the world you might be; I appreciated your quick response to any question to bring light into the darkness and your constant belief in me. 
Andrea Ullmann-Bremi, thank you for the way we worked together at the Kinderspital Zurich. Since we first met I liked your way of discussion, of being almost visionary in believing in the ability of people. It was and always will be a pleasure to work together with you and I really appreciate every single minute with you. This last year was not an easy one for you. But still along with your own fight for health you still were always thinking of me, and for that l'm most grateful. Thank you for your support, for believing in me, for letting me do it my way and for always having an open ear to listen.

Yvonne Huber, I'm most grateful to have you as the nursing director of the Kinderspital Zurich. To experience the vision and enthusiasm of a powerful and independent but most professional and proud nurse is very stimulating. Thank you for all your support, your open door, your ideas and your continued fight for this wonderful and important job of nursing. Thank you for always believing in me, in my potential, in my strength.

Iris Zikos, thank you for giving me the opportunity to get knowledge and insight into the care of pediatric burns. With your openness and criticism but also curious interest you gave me all your support on my way to nursing science. I will never forget that morning after a night shift, when you came to work and I surprised you with the idea of starting a master's study the following month. Right from the beginning you were open and interested and always there to find a solution. I appreciated the way we could work together the last ten years and look forward to all our projects that lie in future.

A special thanks goes to all my colleagues of the team of nursing development at the Kinderspital Zurich, namely Marlis Pfändler-Poletti, Maria Flury, Brigitte Seliner, Judith Wieland, Gaby Stoffel, Elfriede Natterer. Thank you for all your understanding when I was not available for your time frames. Thank you for all the interest you showed in my studies, your support, your critical thinking. It is a pleasure to work with you in a team and to live enthusiasm for the nursing profession together. 
Eva Cignacco, thank you for always believing in me. You are an inspiring person with very high expectations to yourself. This was and always will be an incentive for me in my work. I really appreciate the fact that you accompanied me on this journey right from the beginning until now. I appreciate that I can profit and learn from your experience; discussion with you is always very stimulating but also enriching.

I would like to thank the head nurses and nursing directors of all the Swiss pediatric hospitals in the German speaking part for their interest, their support and their approval to my study interest. Without your support this project would never have been possible to realize. Getting insight into the topic of pressure ulcers is a real problem in the pediatric care setting, so therefore I'm most grateful to all of you. Besides that my thanks goes to all the study nurses in each setting for your support, your time, your critical reflection and also your interest. All of you did a wonderful job, bringing the topic into your teams and wards, supporting me in getting access to the clinics and patients. You spent time with me, your ideas were always inspiring and all of you really enriched this work.

Sincere thanks also go to Mrs. Marianne Wietlisbach, who organized and realized the translation of the parent information and informed consent, and to all raters for their interest and engagement.

I would like to thank all my colleagues from the academic association of pediatric nursing in Switzerland, the colleagues from the network of clinical nurse specialists in pediatric nursing and all the staff members of the Kinderspital Zurich for the everyday support, interest and motivation that I get from your experience at the bedside and every day nursing care. In this field I would like to specially thank Veronica Cortés, clinical nurse specialist at the Pediatric Burn Center for having a happy and open minded but also very direct way of communicating and always thinking of me and my family. Johanna Degenhardt, clinical nurse specialist at the Pediatric Intensive Care Unit, for letting me know about all the differences in mechanical ventilation techniques, always working with enthusiasm and power to make better prevention possible in everyday care in the PICU setting and for being most sincere and human. Thanks also to Bettina Hafner and Jacqueline Wrobel, my new partners at the wound consulting service for supporting me in daily business, for believing in me and for sharing my passion and enthusiasm about 
pediatric wound care. I appreciate it very much to have you as my team and am looking forward to all our future projects and progress together.

And a very special thanks goes to Mrs. Heather Murray for her hours of proofreading this thesis, spending hours within my domain of work, and for her readiness to help me finish everything in time.

I would like to thank Mrs. Maude Rivière for taking time to read my thesis, giving me real external feedback. I would like to thank Mrs. Barbara Simpson and Mr. André Rüegger for the thorough compilation and formatting of the whole manuscript in a very short time. I thank Dave Siddiqui for his support in editing the dutch summary.

And always with gratitude and recognition, to my parents Ruth and Ulrich Schlüer. I learned from them that it is worthwhile believing in one's own possibilities, in one's own strength and potential. I learned from you to reflect and think critically and that everything is possible if you do it with your heart. I appreciate that you always let me go my way, even when my decisions were not possibly equal with yours. I could feel that you believed in me, that I would have the courage to come to the end of this work. To my brother's family, Kaspar Schlüer, Maude Rivière and Julie- thank you for your time, for inviting us, sharing moments of stress and listening when it didn't go as it should. To my sister's family, Verena and Philippe Magnani with Davina and Sasha, for bringing me into another world to see that not only nursing science is a goal to strive for. Thank you for your trust in caring for your daughters. My brother Benjamin Schlüer, thank you for sharing moments of philosophical exchange on the importance of carrying out $\mathrm{PhD}$ work. It is always inspiring to talk to you and to get insight into other perspectives. I wish you all the best in your journey to climb the PhD mountain.

And a warm and special thank goes to my friends Rahel Messmer and Nadja Kröner: thank you for your understanding when a talk was not as long as it should have been, because I was busy writing manuscripts. Thank you for taking me out, for having a walk, talk or extra time to do something fun. 


\section{Curriculum vitae}

Anna-Barbara Schlüer, was born in Winterthur, Switzerland on November 28th, 1973. She completed her training in pediatric nursing in 1995. After that, she worked for the first ten years on a surgical ward and since 2002 in the pediatric burn center of the Pediatric University Hospital in Zurich, Switzerland. She started her further education in 2004 with a diploma as clinical nurse specialist. In 2006 she achieved her master's degree in nursing science at Maastricht University, The Netherlands, and the University of Applied Science in Aarau, Switzerland. During this period she worked as a clinical nurse specialist in the pediatric burn center, plastic and reconstructive surgery at the Pediatric University Hospital, Zurich Switzerland. In this position she was in charge of the most complex pediatric patients with severe wounds. At the same time she implemented a new role in a Swiss pediatric hospital, achieving the post of advanced practitioner nurse for pediatric wound and skin care. Since 2008 she has worked as an advanced nurse practitioner in pediatric wound, skin and ostomy care. In this position she is in charge of pediatric patients with highly complex and severe wound and skin conditions as well as challenging enterostoma and fistula care. Since 2011 she has been an elected member of the ethical board for human research of the Canton of Zurich as a representative for the nursing profession and pediatric health care.

Next to her clinical expertise and work as an advanced nurse practitioner, she has been head of the department of clinical nursing science at the Pediatric University Hospital in Zurich since 2009, and a member of the research center for the child at the same institution, representing nursing as a research discipline. She is copresident of the Swiss academic association for pediatric nursing and a member of the association Swiss Advanced Nursing Practice (SwissANP).

She is married and mother of four daughters, born in 2006, 2008, 2009 and 2011 and lives with her family in Winterthur, Switzerland. In 2008 she started her PhD studies in the PhD program at Maastricht University, Maastricht, The Netherlands, Charité Center for the Humanities and Science, Berlin, Germany and the Medical University, Graz, Austria. 


\section{CAPHRI}

The Research presented in this thesis was conducted at the School of Public Health and Primary Care; CAPHRI, Departement Health Sciences Research, of Maastricht University. CAPHRI participates in the Netherlands School of Primary Care Research CaRe. CAPHRI was classified as 'ecxellent' by the external evaluation committee of leading international experts that reviewed CAPHRI in December 2010. 